\title{
Nucleic acids analysis
}

Yongxi Zhao ${ }^{1 \dagger}$, Xiaolei Zuo ${ }^{2 \dagger}$, Qian $\mathrm{Li}^{3 \dagger}$, Feng Chen ${ }^{1}$, Yan-Ru Chen ${ }^{4}$, Jinqi Deng ${ }^{5}$, Da Han ${ }^{2}$, Changlong $\mathrm{Hao}^{6}$, Fujian Huang ${ }^{7}$, Yanyi Huang ${ }^{8}$, Guoliang $\mathrm{Ke}^{9}$, Hua Kuang ${ }^{6}$, Fan $\mathrm{Li}^{2}$, Jiang $\mathrm{Li}^{10,11}$, Min $\mathrm{Li}^{2}, \mathrm{Na} \mathrm{Li}^{12}$, Zhenyu Lin ${ }^{13}$, Dingbin Liu ${ }^{14}$, Juewen Liu ${ }^{15}$, Libing Liu ${ }^{16}$, Xiaoguo Liu ${ }^{3}$, Chunhua Lu ${ }^{13}$, Fang Luo ${ }^{13}$, Xiuhai Mao ${ }^{2}$, Jiashu Sun ${ }^{5}$, Bo Tang ${ }^{12}$, Fei Wang, Jianbin Wang ${ }^{17}$, Lihua Wang ${ }^{10,11}$, Shu Wang ${ }^{15}$, Lingling $\mathrm{Wu}^{2}$, Zai-Sheng Wu ${ }^{4}$, Fan Xia ${ }^{7}$, Chuanlai Xu ${ }^{6}$, Yang Yang ${ }^{2}$, Bi-Feng Yuan ${ }^{18}$, Quan Yuan ${ }^{9}$, Chao Zhang ${ }^{2}$, Zhi Zhu ${ }^{19}$, Chaoyong Yang $^{2,19^{*}}$, Xiao-Bing Zhang ${ }^{9^{*}}$, Huanghao Yang ${ }^{13^{*}}$, Weihong Tan $^{2,9^{*}}$ \& Chunhai Fan ${ }^{2,3^{*}}$

${ }^{1}$ Institute of Analytical Chemistry and Instrument for Life Science, The Key Laboratory of Biomedical Information Engineering of Ministry of Education, School of Life Science and Technology, Xi'an Jiaotong University, Xi'an 710049, China;

${ }^{2}$ Institute of Molecular Medicine, Shanghai Key Laboratory for Nucleic Acid Chemistry and Nanomedicine, Renji Hospital, School of Medicine, Shanghai Jiao Tong University, Shanghai 200127, China;

${ }^{3}$ School of Chemistry and Chemical Engineering, Frontiers Science Center for Transformative Molecules, Institute of Translational Medicine, Shanghai Jiao Tong University, Shanghai 200240, China;

${ }^{4}$ Cancer Metastasis Alert and Prevention Center, Fujian Provincial Key Laboratory of Cancer Metastasis Chemoprevention and Chemotherapy, State Key Laboratory of Photocatalysis on Energy and Environment, College of Chemistry, Fuzhou University, Fuzhou 350108, China;

${ }^{5}$ CAS Key Laboratory of Standardization and Measurement for Nanotechnology, CAS Center for Excellence in Nanoscience, National Center for Nanoscience and Technology, Beijing 100190, China;

${ }^{6}$ State Key Lab of Food Science and Technology, International Joint Research Laboratory for Biointerface and Biodetection, School of Food Science and Technology, Jiangnan University, Wuxi 214122, China;

${ }^{7}$ Faculty of Materials Science and Chemistry, Engineering Research Center of Nano-Geomaterials of Ministry of Education, China University of Geosciences, Wuhan 430074, China;

${ }^{8}$ College of Chemistry and Molecular Engineering, Biomedical Pioneering Innovation Center (BIOPIC), Beijing Advanced Innovation Center for Genomics (ICG), Peking-Tsinghua Center for Life Sciences, Peking University, Beijing 100871, China;

${ }^{9}$ State Key Laboratory of Chemo/Biosensing and Chemometrics, College of Chemistry and Chemical Engineering, Hunan University, Changsha 410082, China;

${ }^{10}$ Division of Physical Biology, CAS Key Laboratory of Interfacial Physics and Technology, Shanghai Institute of Applied Physics, Chinese Academy of Sciences, Shanghai 201800, China;

${ }^{11}$ Bioimaging Center, Shanghai Synchrotron Radiation Facility, Zhangjiang Laboratory, Shanghai Advanced Research Institute, Chinese Academy of Sciences, Shanghai 201210, China;

${ }^{12}$ College of Chemistry, Chemical Engineering and Materials Science, Key Laboratory of Molecular and Nano Probes, Ministry of Education, Shandong Normal University, Jinan 250014, China;

${ }^{13}$ Ministry of Education Key Laboratory for Analytical Science of Food Safety and Biology, Fujian Provincial Key Laboratory of Analysis and Detection for Food Safety, College of Chemistry, Fuzhou University, Fuzhou 350116, China;

${ }^{14}$ College of Chemistry, Research Center for Analytical Sciences, State Key Laboratory of Medicinal Chemical Biology, and Tianjin Key Laboratory of Molecular Recognition and Biosensing, Nankai University, Tianjin 300071, China;

${ }^{15}$ Department of Chemistry, Waterloo Institute for Nanotechnology, University of Waterloo, Waterloo, Ontario N2L 3G1, Canada;

${ }^{16}$ Laboratory of Organic Solids, Institute of Chemistry, Chinese Academy of Sciences, Beijing 100190, China; College of Chemistry, University of Chinese Academy of Sciences, Beijing 100049, China;

${ }^{17}$ School of Life Sciences, Tsinghua-Peking Center for Life Sciences, Beijing Advanced Innovation Center for Structural Biology (ICSB),

$\dagger$ These authors contributed equally to this work.

*Corresponding authors (email: cyyang@xmu.edu.cn; xbzhang@hnu.edu.cn; hhyang@fzu.edu.cn; tan@hnu.edu.cn; fanchunhai@sjtu.edu.cn) 
Chinese Institute for Brain Research (CIBR), Tsinghua University, Beijing 100084, China;

${ }^{18}$ Department of Chemistry, Wuhan University, Wuhan 430072, China;

${ }^{19}$ The MOE Key Laboratory of Spectrochemical Analysis and Instrumentation, Key Laboratory for Chemical Biology of Fujian Province, State Key Laboratory of Physical Chemistry of Solid Surfaces, Department of Chemical Biology, College of Chemistry and Chemical Engineering, Xiamen University, Xiamen 361005, China

Received July 9, 2020; accepted September 4, 2020; published online December 2, 2020

\begin{abstract}
Nucleic acids are natural biopolymers of nucleotides that store, encode, transmit and express genetic information, which play central roles in diverse cellular events and diseases in living things. The analysis of nucleic acids and nucleic acids-based analysis have been widely applied in biological studies, clinical diagnosis, environmental analysis, food safety and forensic analysis. During the past decades, the field of nucleic acids analysis has been rapidly advancing with many technological breakthroughs. In this review, we focus on the methods developed for analyzing nucleic acids, nucleic acids-based analysis, device for nucleic acids analysis, and applications of nucleic acids analysis. The representative strategies for the development of new nucleic acids analysis in this field are summarized, and key advantages and possible limitations are discussed. Finally, a brief perspective on existing challenges and further research development is provided.
\end{abstract}

nucleic acids analysis, signal amplification, DNA nanotechnology, aptamer, biosensing

Citation: Zhao Y, Zuo X, Li Q, Chen F, Chen YR, Deng J, Han D, Hao C, Huang F, Huang Y, Ke G, Kuang H, Li F, Li J, Li M, Li N, Lin Z, Liu D, Liu J, Liu L, Liu X, Lu C, Luo F, Mao X, Sun J, Tang B, Wang F, Wang J, Wang L, Wang S, Wu L, Wu ZS, Xia F, Xu C, Yang Y, Yuan BF, Yuan Q, Zhang C, Zhu Z, Yang C, Zhang XB, Yang H, Tan W, Fan C. Nucleic acids analysis. Sci China Chem, 2021, 64: 171-203, https://doi.org/10.1007/s11426-020-9864-7

\section{Introduction}

Nucleic acids, deoxyribonucleic acid (DNA) and ribonucleic acid (RNA), are natural biopolymers of nucleotides that store, encode, transmit and express genetic information [1,2]. DNA is composed of a phosphate-deoxyribose sugar backbone and the nitrogenous bases adenine (A), cytosine (C), guanine $(\mathrm{G})$, and thymine $(\mathrm{T})$, while RNA has a ribose sugar backbone and another base uracil (U) instead of T. Singlestranded nucleic acids can form double helix structures when hybridizing to complementary sequences, following the Watson-Crick base-pairing rules (A:T or A:U, G:C) [3]. Both DNA sequences and RNA transcripts play crucial roles in diverse biological events, which can be exploited to serve as biomarkers for biological studies and clinical diagnosis. Electrophoresis and blotting are the most widely used analytical techniques for analyzing nucleic acids, which remain to be used to analyze the length or structure and sequence, respectively. Their sensitivities, however, are limited to the sub-microgram regime.

Inspired by intracellular DNA replication and RNA transcription, in vitro nucleic acid amplification techniques have been developed to improve signal response and detection sensitivity. They can be in general classified into two categories, thermal-cycle amplification such as best-known polymerase chain reaction (PCR) [4] and isothermal amplification $[1,5,6]$. The later one is especially useful for temperature-sensitive targets such as live cells and proteins. Bioanalysis at single-cell and even single-molecule levels has been achieved by employing these methods [7-9].
Moreover, high-throughput detection techniques, including microarray chip $[10,11]$ and next-generation sequencing (NGS) $[12,13]$, have been developed for simultaneous detection of thousands of and even more nucleic acid sequences of interest. The NGS technique can also be expanded for other biological and biomedical applications, including the analysis of non-nucleic acid targets [14] and the rapid screening of small-molecule drugs [15]. Several amplification methods have been utilized to improve the quality of sequencing library [16-18]. Furthermore, these nucleic acid techniques play important roles in cellular and in vivo applications. Live-cell imaging analysis with high signal gain has been realized by enzymatic or enzyme-free amplification methods [19-25]. Single-molecule visualization of nucleic acids or proteins in fixed cells or tissues has also been reported based on in situ DNA amplification methods [26-29].

DNA or RNA oligonucleotides have been selected as recognition probes such as aptamers and DNAzymes by the systematic evolution of ligands by exponential enrichment (SELEX) [30,31]. Most of these probes bind to target molecules (proteins, small molecules, ions, etc.) with equal or even higher affinity and specificity than those of antibodies. Innovative bioanalysis methods based on aptamers or DNAzymes have been proposed to enhance detection performance [32,33]. Unnatural nucleic acids, such as locked nucleic acids (LNAs) and peptide nucleic acids (PNAs), have been synthesized to improve the hybridization or binding stability and nuclease resistance [34,35]. Nucleic acids also work as basic elements in nanotechnology ascribed to their programmable and scalable feature $[2,36,37]$. They are used 
to construct various nanostructures and dynamic devices with diverse technological applications such as nanofabrication, biosensing and nanomedicine. DNA nanostructures have now been widely used to improve analysis performance. Furthermore, above-mentioned nucleic acid techniques are often integrated with portable or miniaturized devices including thermocyclers, microfluidic chips, test strips, and capillary platforms [38,39]. Commercial devices and assay kits have been available for practical testing. The applications of nucleic acids analysis have been expanded to clinical translation, environmental analysis, food safety and forensic analysis.

In the past two decades, explosive increase of research interest in this area has been witnessed along with massive publications. In this review, we summarize recent advances in nucleic acids and nucleic acids-based analysis, as well as device development and applications of nucleic acids analysis, and discuss the challenges and future prospects in this booming field.

\section{Analyzing nucleic acids}

\subsection{In-vitro analysis of nucleic acids}

\subsubsection{Target amplification-based approaches}

With the development of biotechnology and analytical technology, highly sensitive and selective approaches to amplify nucleic acids signals have been proposed to overcome the inherent defects of nucleic acids detection, such as low sensitivity, low selectivity and ultralow concentration. These methods include thermal cycling and isothermal amplification techniques. PCR is the most widely used thermal cycling technique for DNA amplification. The isothermal process includes enzymatic isothermal amplification reactions and enzyme-free DNA circuit signal amplifications. Enzymatic isothermal amplification reactions include strand displace amplification (SDA), rolling circle amplification (RCA), loop-mediated isothermal amplification (LAMP), nucleic acid sequence-based amplification (NASBA) and biological signal amplifications. Enzyme-free DNA circuit signal amplifications include hybridization chain reaction (HCR) and catalyzed hairpin assembly (CHA) (Figure 1).

PCR is the first developed nucleic acid amplification approach, which has been regarded as the "gold standard" to amplify and detect specific nucleic acid sequences through thermal cycling [40,41]. PCR technique was first conceptualized by Kary Mullis in 1985 [42], and has been rapidly developed as one of the most commonly used amplification approaches with high sensitivity and rapidity for in-vitro analysis of nucleic acids [43,44]. While the early generations of PCR-based detection technology are timeconsuming and cannot be used to quantitatively detect target nucleic acids, especially RNA samples, quantitative reverse

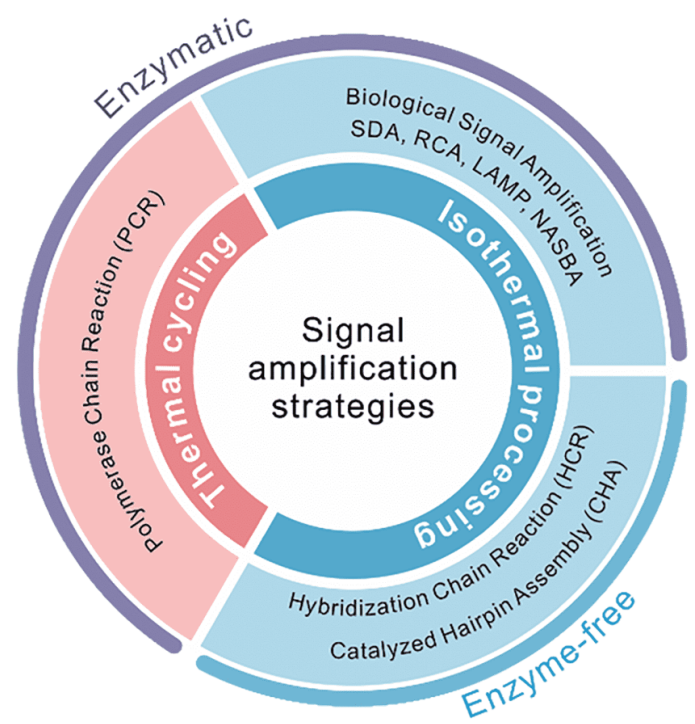

Figure 1 Signal amplification strategies for nucleic acids detection, including thermal cycling and isothermal methods. The isothermal methods mainly include enzymatic isothermal amplification reactions and enzymefree DNA circuit signal amplification reactions (color online).

transcription PCR (qRT-PCR) has been engineered for sensitive amplification and detection of target RNAs via dynamically fluorescence monitoring [45-48]. qRT-PCR allows the reverse transcription of target RNA to its complementary DNA, which realizes the effective amplification and quantitative analysis of the target RNA [49]. In addition, to further develop more sensitive and accurate PCR technology, digital PCR (dPCR) was emerged to actualize the absolute quantification for nucleic acid detection and nucleotide copy number variant analysis [50]. With dPCR technique, the absolute quantitative results can be calculated with higher sensitivity through the statistical analysis of the target nucleic acid signals [51]. By combining with microfluidic chips [52] and droplet-based technology [53], many commercial dPCR systems have been widely applied and significantly broadened the applications of dPCR.

PCR remains to be the most widely used technique for DNA amplification, which involves template strands to be amplified, repeated cycles of heat denaturation, hybridization with annealed primers to form duplex, extension by DNA polymerase with the aid of dNTPs [42,54-56]. Nevertheless, PCR requires precisely controlled temperature cycling, complex and time-consuming sample preparation, which limits its applications in resource-limited conditions. To circumvent this barricade, isothermal amplification techniques were proposed. To detect target oligonucleotides, enzymatic isothermal amplification reactions have come up. SDA is based on polymerization and scission, adapting to several sensitive DNA detection [57,58]. RCA refers to a circular oligonucleotide as a template. DNA polymerase replicates the template hundreds to thousands of times to obtain a long single-stranded DNA product [59-61]. Another 
technique, LAMP, which is based on 4 primers being used to recognize the 6 regions on the template DNA to amplify nucleic acids at the range of $65^{\circ} \mathrm{C}$, can amplify the amount of DNA to $10^{9}-10^{10}$ in less than one hour $[62,63]$. In NASBA, three enzymes are used to detect RNAs at constant temperature of $41{ }^{\circ} \mathrm{C}[64,65]$. These enzymatic isothermal amplification approaches proceed at constant temperature, which spend less time than the thermal cycling approaches. Although these methods can reach high selectivity and sensitivity in the detection of oligonucleotides, they cannot adapt to amplify proteins, enzymes and small molecules in vitro. To detect these targets at low level, biological signal amplification technology has been put forward. Biological signal amplification techniques do not amplify targets in vitro, but improve the signal intensity of biomarkers or the amount of bioprobes to improve the sensitivity of detection. Biological signal amplification techniques include reactions based on nuclease nicking enzyme signal amplification [6669] and DNAzyme signal amplification [70,71]. These methods are widely used in the detection of metal ions, proteins and small molecules, and are dependent on enzymes suffering from high price and strict reaction conditions, e.g. certain temperature and buffer. To overcome this bottle-neck, enzyme-free DNA circuit signal amplification techniques have been proposed. HCR and CHA are the most widely used methods. HCR is the first reported enzyme-free DNA circuit signal amplified technique [72]. In HCR reaction, two
DNA hairpins are stable in the solution until a target initiates the cascade of hybridization events to produce a liner, long double-stranded DNA (dsDNA) copolymer [73-77]. In CHA system, two stable DNA hairpins coexist in solution until a target is introduced. In the presence of the target, one of the hairpins hybridizes with target by toehold-mediated strand displacement, exposing the sticky end of hairpin 1 (H1), then hybridizing with the sticky end of hairpin 2 (H2) to form target-H1-H2 duplex. The duplex is unstable and the target is released to solution by $\mathrm{H} 2$ spontaneous disassembly to form H1-H2 complex. The released target initiates the next cycle to form the additional $\mathrm{H} 1-\mathrm{H} 2$ complex, then the target is used to amplify the signal [78-81]. The most attractive feature of enzyme-free DNA circuit signal amplification techniques is that they are kinetic controlled reactions without requirement of enzymes.

\subsubsection{Hybridization-based approaches}

Hybridization-based detection platforms with high selectivity and excellent sensitivity have been developed based on Watson-Crick base-pairing rules. The most classic hybridization-based in vitro analysis is implemented by the hybridization of two complementary DNA strands (Figure 2 (a)). By labeling functional groups or introducing nanomaterials on DNA strands, numerous strategies have implemented in the analysis of nucleic acids [82-85]. The nucleic acid analogs (NAA), which are synthesized by (a)
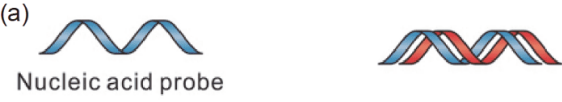

(b)
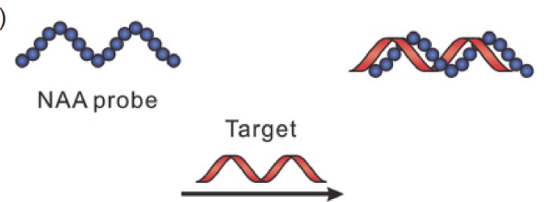

(c)
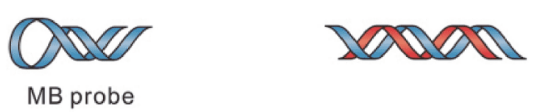

MB probe

(d)
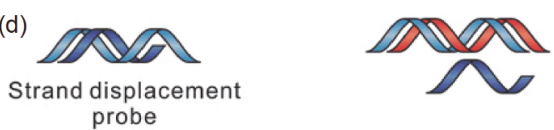
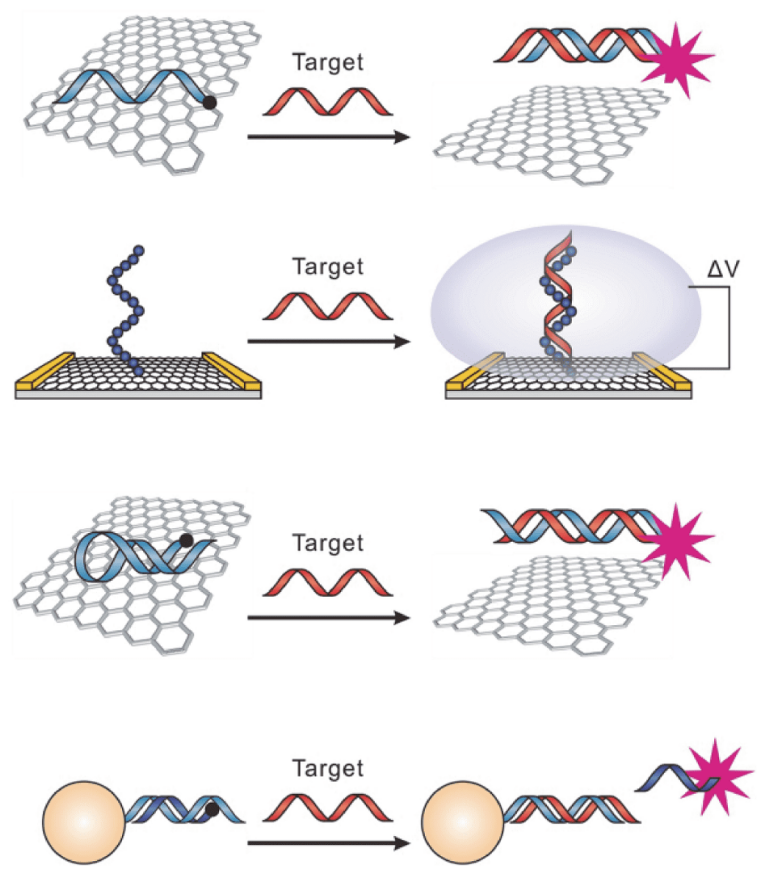

Figure 2 Representative DNA detection strategies based on nucleic acids hybridization. (a) The classic hybridization-based in vitro analysis strategy [8385], Copyright 2013 Wiley-VCH. (b) The NAA analysis approach [86-88], Copyright 2014 American Chemical Society. (c) MB detection system [89-93], Copyright 2010 Royal Society of Chemistry. (d) The SDR detection strategy [94,95], Copyright 2014 National Academy of Sciences of the United States of America (color online). 
modifying inter-nucleoside linkages or interspersing natural nucleobases with artificial nucleobases, also play important role in the hybridization-based in vitro analysis for their high selectivity and chemical stability (Figure 2(b)) [86-88]. In order to increase the selectivity, molecular beacon (MB), a single-stranded, stem-loop folded oligonucleotide chain structure with a donor (fluorophore) and an acceptor (quencher) conjugated to the opposite ends, is developed to detect target nucleic acids based on the switch of the stemloop structure (Figure 2(c)) [89-93]. The MB is normally in the "fluorescence off" or closed state in the absence of target DNA. And it switches to the "fluorescence on" or open state after hybridizing with target DNA. In the system of duplex probes, the strand displacement reaction (SDR) can be used for in vitro analysis with high sensitivity, high controllability, and low interference (Figure 2(d)). Such an approach has been demonstrated to implement multiplexed detection for several classes of biomolecules [94,95].

The sandwich assay has been widely applied for the detection of nucleic acids, since Hassell et al. [96] applied "sandwich hybridization" to investigate viral RNA transcripts in 1970s. Typically, it often involves a target of nucleic acids inserting within two recognition probes [6]. To complete this assay, a recognition probe is modified onto surface to capture target nucleic acids from the solution via hybridization, while a second probe, coupled with signal reporter, such as radioactive isotopes, enzymes, fluorescein, and redox tags, is hybridized to a second region of the target nucleic acids. Upon the target nucleic acids binding to the recognition probe, the signal probe produces a readily sensitive measurable signal, enabling detection of the presence and concentration of target nucleic acids. Owing to simultaneous binding of the recognition probes to the target analyte, this method exhibits extremely high specificity [97]. More importantly, both surface bound probe and signal probe do not interact with each other in the absence of target, resulting in reduced noise and thereby ultimate low detection limits $[98,99]$.

Recent advances in the field of DNA nanotechnology have opened new possibilities to develop novel sandwich assays with impressive detection performance (Figure 3) [100102]. For example, Lin et al. [103] reported an E-DNA based sandwich assay by folding the tetrahedral framework-modified capture probe into stem-loop structure to further reduce the background signal and increase its detection sensitivity. In the presence of nucleic acids target, the capture probe opens its stem-loop structure, generating a new sticky-end to hybridize to signal probe, and enabling this sensor detecting microRNA (miRNA) with high specificity in the diverse miRNA family members. Furthermore, Lu et al. [104] introduced this E-DNA based sandwich assay into electrochemiluminescence resonance energy transfer (ECL-RET) detection system with high sensitivity and specificity by using $\mathrm{Ru}(\mathrm{bpy})_{3}{ }^{2+}$-modified silica nanoparticles (RuSi NPs) and hollow Au nanocages as ECL donor and acceptor, respectively. In addition, Zuo et al. proposed a supersandwich assay by extending signal probe with a "sticky end" to further hybridize another target of nucleic acids $[99,105]$. Specifically, this hybridization of single signal probe between two target molecules results in the formation of supersandwich structure with multiple labels, enabling impressive detection limit of this supersandwich assay.

Owing to the high stability, low cost, and convenient labeling, nanoparticles can also serve as signal probes for DNA detection to further improve the performance of sandwich assays [106-115]. For example, Zhang et al. [116] reported a nanoparticle based "sandwich" detection strategy by immobilizing gold nanoparticles (AuNPs) with reporter probes that flank the target nucleic acids. Specifically, hundreds of reporter DNA strands loaded on AuNPs enable a significant amplification by concentrating electrochemical signal of $\left[\mathrm{Ru}\left(\mathrm{NH}_{3}\right)_{6}\right]^{3+}$ proximal to the electrode surface, significantly enhancing its sensitivity and selectivity. Similarly, Liu et al. [100] further applied this AuNPs based sandwich type strategy to detect exosomal miRNAs with neutrally charged PNAs instead of DNAs to further improve its sensitivity and specificity.

The development of framework nucleic acids (FNAs) provides a platform for patterning biosensing interfaces, resulting in uniform biorecognition layers to improve the hybridization efficiency in sandwich assay. As an elegant application, tetrahedral DNA frameworks (TDF) have been used as rigid scaffolds for orientated immobilizing DNA recognition probes. Fan et al. have shown that the DNA hybridization kinetics and thermodynamics were profoundly affected by tuning the size of TDF anchors. The hybridization rate and hybridization efficiency can be increased for 20-fold and 5-fold with TDF anchors, respectively, compared to the conventional single-stranded DNA anchors. When TDFs were used to develop sandwich assay, a detection limit of $100 \mathrm{aM}$ can be achieved, which excels most of the existing sandwich assays [117-119]. In addition, the intrinsic low cost of TDFs meets well the low-cost requirement of biosensor design because the TDFs can be assembled with only four DNA strands [120-122]. More importantly, the FNAs facilitated patterning of biosensing interfaces can be integrated into various sensing devices such as microfluidic devices and paper-fluidic devices [123,124], expanding its applications in many important fields such as miniaturized biosensors and integrated biosensors.

\subsubsection{Sequencing-based approaches}

Sequencing is probably one of the most sophisticated applications of analyzing nucleic acids [126]. Many conventional analytical methods, such as electrophoresis separation [127,128], laser-induced fluorescence [127], fluorescence 
(a)

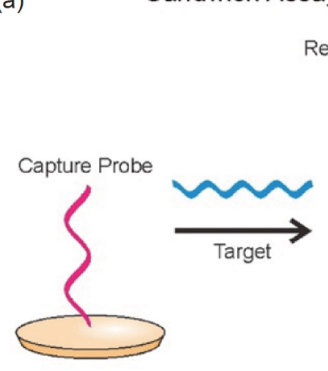

(c)

AuNP based Sandwich Assay

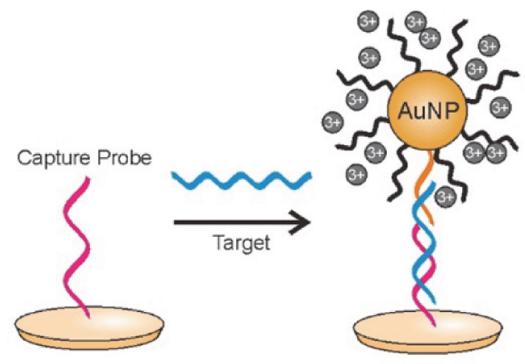

(e)

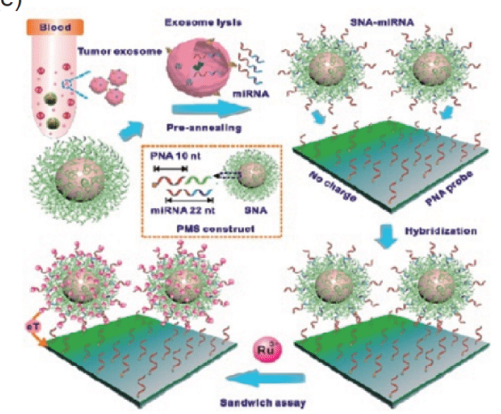

(b)

Supersandwich Assay
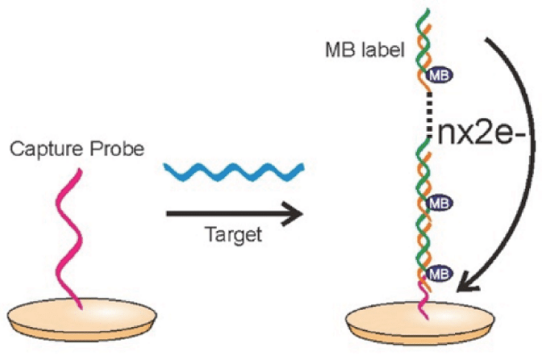

(d)

FNA based Sandwich Assay

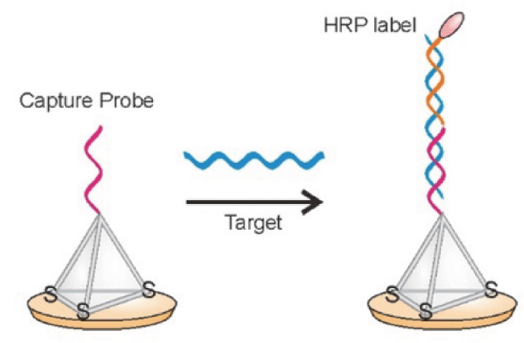

(f)

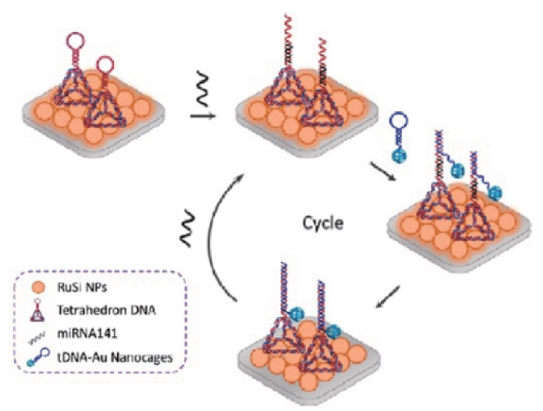

Figure 3 DNA detection based on the sandwich strategy. (a) Scheme of the traditional electrochemical nucleic acid sandwich assays. (b) Scheme of supersandwich assays for the nucleic acids detection. (c) Schematic of showing AuNPs amplified detection: DNA targets, detection probes loaded on AuNPs, and capture probes anchored at the electrode surface form "sandwich" complexes in the presence of target DNA. (d) Scheme of the FNA based E-DNA sensor with DNA tetrahedron. (e) Schematic illustration of miRNA detection using the PNA-miRNA-SNA (PMS) sandwich-based biosensor [95], Copyright 2019 American Chemical Society. (f) Schematic demonstration of structure and modification process of the FNA based ECL Biosensor for miRNA detection [125], Copyright 2018 American Chemical Society (color online).

microscopy [128], electrochemical sensing [129], microfluidics [130], single-molecule detection [131], and the integration between some of these technologies, become the technological foundation of various types of DNA sequencers. DNA sequencing also highly relied on the advances of the understanding and engineering of enzymatic reactions, as well as the nucleic acid amplification techniques [132] to convert the sequence information into measurable optical or electrical signals [133,134]. The first drafts of the human genome were published nearly two decades ago [135], since then we have observed the explosion of genomic data along with the revolutionized instrumental development from the capillary electrophoresis-based Sanger sequencers [136] to high-throughput next-generation sequencers [137-
140]. There have been many review articles that cover all aspects of DNA sequencing and its applications in studying genomic variations [141], transcriptomes [142], epigenomes [143], higher-order chromatin structures [144], protein-nucleic acid interactions [145], and diagnosis applications $[146,147]$. Here we emphasize three major trends that illustrate technological advances built upon analytical chemistry (Figure 4). First, long-read single molecule sequencing, such as the nanopore sequencing [148], has been rapidly developed and is catching the wave to provide solutions with unique advantages including the detection of viral DNAs or RNAs during outbreaks [149]. Although such approaches still face great challenges on the raw accuracy [150], and will not be able to replace prevalent NGS platforms in the near 


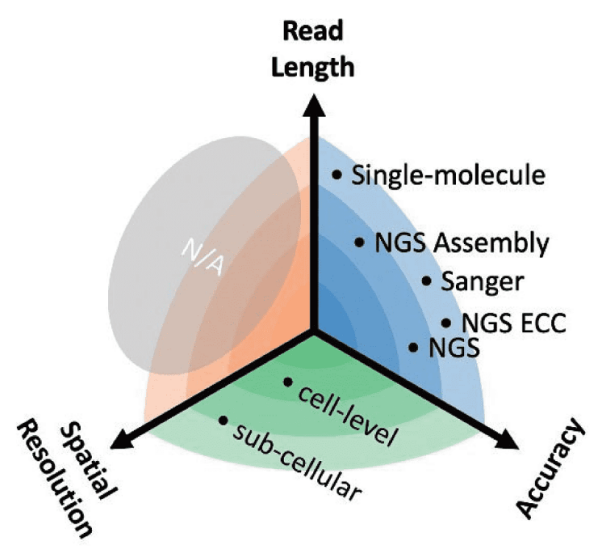

Figure 4 Sequencing technology developing trends. Most improvements have been observed in sequencing read length and accuracy (blue domain), while the progress in increasing sample spatial resolution is relatively slow (orange and green domains). No single technology excels in all three dimensions to date (color online).

term, direct long-read detection scheme has been increasingly used as a synergetic tool to couple with short-read sequencing approaches for acquisition of long-range genomic information [151]. Second, large throughput sequencing will still hold the major role in sequencing business and need to be continuously evolved to reach higher throughput, lower cost, higher accuracy, and longer read length. New concepts of sequencing chemistry, such as error-correction code sequencing [13] and contiguity-preserving transposition sequencing $[152,153]$, will greatly elevate the merits of highthroughput sequencing and benefit majority of applications with familiar experimental and analytical procedures. Third, the capability to sequence low-input samples allows us to explore nucleic acid information with higher spatial resolution. Single cell sequencing is becoming a routine process when dissecting a complex biosystem [154], and it has been highly depending on the advances of microfluidics $[155,156]$, development of amplification methods $[12,17,157]$, and the new functions of enzymes [158]. Meanwhile, spatial-resolved in situ sequencing will become a new frontier in biology and medicine, providing an integrative landscape of both spatial distribution and genomic variation at the single-cell level [159-161], or even finer scales [162], in the context of tissues or organs. The advent of new technologies in sequencing has shown great prospects for deciphering the secrets of life, and will continuously shed light on fundamental biology and medical applications.

\subsubsection{Mass spectrometry-based approaches}

Mass spectrometry (MS) has long played a significant role in the characterization of constituents, modifications and sequences of nucleic acids due to its excellent performance in identification of compounds [163]. The fast advances of MSbased analytical methods make MS an increasing important tool in nucleic acids research. Specially, liquid chromato- graphy-electrospray ionization-tandem mass spectrometry (LC-ESI-MS/MS) and matrix-assisted laser desorption/ionization mass spectrometry (MALDI/MS) are the most widely employed platforms for analyzing nucleic acids.

Nucleic acids typically undergo hydrolysis, resulting in formation of small compounds, such as nucleotides, nucleosides, or nucleobases, followed by the determination of these components with MS (Figure 5) [164]. The chromatographic retention time, mass-to-charge ratios and fragmentation MS spectra could afford the identification information of components from nucleic acids. Stable isotope internal standards were commonly used in MS analysis to improve quantification accuracy. Apart from the canonical nucleic acids, a number of modifications that play critical roles in regulating the structures and functions of nucleic acids have been identified in both DNA and RNA [165]. The analysis of these modifications shows great promise in clinical diagnosis and prognostics of certain diseases $[166,167]$. However, nucleic acid modifications generally exist in low abundance, and thus cause challenges in the MSbased analysis. In this respect, chemical labeling in combination with MS analysis has been proposed and proved to be an attractive strategy to increase the detection sensitivities of analytes (Figure 5) [168,169]. Along this line, a variety of chemical labeling-MS-based methods have been developed for the sensitive and accurate analysis of nucleic acid modifications with the detection sensitivities of nucleosides being down to subfemtomole or even attomole levels [170175].

MS also plays an ever-widening role in determining sequence of oligodeoxynucleotides. The large nucleic acids generally have to be cleaved to short fragments for subsequent MS analysis (Figure 5). As for RNA, the nucleases of RNase T1 and RNase A are typically utilized to digest RNA to produce small oligonucleotide fragments followed by MS analysis [176]. Electrospray ionization (ESI) and matrix-assisted laser desorption ionization (MALDI) normally create protonated or deprotonated molecular ions in the form of $(\mathrm{M}+n \mathrm{H})^{n+}$ and $(\mathrm{M}-n \mathrm{H})^{n+}$, respectively [177]. To obtain the sequence information, the selected oligodeoxynucleotides need to be further fragmented. A typical fragment ion spectrum of an oligodeoxynucleotide is composed of a series of peaks. Starting from the 5'-terminus, a, b, c, and $\mathrm{d}$ fragment ions, are created by fragmentation at different positions of phosphodiester group in oligodeoxynucleotide (Figure 5) [163]. Meanwhile, $z, y, x$, and $w$ fragment ions are produced from the 3'-terminus (Figure 5) [163]. The resulting series of 5'-terminal and 3'-terminal ions have characteristic mass differences, which are thereby employed to deduce the sequence of oligodeoxynucleotide [178]. In addition to the sequence information, the sites of modifications in oligodeoxynucleotides also can be obtained by MS/ MS analysis, which is very valuable for the detection and 


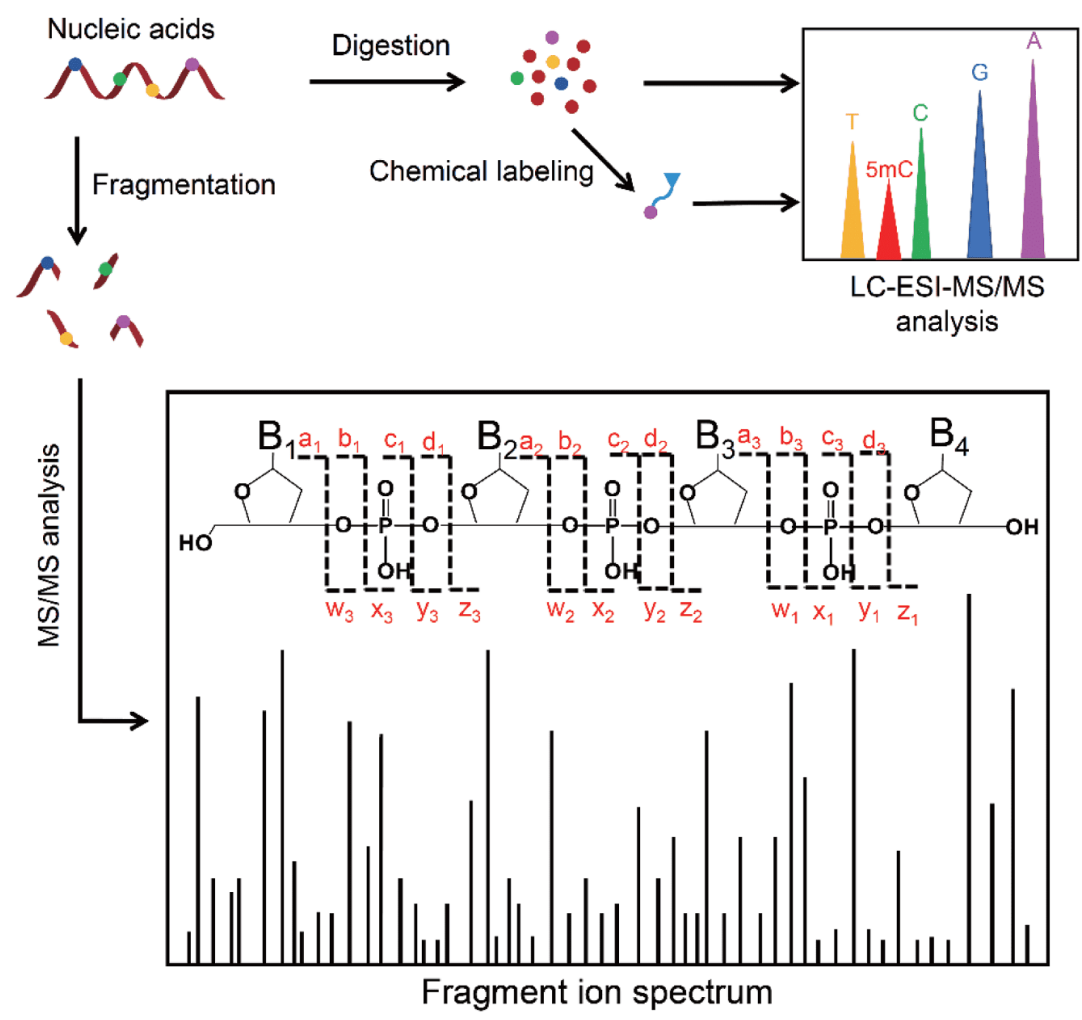

Figure 5 Schematic illustration of MS-based analysis of nucleic acids. Nucleic acids undergo hydrolysis to form nucleotides, nucleosides, or nucleobases followed by determination of these compounds by LC-ESI-MS/MS. Chemical labeling in combination with MS analysis can increase the detection sensitivities of these compounds. Nucleic acids also can be cleaved into short fragments and the sequence information of these oligodeoxynucleotides can be obtained by MS/MS analysis (color online).

mapping of DNA adducts in oligodeoxynucleotides [179]. Moreover, the capability of MS for sequencing oligonucleotides has also enabled the discovery and identification of various modifications in different RNA species [180]. With the development of advanced MS instruments, the mass resolution and detection sensitivity have been greatly improved. We envision that MS will play increasing important roles in analyzing nucleic acids.

\subsection{Intracellular and in vivo analysis of nucleic acids}

\subsubsection{Fluorescence}

Fluorescence analysis has been widely used for the detection of nucleic acids of interest as a non-invasive analytical method with high sensitivity and spatiotemporal resolution, which would be beneficial to understand the progress of physiology and pathology [181-184]. Using fluorescent probes, the monitoring of nucleic acid molecules could be realized at the cellular and in vivo level on a real time scale. The fluorescent probes usually employ external fluorochromes with unique properties such as highly separated excitation/emission wavelengths, high quantum yield, long fluorescence lifetime, high extinction coefficient, and fluorescence anisotropy [185-188]. Furthermore, simultaneous detection of multiple targets can be achieved in the same sample by using different fluorochromes that can be spectrally resolved $[189,190]$. With these features, a variety of strategies have been designed for imaging and detecting nucleic acids with superb sensitivity, high selectivity and good biocompatibility in living cells and in vivo [190-194].

Chen et al. have developed a new activatable NIR fluorescence nanoprobe (QD-Al-GFLX) for efficient detection of dsDNA in aqueous solution and imaging of dsDNA in living cancer cells. As shown in Figure 6(a), only the HeLa cells incubated with QD-Al-GFLX produced strong intracellular NIR fluorescence upon interaction with dsDNA in the nucleus, indicating that QD-Al-GFLX was capable of fluorescence imaging of endogenous dsDNA in living cells [195]. Han and his coworkers reported an organelle-trappable DNA sensor (SG-RB) for dual-color imaging of mitochondrial DNA (mtDNA). As shown in Figure 6(b), SG-RB selectively bound mtDNA in mitochondria, thereby giving rise to turnon green fluorescence [196]. Tang and his coworkers presented a multicolor nanoflares based novel nanoprobe that can detect and image three kinds of tumor-related mRNAs in living cells simultaneously. The fluorescent signals observed under confocal laser scanning microscopy (CLSM) were consistent with the levels of tumor-related mRNA gene expression, which revealed that this novel nanoprobe could be used to discriminate cancer cells from normal ones (Figure 6 

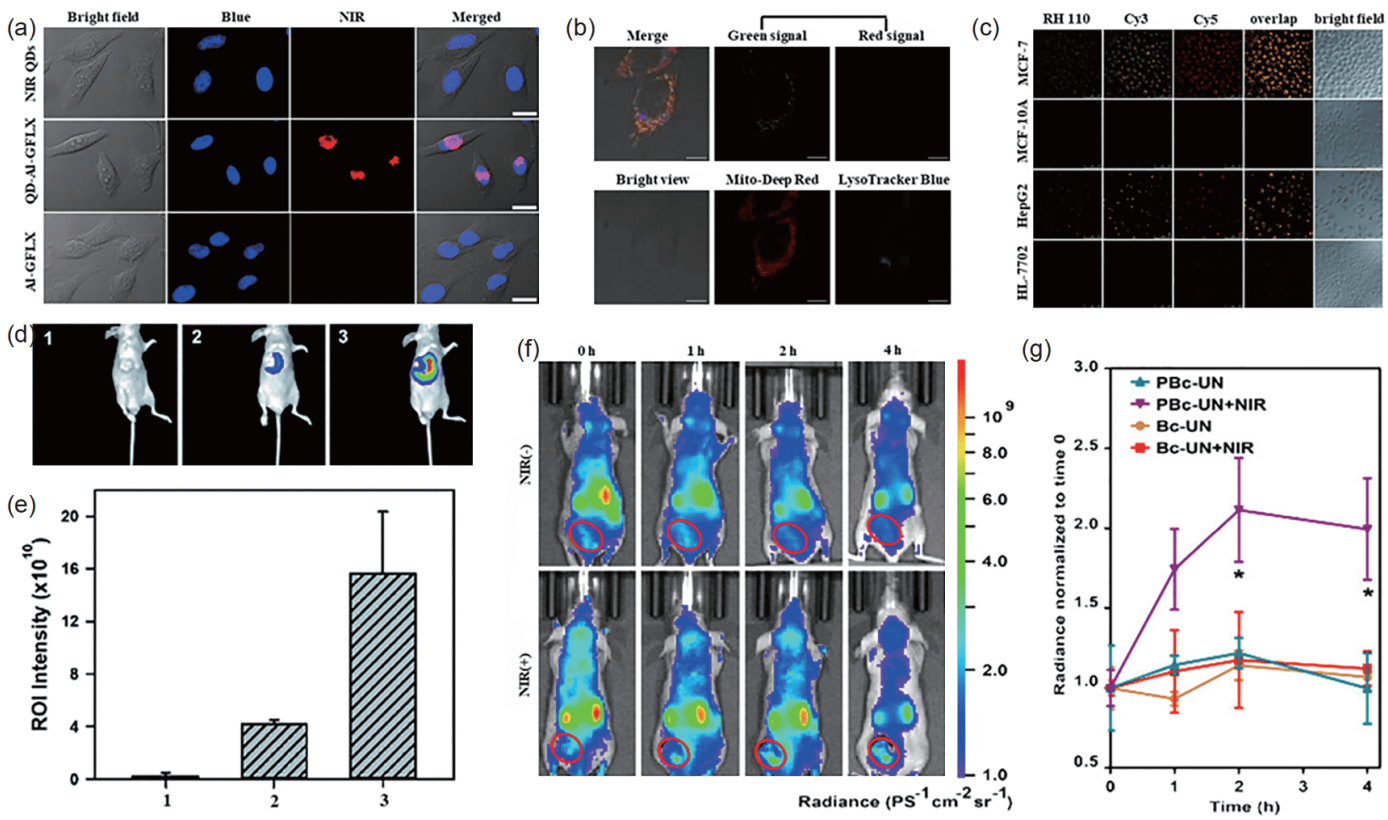

Figure 6 Intracellular and in vivo fluorescence analysis of nucleic acids. (a) Fluorescence imaging of dsDNA in living HeLa cells [195]. (b) "Turn-on" fluorescence imaging of mtDNA with SG-RB [196]. (c) Intracellular imaging of c-myc mRNA, TK1 mRNA, and GalNAc-T mRNA under CLSM [197]. (d) In vivo fluorescence images of HeLa tumor-bearing with injection of physiological saline injection (1) and Y-H1-H2-FAP probe (3) and MCF-7 tumorbearing mice with injection of the Y-H1-H2-FAP probe (2) [198]. (e) Mean fluorescence intensities of the treated mice in (d). (f) Whole-body fluorescence imaging of HeLa tumor-bearing mice after intravenous administration of PBc-UN with or without subsequent NIR illumination. Red circles indicate tumor sites. (g) Quantification of the fluorescence intensity at the tumor sites in (f) [199] (color online).

(c)) [197]. In addition to the intracellular detection of nucleic acids, the imaging and analysis of nucleic acids in vivo are also reported and help decipher biology. Jiang et al. developed a novel tripartite DNA probe (Y-H1-H2-FAP) that enabled fluorescent RNA imaging in living mice via an in vivo HCR circuit. The intense fluorescence signal observed for the HeLa tumor-bearing mice (Figure 6(d)) and the fluorescence intensities (Figure 6(c)) in the tumor regions of interest suggested the overexpression of microRNA-21 (miR21) in tumors [198]. Li and his coworkers developed a DNA nanodevice (PBc-UN), permitting NIR light triggered, spatiotemporally controlled miRNA imaging in living cells and animals. Stronger fluorescence was shown by the PBc-UN + NIR treated group at the tumor site than by the PBc-UN treated group (Figure 6(f) and 6(g)), achieving remotely activated miRNA imaging in tumors [199].

\subsubsection{SERS}

Raman spectroscopy has attracted wide attention due to its prominent chemical specificity that provides fingerprint information of various molecules [200]. However, the inherently weak scattering characteristic limited its biological application. Fleischmann et al. firstly reported the surface enhanced Raman scattering (SERS) phenomenon at roughened silver substrates. Up to date, SERS has been considered as potential tools for analytical sciences and biomedical applications because of its remarkable sensitivity of detec- tion and undisturbed property to surrounding interference factors [201]. SERS sensing are mainly based on two strategies, direct detection and indirect detection with Raman tags. Direct detection of analytes is performed by monitoring the characteristic fingerprint information of the analytes' immediate vicinity by the enhanced substrates (such as noble metal nanoparticles). The indirect determination of analytes in biological samples depends on Raman tags that could specifically respond to or combine with the analytes, which is suitable for sensing analytes in complex samples [202].

Since Kneipp et al. firstly reported SERS applied in the direct detection of biochemical components in a single cell in 2002, SERS has been blossomed into intracellular analysis and in vivo imaging [203]. SERS can provide a wealth of components and structural information, as well as structural changes like mutations in DNA strands of the biological samples. Therefore, various studies about label-free direct detection of nucleic acids were reported [204,205]. For example, Kneipp et al. [206] monitored the cellular SERS signatures including nucleotides at different time points after the uptake of AuNPs. Gold or silver nanoparticles also can serve as specific SERS tags based on the surface-enhanced Raman signature of an attached reporter molecule to highlight cellular structures and indirect detection of the characteristic analytes [207,208]. MiRNAs are a non-coding small RNAs that are considered as diagnostic markers or therapeutic targets of diseases [209]. Various nanostructure- 
based SERS tags were developed to improve the detection signals for sensitively and precisely determining miRNAs [206,209-212]. For example, Kuang et al. developed realtime in situ determination of the miRNA in living cells using self-assembly nanorod dimers. Distinct intense SERS signals were introduced by the self-assembly of plasmonic dimers simultaneously caused by miRNA [212]. GO-Au nanostructures were coupled with hybrid DNA linkers to detect miR-21 and surface glycoprotein in living cells with great selectivity and stability, in which the SERS signal would turn off as the concentration of intracellular miR-21 increased [210]. This research group also reported SERS and up-conversion fluorescence imaging platform for quantitative detection of the miR-21 and telomerase in living cells based on DNA-programmed AuNP dimer-UCNP core-satellite assemblies, in which the complementary DNA fragments for miR-21 were localized in the gaps of Raman tag-labeled AuNP dimers, while the hybridization of the complementary DNA fragment to miR-21 caused the AuNPs to separate, resulting in SERS signal turn off [210]. Moreover, based on the turn-on strategy for miR-21 detection, Liu et al. reported a serious of methods, such as target triggered self-assembly method and target-mediated nanoparticle dimerization strategy. In detail, the authors designed dimeric AgNPs for quantitatively monitoring miRNAs in single cells, which can be controllably assembled to large aggregates for the formation of hot-spots, thus significantly enhancing the brightness of the Raman tags and achieving accurate detection of miRNAs at single-biomolecule level (Figure 7(a)) [213]. They also developed a target-mediated plasmonic dimerization method for in situ imaging of miRNAs in living cells based on the background-free Raman tags (alkyne, $\mathrm{C} \equiv \mathrm{C}$; nitrile, $\mathrm{C} \equiv \mathrm{N}$ ), with single peaks in the Raman-silent region and no overlap within the cellar fingerprint region. With the strategy, the electromagnetic hot spots would be built responsively to the target miRNAs, leading to significant enhancement of Raman scattering, thus reducing the interference of background signals (Figure 7(b)) [211].
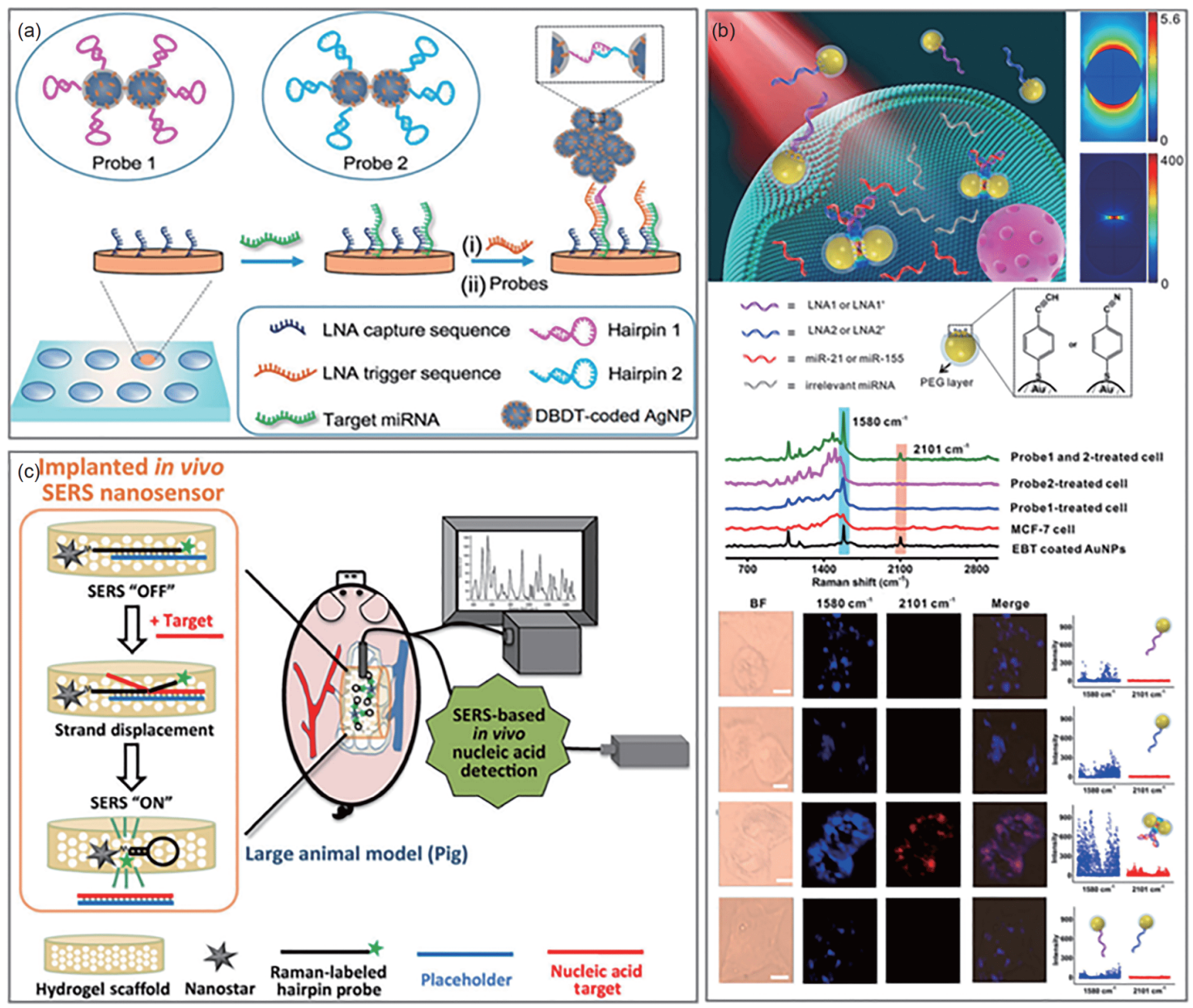

Figure 7 SERS strategies for nucleic acid detection. (a) Quantitatively miRNA detection using dimeric AgNPs, which can be assembled to large aggregates upon the presence of miRNA. Adapted with permission from Ref. [213], Copyright 2017 American Chemical Society. (b) In situ imaging of miRNAs in living cells, based on hot spots building in the presence of miRNAs. Adapted with permission from Ref. [211], Copyright 2017 American Chemical Society. (c) In vivo nucleic acid detection by implanted a SERS sensor in the skin of pig based on a SERS signal turn-on strategy. Adapted with permission from Ref. [214], Copyright 2018 Springer-Verlag (color online). 
Up to now, SERS technology has been widely applied for in vitro and cellular nucleic acid analysis [204]. However, in vivo nucleic acid analysis based on SERS methods is still extremely challenging. In vivo nucleic acid analysis is crucial for monitoring health, predicting the occurrence and progression of disease, and revealing potential targets for treatment. Tuan Vo-Dinh et al. reported in vivo nucleic acid detection by implanting a SERS sensor in the skin of pig based on a SERS signal turn-on strategy. The turn-on sensing system consisted of a plasmonic nanostar modified with a Raman tag-labeled DNA fragment and a complementary DNA fragment. The SERS signal was kept on turn-off status as the Raman label departed away from the nanostar surface, and would be enhanced significantly (turn-on status) when exposed to the target nucleic acids. The authors also demonstrated ex vivo SERS detection of target nucleic acid by implanting the SERS sensors in the human skin grafts (Figure 7(c)) [214], showing great potential for clinical translation applications of SERS technology.

\subsubsection{Electrochemistry}

Electrochemical approaches can offer rapid, low-cost and simple platform for the analysis of intracellular nucleic acids. Up to date, many electrochemical techniques have been developed for the intracellular sensing of nucleic acids in the diagnosis of human cancers [215-218], clinical and pathological diagnosis of genetic or infectious diseases [219-225], environmental monitoring, food analysis [226-230], and so on. For example, an amplification-free electrochemical approach was proposed for the analysis of FAM134B messenger RNA in tissues samples from patients with oesophageal carcinomas using a screen-printed gold electrode [217]. Such approach avoided the tedious fabrication procedure of electrode and the analytical performance accorded with a standard qRT-PCR analysis. Quantitative data are normally necessary for genetically modified organisms in foods to evaluate whether foods in trade are in compliance with particular specifications legally established. Monitoring of genetically modified organisms in food was achieved by electrochemical detection of magnetically-entrapped DNA sequences by multiplexed enzymatic labelling from complex samples [226]. Generally, these methods need to lyse the cell to extract the intracellular nucleic acids, which may prevent the knowledge of prior or future states of the cells [231]. It is still critical to observe the intracellular nucleic acids within living cells. Except fluorescence imaging, electrochemical technique has also been employed for intracellular sensing in situ owing to the excellent analytical features. For example, a switchable electrochemical sensor was designed for survivin mRNA in living cells on the basis of the changes of electron transfer efficiency between the electrode surface after reaction with the mRNAs and ferrocene at the end of DNAs [232].
In addition to the abovementioned potentiometric and amperometric assays, ECL technique that combines the advantages of electrochemical and chemiluminescence methods is also increasingly used for intracellular sensing of nucleic acids because of the advantages of high sensitivity, low background, and good temporal and spatial resolution [233]. For example, an ultrasensitive wireless ECL assay was proposed for the detection of c-Myc mRNA in breast cancer cells on an indium tin oxide bipolar electrode in a poly (dimethylsiloxane) microchannel [234]. Such ECL biosensor could accurately quantify c-Myc mRNA copy numbers in living cells. ECL imaging of intracellular miR-21 in single HeLa cells was achieved by EMCCD using $\mathrm{H}_{2} \mathrm{O}_{2}$ as coreactant and luminol as ECL active material [235]. To the best of our knowledge, it is the first reported example to employ the high resolution ECL-microscopy for imaging of intracellular miR-21.

\section{Nucleic acids-based analysis}

In addition to the above-mentioned nucleic acids targets, nucleic acid elements also enable the bioanalysis of nonnucleic acid targets, including ions, metabolites, proteins, and even cells. This feature contributes to the nucleic acidbased molecular recognition elements such as aptamers and DNAzyme, which can bind to their targets with strong affinity and high specificity. Moreover, benefiting from their programmable and scalable features, nucleic acids can be constructed into DNA/RNA nanostructures, which can significantly improve the analysis performance of probes. In this section, these nucleic acid elements including aptamers, DNAzymes and DNA/RNA nanostructures are first introduced, then several strategies for their bioanalysis applications are discussed, and finally some representative examples for the bioanalysis of various kinds of targets are provided.

\subsection{Nucleic acid elements for molecular recognition}

\subsubsection{Aptamers}

Nucleic acid aptamers are oligonucleotide sequences of DNA or RNA. The aptamer can achieve specific recognition due to its spatial structure that matches the target molecule [236]. Aptamers are usually obtained by SELEX screening [237]. Specifically, nucleic acid libraries were incubated with target molecules to obtain conjugates of aptamers and target molecules [238,239]. Then the unbound sequences were eluted. After multiple cycles of selection, aptamers with high affinity can be obtained [240].

In recent years, nucleic acid aptamers have been widely used in bioscience and biomedicine due to their high affinity, specific binding ability and excellent programmability 
[30,241]. At present, researchers have synthesized and screened a variety of nucleic acid aptamers that can specifically bind to biomarkers such as antigens [242], biological enzymes [243], cell surface receptors [244] and nucleic acid molecules. For example, AS1411 is a star DNA aptamer that binds nucleolin with high affinity, thereby inhibiting cell proliferation and achieving the effect against cancer [245].

In addition to using nucleic acid aptamers for recognition analysis, some researchers have begun to introduce functional groups into nucleic acid libraries to obtain chemically modified aptamers [37]. Compared with traditional aptamers, chemically modified aptamers have a richer spatial conformation, which increases the possibility of obtaining suitable aptamers from nucleic acid libraries [37,246]. At the same time, the introduction of chemical modification is expected to expand the function and application of chemically modified aptamers [247]. An example is a chemically modified aptamer containing 2-amino-3-nitropyridin-6-one (denoted as Z) and imidazo[1,2-a]-1,3,5-triazin-4-(8H)-one (denoted as P) bases. Many researchers have introduced $\mathrm{Z}$ and $\mathrm{P}$ bases into nucleic acid libraries. The desired chemically modified aptamer is screened from the library (Figure 8) [248]. Currently, chemically modified aptamers have been widely used to recognize and analyze more biomarkers due to their high affinity and specificity.

Furthermore, chemically modified nucleic acids cannot be recognized by traditional nucleases due to the introduction of chemically modified nucleotides. As a result, the biological stability of the nucleic acid sequence is greatly improved [249]. There are also some chemically modified nucleotides that can be complementary paired with traditional natural nucleotides, which can further improve the stability of nucleic acid aptamers based on "locking" the spatial structure of the aptamers.

Numerous studies have shown that nucleic acid aptamers are widely used as multifunctional tools for recognition, analysis, drug delivery, cancer treatment and other fields $[30,250]$. Among them, the introduction of functional groups into nucleic acid aptamers is expected to further expand the structure and function of aptamers. These studies will provide new opportunities for future research and develop- ment of excellent analysis equipment and disease treatment drugs.

\subsubsection{DNAzymes}

With the discovery of ribozymes in the early 1980 s, the notion that all enzymes are proteins was changed. Ribozymes can catalyze biochemical transformations in the absence of proteins. The use of ribozymes for sensing was less explored due to the poor stability and high costs of RNA. In 1994, the first catalytic DNA (DNAzyme) was isolated with the RNA cleavage activity (Figure 9(a)) [251], and its activity requires $\mathrm{Pb}^{2+}$ as a cofactor while other metal ions cannot catalyze the reaction [252]. The DNAzyme was obtained by in vitro selection from a large random library containing around $10^{15}$ DNA sequences, and the process was quite similar to aptamer selection also including the isolation of active sequences followed by PCR amplification.

Many DNAzymes require specific metal ions [253]. Taking advantage of it, $\mathrm{Li}$ and $\mathrm{Lu}$ reported a DNAzyme-based biosensor for $\mathrm{Pb}^{2+}$ detection [254]. This sensor was composed of an RNA containing substrate strand bearing a fluorophore label hybridized to a quencher labeled enzyme strand (Figure 9(e)). In the hybridized state, the fluorescence was low. Upon cleavage of the substrate and release of the fluorophore bearing fragment in the presence of $\mathrm{Pb}^{2+}$, a timedependent fluorescence increase was obtained [255]. Such DNAzyme-based sensors are highly sensitive and selective. Moreover, they solved the problem of detecting metal ions, which is challenging for aptamers and antibodies. Later, in vitro selections were intentionally carried out in the presence of different metal ions such as $\mathrm{UO}_{2}{ }^{2+}$ (Figure 9(b)) [256], $\mathrm{Na}^{+}$ (Figure 9(c)) [257], and lanthanides (Figure 9(d)) [258], and all of them achieved highly selective sensors for the target metal ions. By measuring catalytic activity, the problem of non-specific DNA binding by metal ions can be largely avoided to further increase specificity [259]. To further improve the chemical diversity of DNAzymes, chemically modified DNA was used such as phosphorothioate DNA [260], modified DNA bases [261], and synthetic metal ligands [262].

The same selection method has also been applied to nonmetal targets. For example, an early DNAzyme reported by

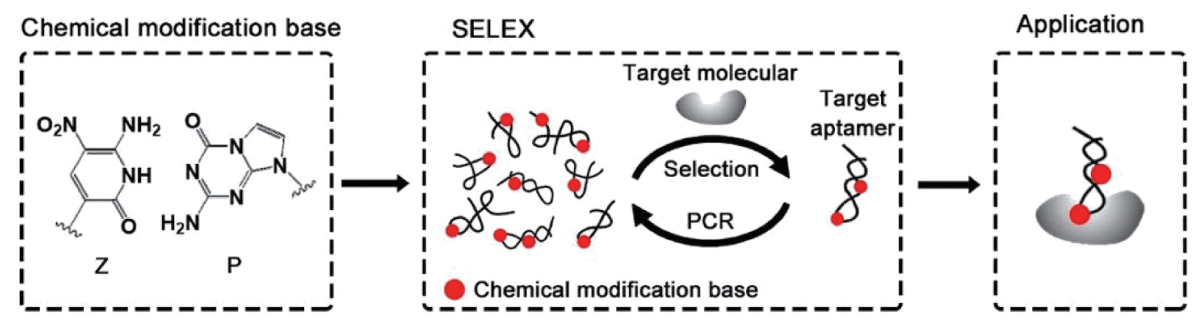

Figure 8 Generation and selection of DNA aptamer containing chemically modified bases towards recognition, analysis, drug delivery, cancer treatment application. An example is a chemically modified aptamer containing 2-amino-3-nitropyridin-6-one (denoted as Z) and imidazo[1,2-a]-1,3,5-triazin-4-(8H)one (denoted as P) bases (color online). 

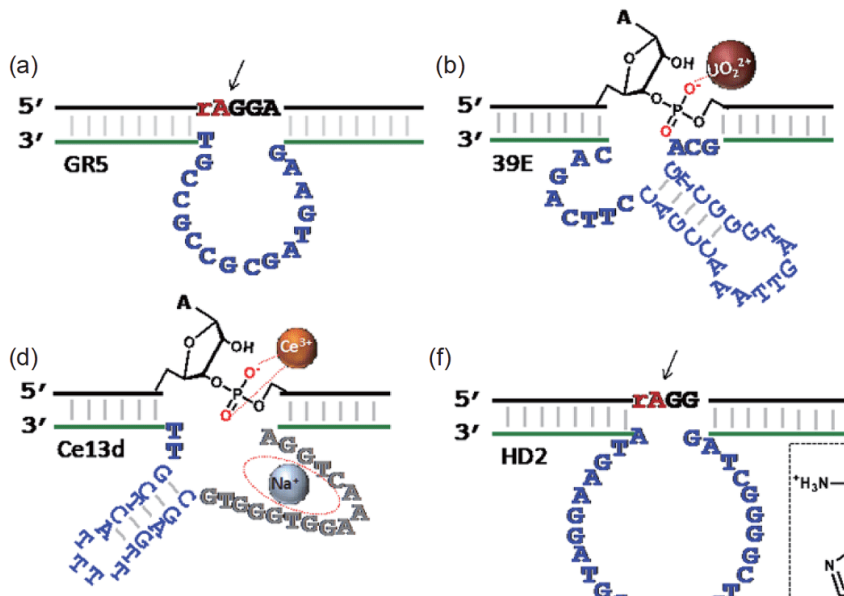

(f)

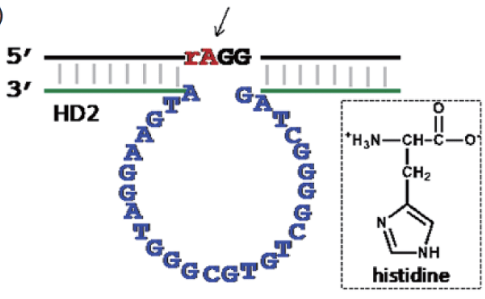

(g)
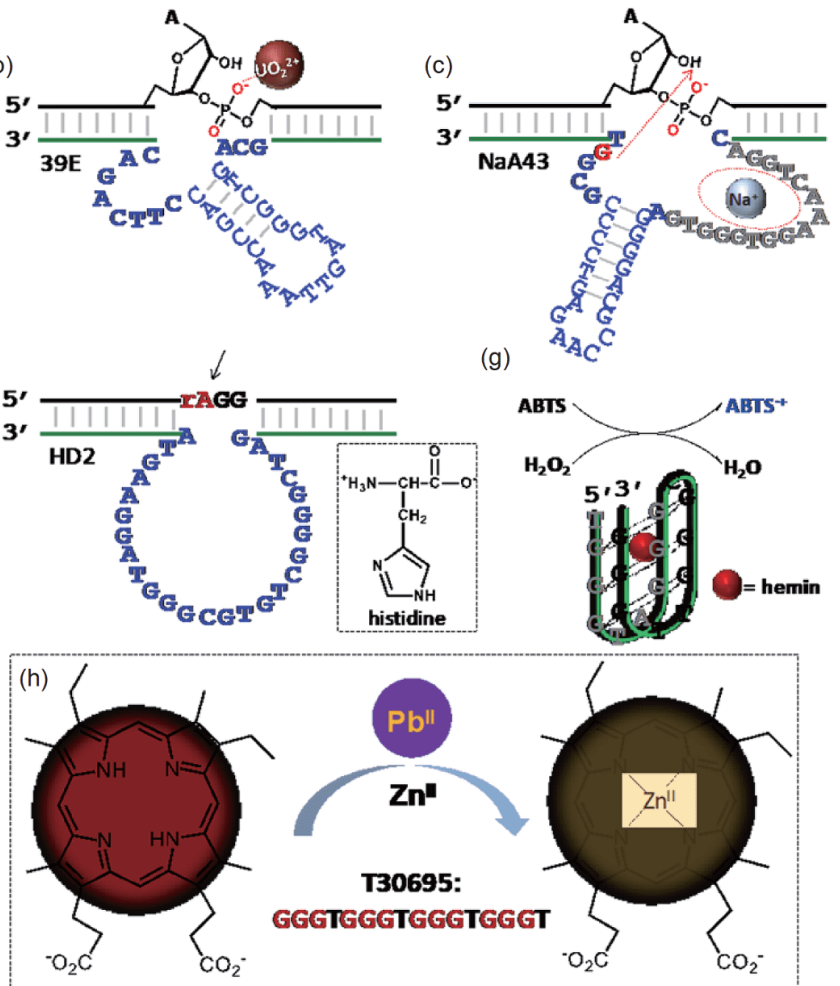

Figure 9 DNAzymes for molecular recognition. (a) The first reported RNA-cleaving DNAzyme named GR5 specific for Pb ${ }^{2+}$. The secondary structures of representative DNAzymes requiring (b) $\mathrm{UO}_{2}{ }^{2+}$ (39E), (c) $\mathrm{Na}^{+}$(NaA43), (d) lanthanide ions (Ce13d), or (f) L-histidine (HD2) as cofactors. (e) The cleavageinduced fluorescent beacon based on RNA-cleaving DNAzymes. (g) The G-quadruplex DNAzyme/hemin complex with peroxidase-like activity catalyzing the oxidation of ABTS in the presence of $\mathrm{H}_{2} \mathrm{O}_{2}$ into ABTS ${ }^{+}$. (h) T30695 can catalyze porphyrin metalation in the presence of $\mathrm{Pb}^{2+}$ and induce a red-to-orange emission change upon inserting $\mathrm{Zn}^{2+}$ (color online).

the Breaker group [263] requires L-histindine for its activity (Figure 9(f)). Later, the Li group [264,265] has isolated a series of DNAzymes that can detect specific bacterial strains by selecting against their crude extracellular matrix. In addition to the DNAzymes for RNA cleavage, another type of commonly used DNAzyme has peroxidase-like activity [266]. These DNAzymes often have a G-quadruplex binding hemin as a cofactor (Figure $9(\mathrm{~g})$ ). They are attractive in terms of replacing horseradish peroxidase in immunoassays for signal amplification. Since DNAzymes are programmable in structure and can achieve site-selective labeling, they are more versatile than protein-based enzymes for sensor design.

DNAzymes with other types of activities have also been used for analytical applications. For example, a sequence named T30695 was recently discovered to catalyze porphyrin metalation in the presence of $\mathrm{Pb}^{2+}$ (Figure 9(h)). By inserting $\mathrm{Zn}^{2+}$ into the porphyrin substrate, a red-to-orange emission color change was observed [267]. DNAzymes for oxidative and hydrolytic cleavage of DNA were developed for measuring $\mathrm{Cu}^{2+}$ [268] and $\mathrm{Zn}^{2+}$ [269], respectively. DNAzymes with phosphatase and ligase like activities are also known and they can also be potentially used for signaling or target recognition in sensors [270,271].
Overall, DNAzymes can be used for both target recognition and signal generation and amplification. Thus, they are very useful molecules for designing biosensors, especially for metal detection. DNAzymes are complementary to aptamers in terms of target recognition, and they can also be combined to obtain aptazymes to have the advantages of both [272].

\subsubsection{DNA/RNA nanostructures}

The analysis aiming at targets with larger dimension or higher complexity (e.g. protein, biochemistry pathway and cell membrane) requests accordingly larger molecular objects to accommodate the geometric, procedural and affinity demands. DNA/RNA nanostructures have exhibited the corresponding properties and great potentials in the realm of biochemical analysis.

Initiated by Nadrian Seeman in the 1980's, the concept of DNA nanotechnology $[2,273]$ inspired scientists to design nanoscale structures precisely assembled with programmable DNA oligonucleotides (Figure 10(a)). Different from aptamer or ribozyme whose functions are embedded in the sequence determined secondary structure of a single (sometimes more than one) DNA/RNA strand, the construction of DNA nanostructures requires less in sequence 


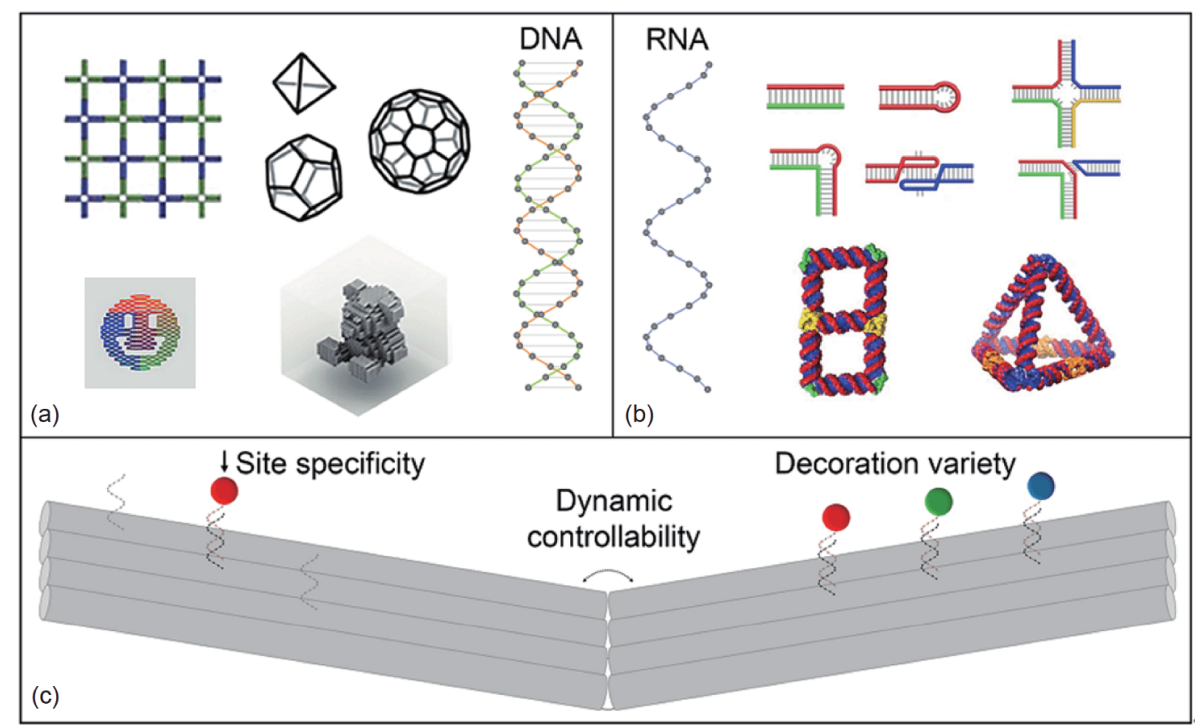

Figure 10 Schematic illustration of DNA/RNA nanostructures. (a) Nanostructures constructed by DNA in two and three dimension. (b) Motifs, binding/ folding principles and 2D/3D nanostructures based on RNA molecules. (c) DNA/RNA nanostructures can be precisely functionalized and manipulated for senescing and many other purposes (color online).

specificity, but more in geometrical rules (such as the distance between crossovers) to regulate the hybridized DNA segments to form proper spatial arrangements. Simple DNA nanostructures designed in the early days, commonly termed "tiles", are able to further assemble into larger structures (e.g. $1 \mathrm{D}$ tubes, $2 \mathrm{D}$ arrays and 3D crystals) with certain freedom in 1-3 directions to grow infinitely [274,275]. To fabricate more specific structures, DNA origami $[248,276]$ and Single-Strand Tile (SST) $[277,278]$ techniques have made great progress in the last decade. They sequester hundreds of DNA oligos recognizing and binding to a single-stranded DNA scaffold or to each other to form the pre-designed structures with very high fidelity and efficiency. Various geometrical shapes across 1D to 3D (e.g. tubes, 2D patterns, bricks, spheres, webs) have been realized with controllable parameters (e.g. distance, angle, curvature) in nanometer precision. Moreover, by employing dynamic DNA nanotechnology [279-281], properly designed DNA structures can transform between two or more isomers mostly through SDR that triggered by physical or chemical stimulus (e.g. photons, $\mathrm{pH}$ changes, ions, DNA oligos). The above progress in DNA nanotechnology suggests the unlimited possibility of engineering arbitrary nanodevices for specific tasks in both basic and applicable researches.

RNA molecules, in principle, can be manipulated to fold or assemble into various nanostructures just like DNA with a few distinct parameters [282]. However, considering the valuable cellular functions of RNA, which rely on their sequences and secondary structures, it makes less sense to assemble a static RNA structure using dozens of commercially synthesized RNA oligos with arbitrary sequences at high cost. Thus, the field of RNA nanotechnology [283-285] has been focusing on achieving higher order RNA structures through natural RNA motifs and their association methods, such as kissing loops and sticky ends (Figure 10(b)). Although the architecture species and constructions are not as impressive as the DNA nanostructure family, RNA nanostructures preserve the outstanding ability of cellular amplification and in-vivo assembly [286,287]. Publications in recent years indicate that the merging of DNA and RNA nanotechnology as a current trend may eventually integrate the structural programmability and the bio-functionality of the two kinds of nucleic acids [288-290].

The three major advantages of DNA/RNA nanotechnology (Figure 10(c)), including the abilities of multiple components arrangement, precise spatial positioning and dynamic structure regulation, can improve analysis performance in many ways. First of all, the readout fluorophores (or other molecules) can be easily introduced into DNA/RNA nanostructures with multiple species and copies, which significantly increase the number of detecting channels, and enhance the signal intensities $[291,292]$. Second, the DNA/ RNA nanostructures possess numerous sites on surface with controllable distance to display multiple recognition motifs (e.g. aptamers, antibodies) that enhance the cooperative binding affinity for the target biological analytes [293,294]. Third, employing DNA/RNA nanostructures as frameworks, other nanomaterials (e.g. carbon nanotubes, metal nanoparticles, quantum dots) and biomolecules (e.g. peptide, enzyme, antibody, lipid) can be recruited and rearranged to establish novel analytical platforms with inherited properties (e.g. chirality, surface plasmonic resonance, catalytic activity) [295]. Moreover, DNA/RNA nanostructures are capable of generating motions or investigating dynamic molecular 
behaviors [296,297]. Last but not least, recent studies in DNA nanostructure induced cell uptake and in-situ metabolism tracing suggest a huge potential of using DNA/RNA nanotechnology to facilitate in vivo investigation and nanomedicine discoveries [298-300]. In summary, DNA/RNA nanotechnology offers analytical chemists a convenient toolbox to choose or build up devices for better target detection, signal extraction and sample examination.

\subsection{Strategies for bioanalysis}

Utilizing nucleic acid elements for the analysis of nucleic acid targets and non-nucleic acid targets, such as ions, metabolites, proteins, virus, cells and tissues, originates from their abilities in accurate recognition and transduction of target signals as well as versatile reporting methods of output signals. With the help of molecular engineering, different functional nucleic acid probes have been generated for target recognition. Meanwhile, detailed understanding of intra-and inter-molecular interactions between nucleic acids and their targets encouraged further development of nucleic acidbased signal transduction strategies. Furthermore, combined with optical, electrical, magnetic and acoustic technologies, nucleic acid-based bioanalytical strategies can be reported in versatile outputs and applied to different application scenarios. Herein, we will briefly discuss strategies for bioanalysis using nucleic acids in the context of signal recognition, transduction and reporting (Figure 11).

\subsubsection{Signal recognition and transduction strategies}

As discussed in the previous sections, functional nucleic acids such as aptamers, DNAzymes and DNA nanostructures can be used for recognizing targets, either by intramolecular allosteric or intermolecular interactions that can induce changes for signal propagations. Herein, we briefly divide the signal recognition and transduction strategies for nucleic acid-based bioanalysis into two categories: integrated and unintegrated methods.

The integrated method involves single molecule or module that integrates the functions of both target recognition and signal transduction. For instance, the Tan group [301] has reported an aptamer-based molecular probe with intramolecular signal transduction ability. The aptamer binding to its target molecule will disturb the intramolecular DNA hybridization and induce signal transduction for reporting output. Similar design has been adapted by Wilson et al. [302] with tunable control of the thermodynamic and kinetic properties of the aptamer switches for a series of targets. This integrated strategy can ensure the fast activation and quick reporting for bioanalysis due to the two-in-one configuration but may suffer from the disadvantages of less sensitivity owing to no module for signal amplification.

The unintegrated method mainly involves multiple molecules or modules in the nucleic acid-based analysis. For instance, a change induced by the recognition module can propagate to the subsequent module for signal transduction. This strategy allows the enrollment of more functions such as signal amplification and information processing in the bioanalysis, therefore is greatly adopted in different configurations. For example, the Lu group [303] reported a method of using aptamers and DNAzymes as recognition modules and the CRISPR-Cas systems for signal transduction modules with signal amplification ability. Combination of these two modules enables the quick and sensitive detection on a broad range of targets. Han et al. [304] developed a DNA displacement reaction-based dynamic system with an aptamer in which the nanostructure can be transformed in response to the epithelial cell adhesion molecule (EpCAM) on
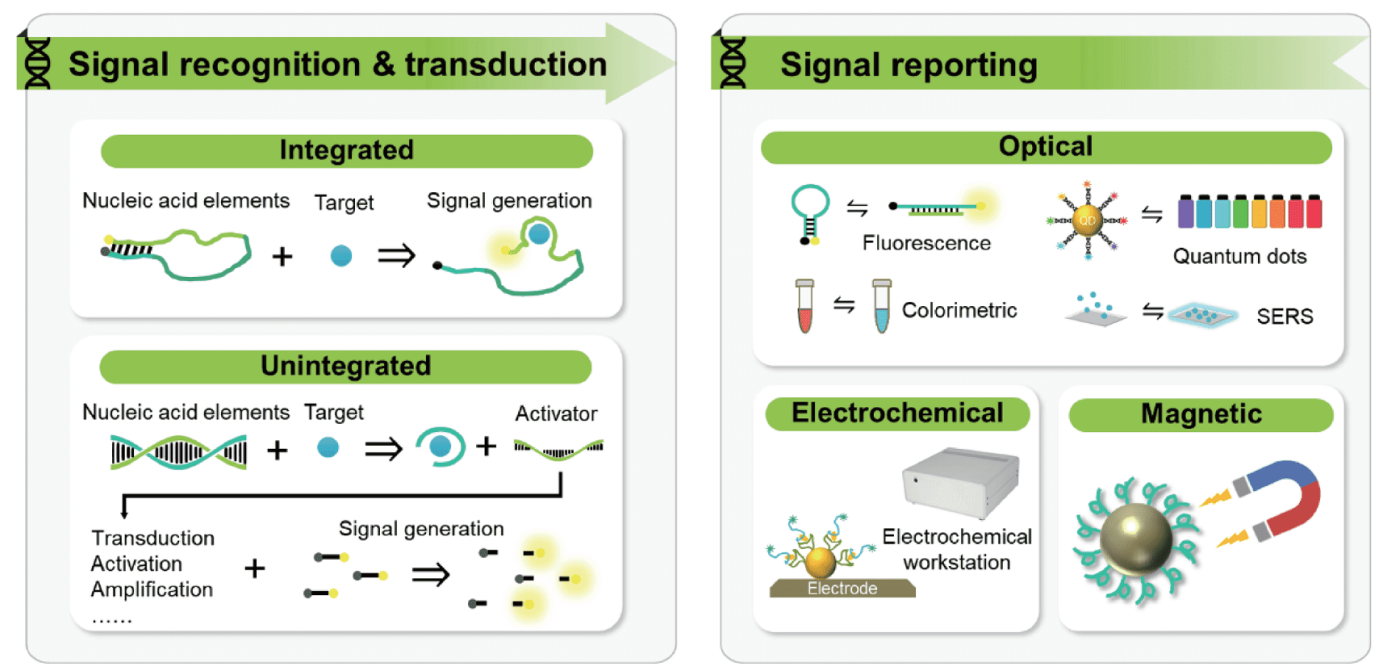

Figure 11 Strategies for nucleic acid-based bioanalysis. The basic modules include signal recognition, transduction and reporting. In the signal recognition and transduction modules, we focused on introducing integrated and unintegrated methods. In the reporting module, optical, electrochemical and magnetic methods for bioanalysis were discussed (color online). 
live cell membranes and propagate signals through DNAbased signal amplification reactions. Overall, the unintegrated method that involves multiple molecules for signal recognition and transduction is more utilized due to its high flexibility in designing and engineering for different application scenarios.

\subsubsection{Signal reporting strategies}

As the mostly used methods for detection, optical methods are playing important roles in bioanalysis of various targets. Detection techniques, including fluorescence, colorimetric, and SERS are typical examples. Because nucleic acids can be easily modified with a variety of organic dyes, quantum dots and other fluorescent materials, the fluorophore-based detection methods have been widely demonstrated. For instance, targets such as ions, metabolites, and proteins can be detected by fluorescence due to the binding-induced fluorescence restoration either from proximity change of the fluorophore and quencher pairs or molecular environmental changes of the fluorophores. This strategy has been further expanded to complex biological samples including cells and tissues. You et al. [305] used a pair of orthogonal fluorogenic RNA aptamers to quantify the metabolites in live cells. To further fulfill the requirement of deep optical penetration to tissues for in vivo probing, nucleic acid probes with Near Infrared (NIR) fluorescence have been developed with the employment of long emission wavelength fluorophores and carbon nanomaterials $[306,307]$. Until now, the fluorescent reporting strategies still play major roles in nucleic acidbased bioanalysis, especially in the biological and biomedical applications.

In addition, colorimetric and SERS techniques are supplementing the dominant fluorescence-based methods and providing unique advantages for different application scenarios. For example, point of care detection requires readings with either naked eyes or portable equipment, which presents opportunities for colorimetric detection methods. As a kind of indicator, AuNPs can generate colored signals from red to blue on their different aggregation status, which enables convenient colorimetric signal readouts [308]. Similar to the AuNPs, some chemicals and nanomaterials with UV-vis absorption changes upon specific inducement can also be engineered for colorimetric readouts. By coupling functional nucleic acids to these indicators, colorimetric biosensors with different functions and features can be made and applied for quick and convenient bioanalysis [309]. With the distinct advantages of low background, insensitivity to photobleaching or quenching, single-molecule sensitivity and fingerprint-like spectra, together with the controllable assembly of nanoparticles with functional nucleic acids, SERS can also be used for detection methods in nucleic acidbased bioanalysis. Examples include quantifications of metal ions and proteins in vitro as well as tumor markers and metabolites in situ [310,311]. Overall, with the development of various technological platforms, the optical reporting strategies will continually play important roles in nucleic acid-based bioanalysis.

Other signal reporting strategies for nucleic acid-based bioanalysis include electrochemical, magnetic and acoustic techniques. Compared to optical-based sensing devices, electrochemical bioanalysis platforms offer the advantages of low cost, simplicity, and the capability of being miniaturized. By integration with electronic devices, the electrochemical nucleic acid-based bioanalysis can provide the possibility of analyzing samples sensitively within short time frames [120]. In addition, more and more magnetic and acoustic techniques have been designed towards the clinical applications due to their intrinsic advantages such as high sensitivity and deep tissue penetration [312,313]. Because nucleic acids can be conjugated to different materials with various properties, they can be used to fabricate different biosensing platforms towards more biological and biomedical applications.

\subsection{Representative examples of non-nucleic acid target analysis}

Taking advantages of the analysis strategies based on nucleic acid elements, lots of biosensors for various targets have been developed. Herein, several representative examples based on DNA-driven arrangement of nanomaterials are introduced. DNA-driven arrangement of nanomaterials is one effective way to construct functional assemblies, in which nanomaterials can be arranged into specific configurations with strong inter-particle interaction. By choosing different nanomaterials (including AuNPs, gold nanorods (AuNRs), quantum dots, upconversion nanoparticles (UCNPs), AgNPs) as building blocks, a large number of functional assemblies have been fabricated, such as dimers, trimers, pyramids, core-satellites, and other assembles. Since these DNA driven assemblies possess striking optical features, they can serve as good candidates for fabricating ultrasensitive sensing platforms to detect many significant analytes, such as ions, proteins, DNAs, RNAs, cells, and so on [314].

Many biosensors with circular dichroism (CD), SERS or fluorescent signal have been fabricated based on the DNAdriven nanostructures. For example, using dopamine aptamer as the linkage, the Au@Ag core-shell nanorod dimers with strong SERS activity were developed for ultrasensitive dopamine detection [315]. In addition, DNA-driven chiral nanostructures were used as chiral biosensors. A chiral AuNP dimer-based sensor for detecting silver ions was developed by Xu's group [316]. Through metal ion-mediated base pairs (cytosine- $\mathrm{Ag}^{+}$-cytosine), chiral dimers were assembled by two different-sized AuNPs. The intensity of the plasmonic 
CD signal was related to the concentrations of the silver ions. Also based on chiral AuNP dimers, a chiroplasmonic sensing platform was applied for detecting adenosine-5'-triphosphate (ATP) [317]. Using DNA aptamers of prostate-specific antigen (PSA), the chiral Au@Ag core-shell nanorod dimers were prepared and used for ultrasensitive PSA detection [318]. Moreover, using metal-ion specific DNAzyme, DNA-bridged chiral core-satellites probe was used for multiple metal ions detection in living cells [22,319,320].

Besides single-mode signal detection, some DNA-driven superstructures can be used for dual-signal detection of some important analytes. For example, the DNA-driven gold-upconversion nanoparticle (AuNP-UCNP) pyramids were used for chiral and fluorescent detection of microRNA-21 (miR21) in living cells [321]. The Au-UCNP pyramids were composed of two AuNPs and two UCNPs, showing intense plasmonic $\mathrm{CD}$ response at $521 \mathrm{~nm}$ and strong upconversion luminescence (UCL) signal in the range of 500-600 nm. The Au-UCNP pyramids disassembled in the presence of miR21 , leading to an increase in the luminescence signal and a decrease in the CD signal. In another representative example, a two-signal platform based upon CD and UCL signals, was developed for ultrasensitive DNA detection. Through the DNA-driven self-assemble strategy, three AuNRs and one UCNP were assembled into the propeller-like structure. In the presence of target DNA, the AuNR-UCNP assemblies were destroyed, leading to the decrease of both the $\mathrm{CD}$ and UCL signals [322]. Significantly, miRNA-directed intracellular side-by-side self-assembly of AuNR dimers was used for the detection of miRNA in living cells. The more miRNAs existed, the more AuNR dimers formed. The CD response and SERS intensity were proportional to the amount of target miRNAs. The linear range of the CD signal was $0.11-42.23 \mathrm{fmol} / 10 \mu \mathrm{g}$ RNA, with a LOD of $0.081 \mathrm{fmol} /$ $10 \mu \mathrm{g}$ RNA, while the SERS activity showed the same detection range with a LOD of $1.12 \mathrm{fmol} / 10 \mu \mathrm{g}$ RNA [212].

It is a great challenge for simultaneous detection of different types of biomolecules (i.e., nucleic acids and proteins). With ingenious design of DNA structure, a unique and universal strategy based on dual-model optical sensor (SERS and UCL) was proposed for the quantification of miR-21 and telomerase in living cells [323]. In the presence of miR-21 and telomerase, the hybridization of miR-21 with a MB causes the separation of 3,3'-diethylthiocarbamyl cyanine iodide-modified AuNR dimers, resulting in a decrease in SERS signal. At the same time, the target telomerase elongates the telomerase primer strands, which is followed by substitutional hybridization and release of UCNPs, resulting in an increase in UCL signal (Figure 12(a)). In another example, the AuNP-graphene oxide (GO) assemblies were applied for simultaneously sensing surface glycoprotein (epithelial cell-adhesion molecule, EpCAM) and miR-21 in living cells [210]. The AuNP-GO nanostructures are driven through DNA hybridization, in which the AuNPs are assembled onto the GO surface, forming the hybrid GO-AuNP assemblies with intense CD response and SERS activity. In the presence of targets, the hybridization of miR-21 with the probe causes the separation of 6-fluorescein-phosphoramidite-modified $\mathrm{Au}$ NPs from GO, leading to a decrease in the SERS signal, while EpCAM recognition causes the decrease of CD signal (Figure 12(b)). In a word, DNA directed nanostructure affords powerful tools for bioanalysis in vivo or in vitro.

\section{Device development for nucleic acid analysis}

As an essential biological molecule, nucleic acids participate in many physiological and pathological processes [324]. Aberrant expression and mutations of nucleic acid sequences may lead to occurrence of various diseases, such as cancer [325,326]. Thus, highly efficient detection and analysis of target nucleic acids are of great importance. One of the key demands for accurate nucleic acid analysis is to develop highly sensitive and precise analytical devices that can provide valid information and guidance for molecular diagnosis and disease treatments [327]. Different from bulk and largescale instruments, miniaturized and portable devices with low cost, easy operation, high-throughput and multiplex performance are rather desirable to practical use, especially for clinical applications [328]. Aiming at these advantages, a wide range of devices have been extensively exploited as the promising tools for efficient nucleic acid analysis [329,330]. In this section, we highlight various miniaturized devices used for nucleic acid analysis and detection in vitro, including PCR detection systems, microfluidics, handheld instruments, and paper-based systems.

\subsection{PCR device}

PCR is a molecular biology technique used to amplify specific DNA fragments [331]. Benefiting from the unique properties of high sensitivity, versatility, rapidity and easy to manipulate, PCR has been widely applied for molecular diagnosis of genetic disease, pathogens and oncogene, especially for the field of nucleic acid analysis [332-334]. To meet the rapid advances of PCR technique and molecular analysis, various automated and functional PCR-based devices have been gradually developed for different analytical requirements [335,336]. Conventional PCR thermal cyclers generally focus on the temperature control and nucleic acid duplication during amplification processes [337]. The drawbacks of large instrument size with tedious operation time and high-power consumption hamper their practical applications. With the rapid development of automation and integration technology, more intelligent, miniaturized and 

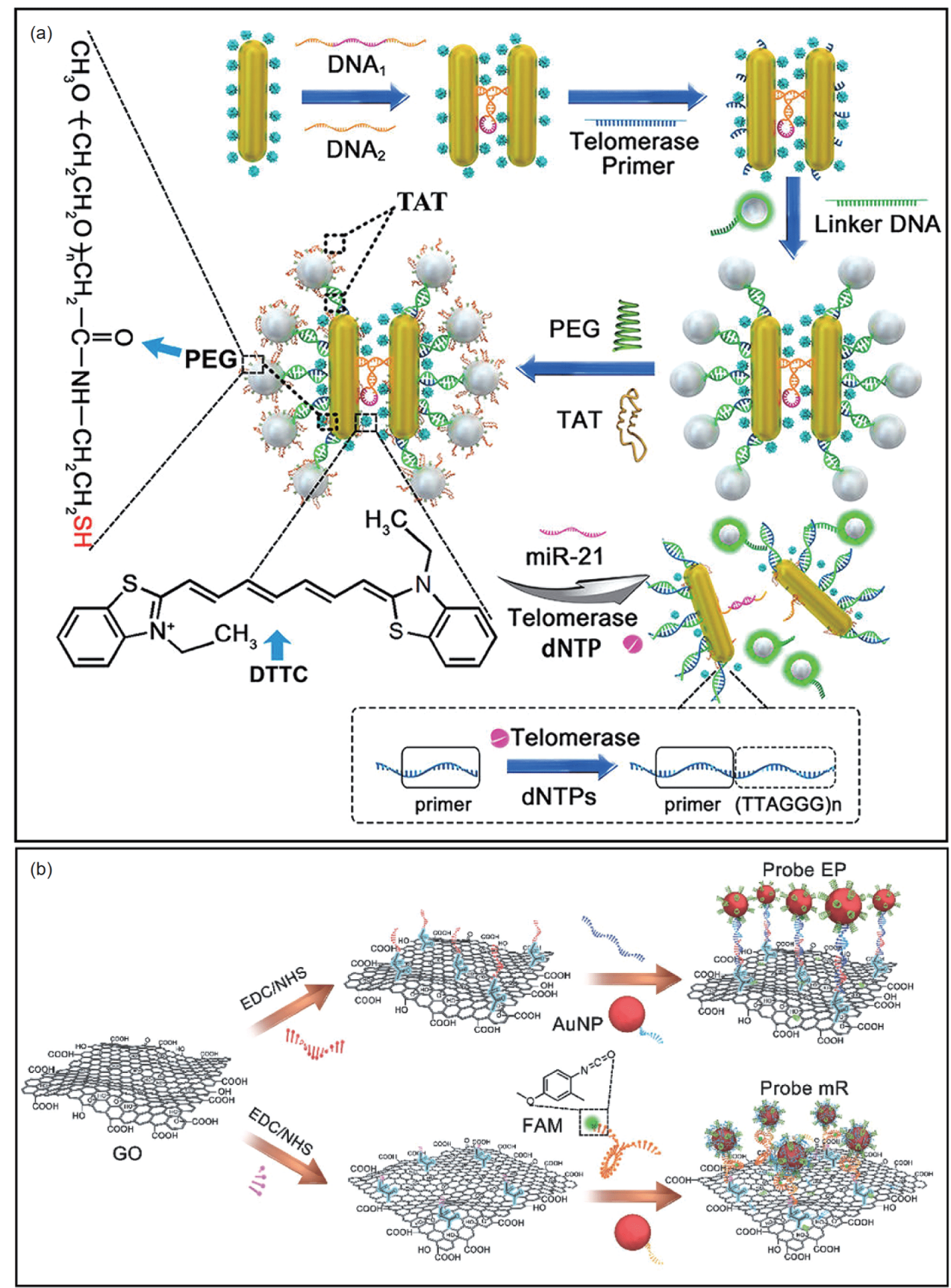

Figure 12 Representative examples of non-nucleic acid target analysis. (a) Schematic of Au NR dimer-UCNP core-satellite nanostructures used for the simultaneous analysis of intracellular miR-21 and telomerase [323], Copyright 2017 American Chemical Society. (b) GO-Au assembly strategy for EpCAM (probe Ep) and miR-21 detection (probe mR) [210], Copyright 2017 WILEY-VCH (color online).

precise PCR devices have been extensively exploited [338,339]. For instance, Helb et al. [340] used a simple cartridge system with real-time PCR, named Cepheid GeneXpert System, to detect Mycobacterium tuberculosis and rifampin resistance. The limit of detection of the $\mathrm{Myco-}$ bacterium tuberculosis DNA was 4.5 genomes per reaction. Hatch et al. [341] reported a low power, high-throughput and portable qPCR device with continuous flow thermal cycling manners that could be used for multiple analyte detections
(Figure 13(a)). Only 0.1-10 $\mu \mathrm{L}$ droplet samples were needed to realize the high PCR amplification efficiency and sensitive fluorescence detection. The PCR efficiency of this device could be reached within the range of $90 \%-110 \%$, and the limit of detection was 10 copies per reaction. Li et al. [342] developed a photonic-PCR system that integrated $\mathrm{Fe}_{3} \mathrm{O}_{4}$ nanoclusters for effective photothermal cycle modulation with a battery-powered device for successful data transfer (Figure 13(b)). The system was energy efficient and easy 


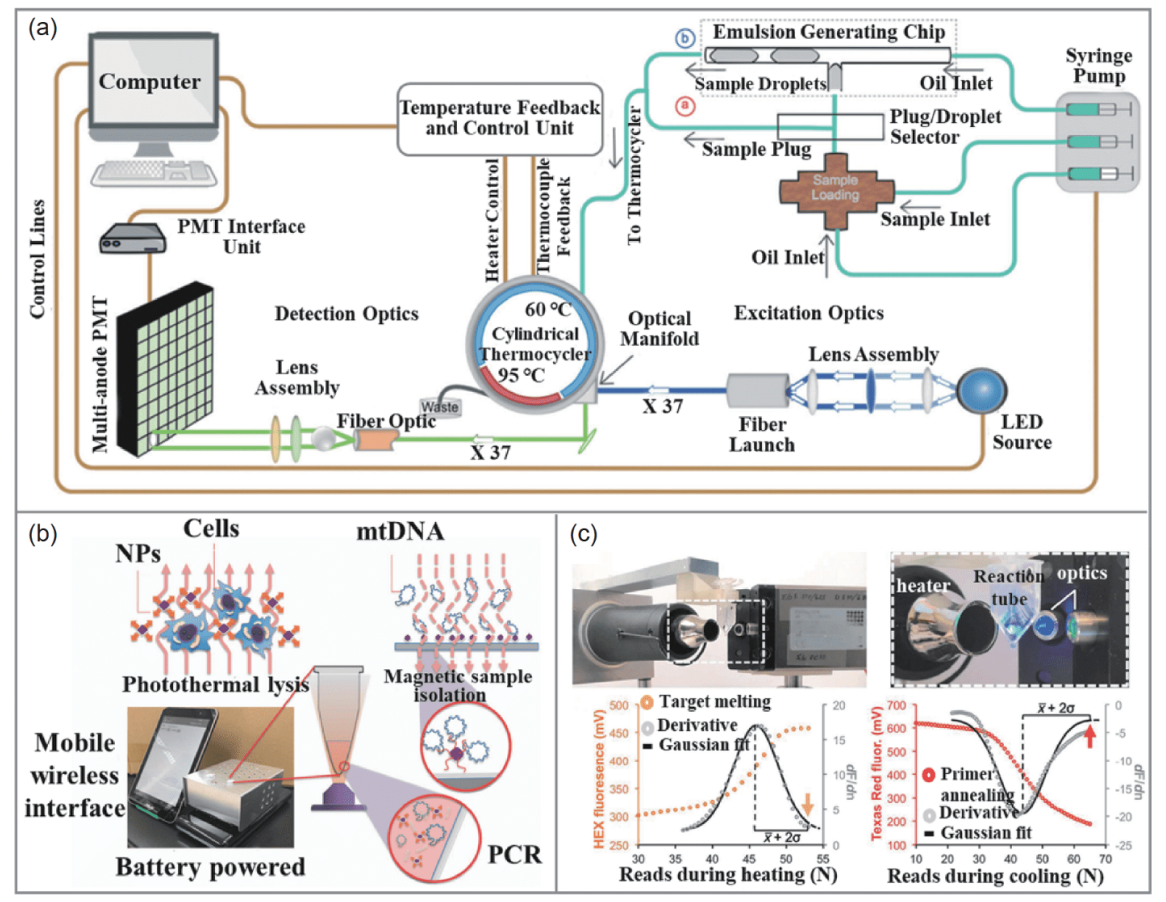

Figure 13 PCR devices for nucleic acid analysis. (a) Schematic illustration of the portable real-time PCR device with continuous flow thermal cycling for multiple DNA sample analysis [341], Copyright 2014 Royal Society of Chemistry. (b) Schematic illustration of the handheld qPCR device integrated with magnetic nanoparticles for effective target DNA detection [342], Copyright 2016 Nature Publishing Group. (c) Schematic illustration of the adaptive PCR device to dynamically control and monitor the DNA replication processes [343], Copyright 2017 American Chemical Society (color online).

establishment, which efficaciously applied for the detection of defective mtDNA in mitochondrial diseases with low initial template concentration (50 pg-500 ng) and highly reasonable linearity. Despite the significant improvements of PCR devices, the highly sensitive reaction condition and the rigorous temperature calibration still remain big obstacles for more precise and controllable PCR-based diagnosis. Based on this circumstance, Adams et al. [343] constructed a prototype adaptive PCR instrument focusing on dynamically sensing the hybridization state during the PCR process instead of the temperature monitoring (Figure 13(c)). This system has been proved more robust and simpler, and it could overcome the limitation of strict temperature calibration in some traditional PCR instruments. Additionally, the occurrence of $\mathrm{dPCR}$ with absolute quantification also largely promotes the advance of PCR devices [344-346]. Gou et al. [347] constructed a handheld smartphone-based dPCR device for the detection of the plasmid DNA with the human $18 \mathrm{~S}$ ribosomal RNA gene fragment. The device functions could be automatically controlled by a custom software, and the accurate detection could reach down to 10 copies. Moreover, Zhou et al. [348] developed a highly integrated real-time dPCR device that constructed based on off-theshelf electronics and 3D printing technology. This $\mathrm{dPCR}$ device was successfully applied to the plasmid DNA targets with enhanced accuracy and could overcome the misclassification of positive partitions in some classical dPCR devices. Overall, PCR is still a promising development direction in the application of nucleic acid analysis. By combining with advanced microanalysis technology and molecular biotechnology, more integrated and smarter PCR devices with higher accuracy and sensitivity will be widely exploited and applied.

\subsection{Microfluidic device}

Microfluidics featuring at reduced sample consumption and shortened reaction time has been extensively studied for nucleic acid analysis, because of its capability to integrate different operation units, such as sample pretreatment, nucleic acid extraction and amplification, and signal detection into a single microfluidic device [349-352]. A microfluidic cassette was designed for nucleic acid detection of Zika Virus [353]. The sensitivity of this platform was less than 5 plaque-forming units (PFU) per sample and the total detection time was less than $40 \mathrm{~min}$. A self-powered integrated microfluidic chip was reported for rapid digital detection of nucleic acids from human blood sample (Figure 14(a)) [354]. This microfluidic chip powered by a vacuum battery was prepatterned with the amplification initiator MgOAC. After mixing with reagents, the blood sample was introduced into microfluidic chip and then separated autonomously into microwells for isothermal recombinase polymerase amplification (RPA) reaction. This microfluidic chip enabled de- 
(a)

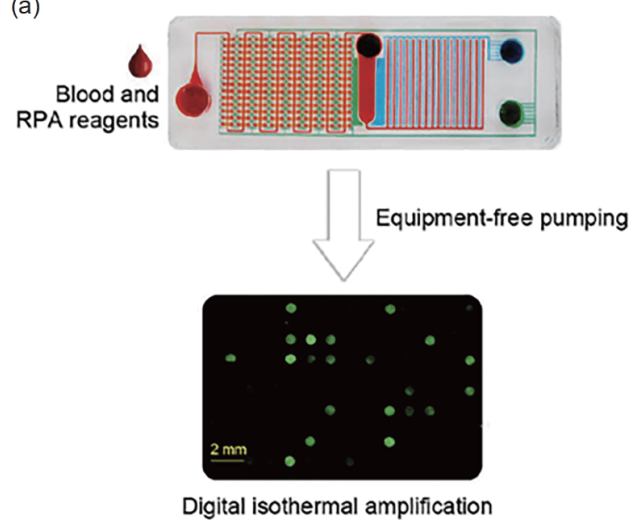

(c)

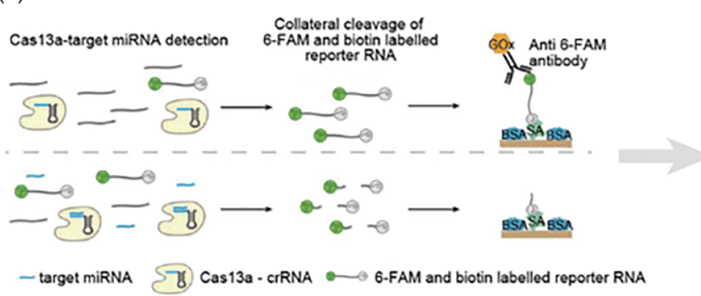

(b)
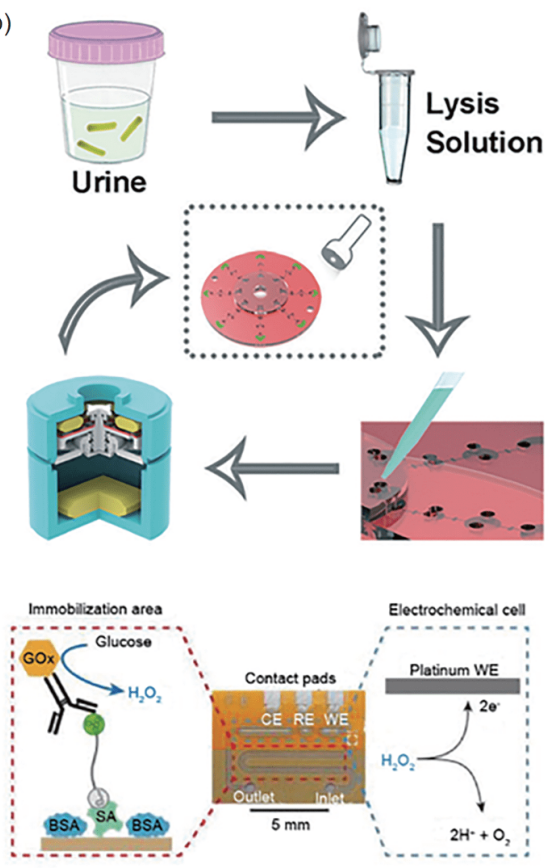

Figure 14 Microfluidic devices for nucleic acid analysis. (a) Self-powered integrated microfluidic chip for RPA-based quantitative detection of DNA (Yeh et al. [354], 2017), Copyright 2017 American Association for the Advancement of Science. (b) Schematic illustration of sample-to-answer nucleic acid detection by the hand-powered centrifugal microfluidic platform [355], Copyright 2018 Royal Society of Chemistry. (c) CRISPR/Cas13a-powered electrochemical microfluidic platform for miRNA diagnostics (Bruch et al. [356], 2019), Copyright 2019 Wiley-VCH (color online).

tection of methicillin-resistant Staphylococcus aureus DNA (10 to $10^{5}$ copies per microliter) within $30 \mathrm{~min}$. In a recent work, a hand-powered centrifugal microfluidic platform was developed for sample-to-answer detection of pathogens (Figure 14(b)) [355]. Through a simple pull-out operation of the customized centrifuge, the pathogen sample was rapidly mixed with the preloaded reagents inside the microfluidic disc. After on-disc LAMP at $65^{\circ} \mathrm{C}$ heated by pocket warmers, the presence of target pathogens can be observed by visible fluorescence. This microfluidic platform allowed for simultaneous detection of six pathogens with the sensitivity of $2 \times 10^{2}$ cells per $\mu \mathrm{L}$. For diagnostics of miRNA in serum, a CRISPR/Cas13a-based electrochemical microfluidic biosensor was designed (Figure 14(c)) [356]. This amplification-free platform showed a limit of detection of $10 \mathrm{pM}$, and the total process time was less than $4 \mathrm{~h}$. A centrifugal microfluidic platform with all reagents prestored was reported for nucleic acid analysis of pathogen by qRT-PCR [357]. The whole detection procedure was carried out within a $2 \mathrm{~kg}$ portable instrumentation and the total time was less than $3.5 \mathrm{~h}$. Self-contained microfluidic platforms integrated with a variety of operations and functions, show great potential for nucleic acid diagnostics in POC formats.

\subsection{Handheld device}

Many commercial and handheld devices, such as glucometer, pressuremeter, thermometer and $\mathrm{pH}$ meter, are successfully available to the public with easy use and excellent sensitivity. Recently, by combining these handheld devices with biological recognition and amplifying transducer components, portable biosensors for various targets detection with high sensitivity have been exploited, such as nucleic acids [358]. Glucometer was the first portable device being used for nonglucose target detection [359,360]. As shown in Figure 15 (a), Xu et al. [361] used DNA sandwich hybridization happened between the HIV target DNA and the capture probes as well as the signal probes to introduce multi-invertase conjugated nanoparticles to the surface, which can enzymatically convert sucrose to glucose for signal amplification and glucometer monitoring. Si et al. [362] reported an oligonucleotide cross-linked hydrogel for recognition and quantification of miRNA with glucometer. In their work, the target miRNA was the essential component to form DNAzyme that can cleave the crosslinkers of hydrogel to destroy hydrogel and release encapsulated amylase, which can further catalyze the hydrolysis of amylose to produce a large amount of glucose for glucometer readout. The dual amplification by DNAzyme and amylase resulted in high sensitivity that as low as 0.325 fmol miRNA can be portably detected by glucometer. Pressuremeter is another userfriendly and portable device with wide dynamic range $(0-3000 \mathrm{kPa})$ and low detection sensitivity $(0.01 \mathrm{kPa})$ [363]. Shi et al. [364] designed target miRNA induced cyclic strand displacement to enrich platinum nanoparticles onto the surface of magnetic beads, which can catalytically decompose 


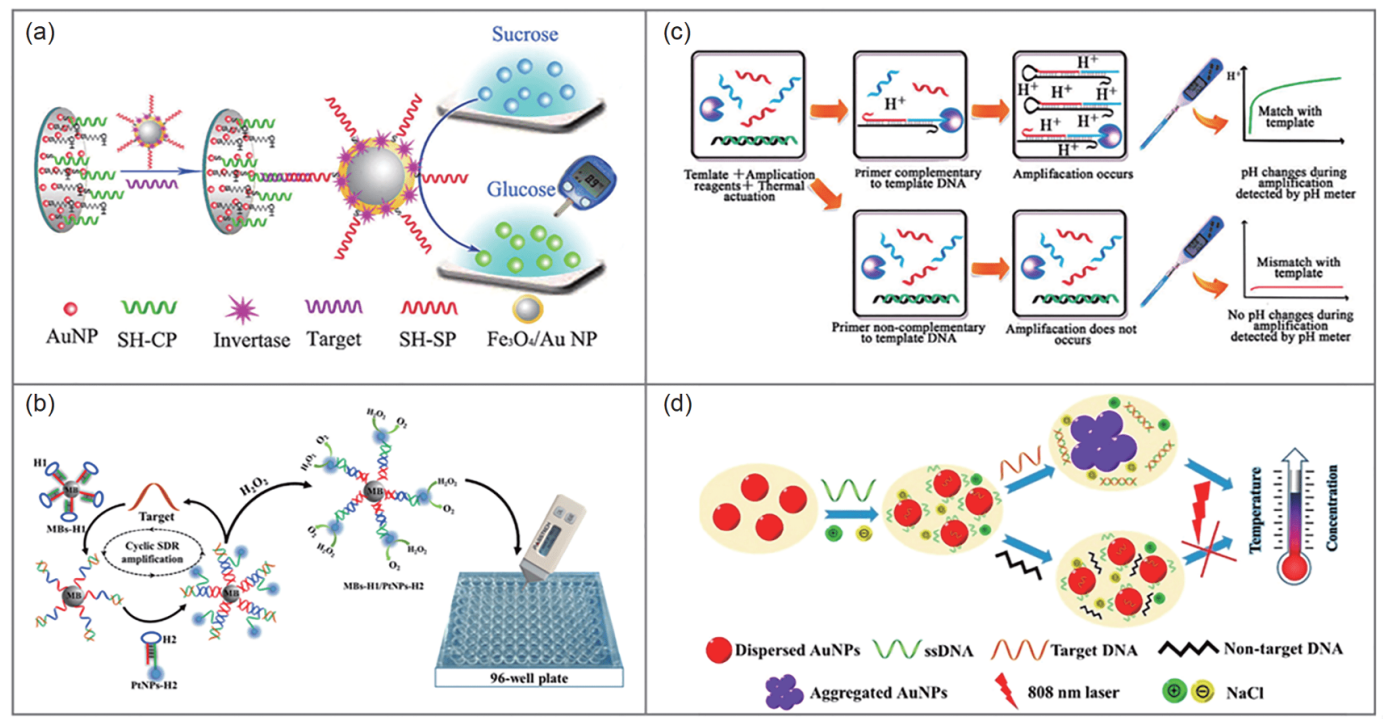

Figure 15 (a) Schematic presentation for sensitive POC detection of HIV DNA fragments using glucometer [361], Copyright 2012 Royal Society of Chemistry. (b) Schematic illustration of gas pressure-based POC assay for sensitive detection of miRNA with pressuremeter [364], Copyright 2018 American Chemical Society. (c) Schematic illustration of the amplified detection of target DNA based on pH meter [366], Copyright 2014 Royal Society of Chemistry. (d) Schematic illustration of AuNP aggregation-induced photothermal biosensing of target DNA using thermometer [367], Copyright 2020 American Chemical Society (color online).

$\mathrm{H}_{2} \mathrm{O}_{2}$ for the generation of $\mathrm{O}_{2}$ to induce pressure change with pressuremeter readout (Figure 15(b)). Toumazou et al. [365] has found out that the released hydrogen ions during nucleotide incorporated DNA amplification can be directly measured to quantify target sequence. Using this strategy, Yuan and coworkers [366] simply used the $\mathrm{pH}$ meter to measure the hydrogen ions generated by loop mediated isothermal amplification for the facile and sensitive detection of Nosema bombycis genomic DNA (Figure 15(c)). Recently, Li group [367] reported the use of a common thermometer for visual and quantitative genetic detection. As shown in Figure 15(d), single-stranded DNA on AuNPs would be deprived because of the hybridization with target DNA, resulting in AuNP aggregation upon the addition of salt. While being irradiated by NIR laser, the temperature was obviously elevated in the aggregated AuNP suspension. As high as $18{ }^{\circ} \mathrm{C}$ temperature change can be readout by thermometer and the detection limit of $0.28 \mathrm{nM}$ was achieved without amplification. Besides, other handheld devices such as electronic balance [368], digital multimeter [369], uric acid meter [370], could also be used for nucleic acid analysis with appropriate signal transduction and signal amplification mechanism. The use of these handheld devices that are widely applied in daily life, opens a new door for simple, cost-effective, user-friendly and portable POC testing of nucleic acids with high specificity and sensitivity and without external bulky instrumentation.

\subsection{Paper-based device}

Traditionally, paper has been extensively used for printing and writing owing to its low price and high yield. Beyond that, because of the fibrous and porous structure, high surface-to-volume ratio and hydrophilicity [371], paper has been also exploited as a substrate material for metal detection [372], paper chromatography [373] and bioanalysis system [373-379]. Using printing techniques, such as inkjet printing [380], wax printing [381] and screen printing [382], paper has been used to construct different analytical devices by modifying with small molecules, nucleic acid, antibodies or other proteins (Figure 16) [377,380,383]. Thus, paper-based analytical devices (PADs) as promising technologies provide alternative platforms to develop low-cost, portable, rapid and disposable biosensors for POC diagnostic [384-388]. With the development of nucleic acid technology, a broad spectrum of nucleic acid-based PADs has been exploited to detect a wide variety of analysts by electrochemical, colorimetric, chemiluminescent or fluorimetric readouts.

Electrochemical PAD biosensors are constructed often through wax-printing or screen printing [378,379,389-391]. In 2009, the first electrochemical PAD was developed by Dungchai et al. [392]. Since then, electrochemical PADs aroused wide interest because of easy use, uncomplicated equipment, cost-efficient and rapid analysis, portable potentiostats, renewable sensing interface and well-known electrochemical signaling methods [393]. The fabrication processes are divided into three steps roughly: Firstly, suitable electrodes were chosen as reference electrode, working electrode and counter electrode, respectively. Secondly, electrodes are printed onto paper by using printing techniques. Thirdly, nucleic acids are modified on working electrodes through chemical reaction, generating sensing 


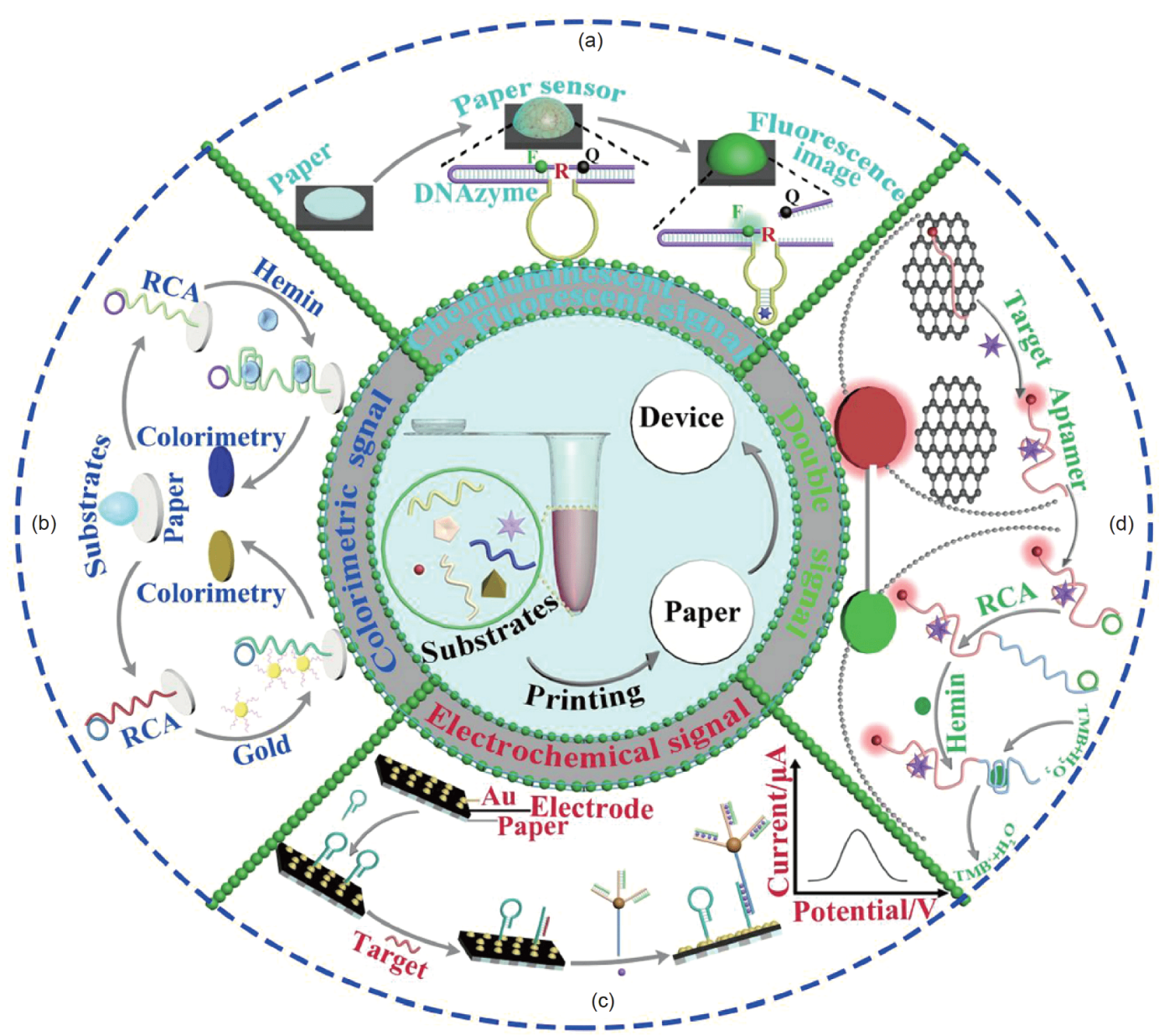

Figure 16 The schematic diagram of paper-based devices. (a) Paper-based chemiluminescent or fluorescent devices based on signaling nanoparticles (e.g., fluorophores and quantum dots) and auxiliary molecules. (b) Paper-based colorimetric device via utilizing the aggregation of noble nanoparticles (such as gold nanoparticle) or the oxidation of chromogenic substrates. (c) Paper-based electrochemistry devices by printing working electrodes with nucleic acids on paper. (d) Paper-based devices with dual output signals (e.g., fluorescent/colorimetric signals) (color online).

interface. Until now, a wide range of electrochemical nucleic acid-based PADs have been developed [394].

Benefiting from the simplicity, sensitivity and low cost, colorimetry detection technique is considered to be suitable for integrating with PADs [395]. Colorimetric assays in PADs are accomplished usually depending on the aggregation of noble nanoparticles [395,396] or the oxidation of chromogenic substrate [396-400]. The target-stimuli signal, color change, can be visualized by naked eyes and the detection zone images can collected by camera phone or portable scanner and then transformed into quantitative information by software [394,401-403]. On account of the optical properties [404] and easy modification with bio-recognition elements [405,406], gold nanoparticle becomes one of the most popular nanoparticles in colorimetric assays. For instance, a colorimetric assay was performed on paperbased analytical device for the detection of prostate specific antigen in human serum taking advantages of AuNPs modified with nucleic acid and horseradish peroxidase capable of oxidizing TMB with the assistance of hydrogen peroxide
[400].

Based on fluorimetic/chemiluminescent molecules and nanoparticles (e.g., fluorophores and quantum dots), paperbased DNA biosensors also are often constructed for the detection of different analysts, such as metal ions, DNAs and cancer cells [407-412]. For example, Wang and partners [412] developed a chemiluminescent PADs to distinguish target DNA from single-mismatched one by employing carbon dots dotted nanoporous gold as amplification signal label. In addition, dual output signals (e.g., electrochemical/ colorimetric signals) paper-based biosensors are also proposed $[123,410,413,414]$.

Various nucleic acid-mediated reactions have been exploited in PADs, including simple DNA hybridization $[378,379,389,395,409]$ and complex reactions, such as PCR [415], RPA [398,416], RCA [396,399,417], and SDA $[418,419]$. The sensing interfaces are composed of oligonucleotide monolayers $[379,412,420]$, composite multilayer [378,409] and 3D nucleic acid materials [399,410] or oligonucleotide-containing heterogeneous nanostructures 
[123]. The analysts include small molecules [375,421], miRNAs [378], DNA strands [123,379,412,420], proteins [375,379,391,422], exosomes [409], cancer cells [422], papillomavirus [389], pathogens [408] and so on, implying the great potential of nucleic acid-based PADs in enormous applications.

\section{Applications of nucleic acid analysis}

Over the past decades, nucleic acid analysis has experienced rapid advances with new analysis techniques, devices and kits. Owing to its merits of sensitivity and specificity, it has been widely applied in clinical translation, environmental analysis, food safety, forensic analysis and so on.

\subsection{Clinical translation}

Nucleic acid-based molecular diagnostics is a collection of techniques used to analyze nucleic acid markers of diseases, promoting the development of personalized medicine [423]. It has been widely applied in clinical practice for the screening, diagnosis, risk assessment, and treatment guidance of diseases, including cancer, congenital anomaly and infectious disease. Thereinto, many techniques have achieved clinical translation with commercial devices and assay kits [424]. For precision diagnosis and therapy of cancer, the detection of DNA mutation, DNA methylation, and miRNA, as well as the expression analysis of key genes from tumor-biopsy specimens has been performed, such as epidermal growth factor receptor (EGFR) mutation, human epidermal growth factor receptor 2 (HER2) amplification.
[425-427]. For prenatal testing, nucleic acids analysis of fetal cells from amniocentesis and chorionic villus sampling enables to detect problems such as chromosome abnormalities and gene mutations, serving as a powerful method to control genetic diseases and birth defect [428]. More importantly, the rapid advance of PCR techniques and NGS together with liquid biopsy allows sensitive and reliable molecular diagnosis of tumor/fetal-derived circulating targets, including circulating tumor/fetal cells (Figure 17(a)), cell free circulating DNA (Figure 17(b)), circulating miRNAs, extracellular vesicles, tumor-educated platelets. [429435]. These approaches offer comprehensive and timely information for personalized anti-cancer therapy and noninvasive prenatal testing (NIPT).

Pathogen infection is a common health problem worldwide. Especially, the pandemic of corona virus-based COVID-19 since the end of 2019 poses great threats to the public health. Thus, it is critically important to develop rapid, sensitive, and reliable methods to detect and identify pathogens for adopting effective therapy and controlling epidemic. Nucleic acid analysis is popularly utilized for infection diagnosis clinically, and also serves as a gold standard method for pathogen identification [436]. Nucleic acid amplification analysis with exquisite sensitivity and specificity allows for rapid and accurate detection of pathogens, free of time-consuming culture (Figure 17(c)) [437]. Multiplex PCR and various hybridization-based biosensors afford multiplex pathogen analysis [438,439]. Besides, high-throughput sequencing enables the identification of unknown pathogens and determination of drug resistancerelated genes or gene mutations [440]. Moreover, sequence data can be used to reconstruct the evolution of pathogens
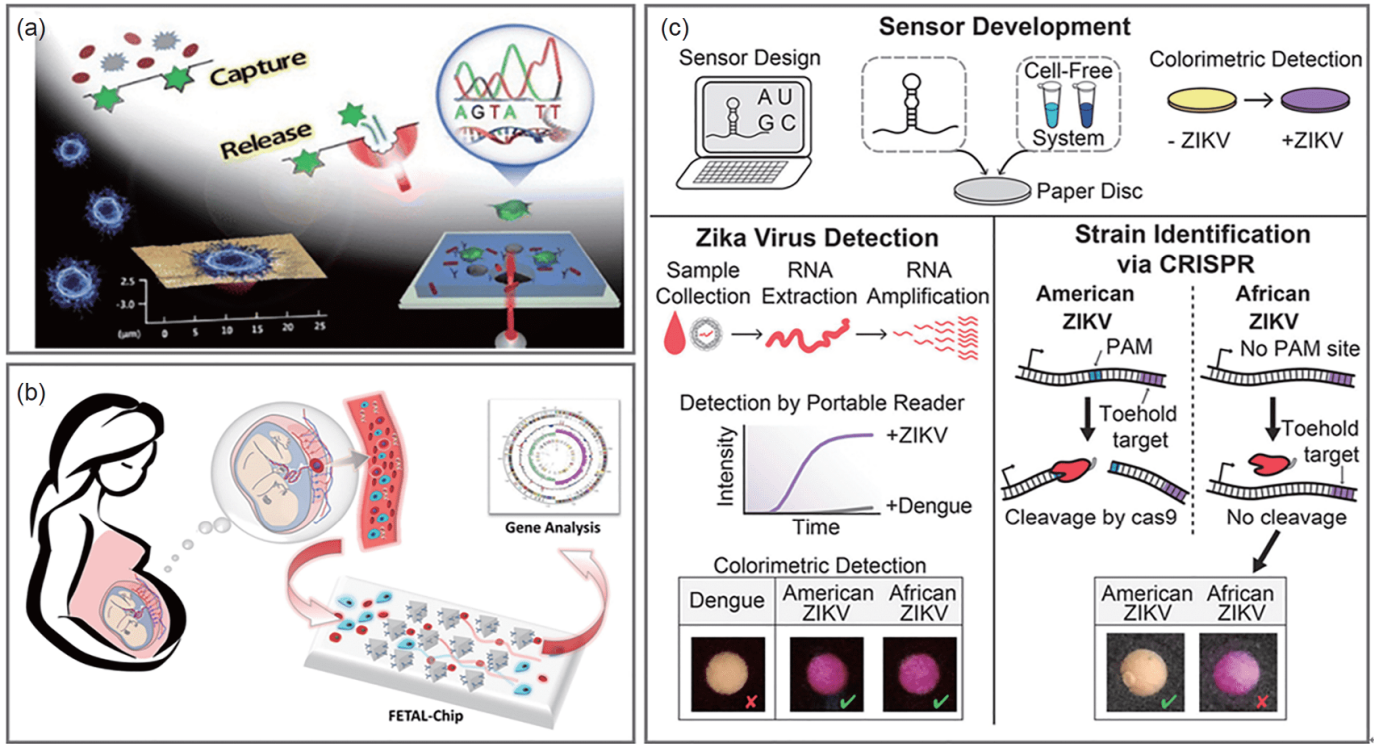

Figure 17 Clinical translation of nucleic acid analysis. (a) Gene mutation analysis of circulating tumor cells [434], Copyright 2016 American Chemical Society. (b) Gene analysis of circulating fetal cells for NIPT [435], Copyright 2018 The Royal Society of Chemistry. (c) Paper-based sensors to detect RNA genome of the Zika virus [437], Copyright 2016 Elsevier (color online). 
and predict future spread for better intervention [441]. Considering that pathogen infection is still the leading causes of death in low-income countries, more efforts should be devoted into the development and clinical translation of reagents and instruments of nucleic acid-based point-of-care testing (POCT).

Besides taking nucleic acids as analysis targets, functional nucleic acids can be utilized as recognition tools and drugs for clinical diagnosis and therapy $[442,443]$. For example, numerous aptamer-based biosensors have been developed for sensitive detection of disease biomarkers and pathogens [444]. Pegaptanib, as a pegylated anti-vascular endothelial growth factor (VEGF) aptamer, was approved by U.S. Food and Drug Administration (FDA) in 2004 for the treatment of age-related macular degeneration [445]. Very recently, several aptamers targeting proteins of $2019-\mathrm{nCoV}$ have been reported [446-448].

\subsection{Environmental analysis}

Earth's biodiversity is undergoing continuous decline, which represents a major environmental crisis. Coupled with sequencing technique, environmental DNA, defined as genetic material from environmental samples, is considered as potential candidate for biodiversity monitoring (Figure 18(a)) [449]. Thereinto, environmental microbiology attracts the most attention due to the vital role of microorganisms in regulating ecosystem system. Metagenomics sequencing and 16S rRNA gene sequencing are capable of characterizing the diversity and abundance of microbial communities [450,451]. Thus, influence factors on microbial communities can be evaluated for pollution abatement and ecosystem management, such as environmental pollution, climate change, introduced species and human activities [452]. Additionally, nucleic acid analysis techniques facilitate the identification and isolation of microorganisms with specific phenotypes, such as mercury resistant bacteria in con- taminated environments [453]. Therefore, nucleic acid analysis is acting as a powerful means in environmental monitoring and management.

The increasing presence of harmful pollutants in the environment affects human health, and calls for analytical methods for pollution monitoring. Nucleic acid-based biosensors with merits of miniaturization, portability and integration open new avenues for the detection of environmental pollution and toxicity (Figure 18(b)). On the one hand, taking target nucleic acid sequences as analytes, hybridization-based biosensors enable to detect pathogens, harmful algae and genetically-modified plants in environmental samples [454]. On the other hand, taking functional nucleic acids as recognition elements, including aptamer, DNAzyme and allosteric DNAzyme, numerous biosensors have been developed for convenient and rapid detection of metal ions, chemical residue, etc. $[455,456]$. Besides, DNA damage caused by pollutants (e.g., heavy metals, pesticide residue) could be detected with electrochemical DNA-based biosensors, allowing for toxicity screening and environmental monitoring [457].

\subsection{Food analysis}

Food analysis is of great significance to prevent foodborne diseases which are mainly originated from foodborne contaminants including chemical and biological hazards. The above-mentioned nucleic acid-based pathogen analysis techniques are also widely used to detect and identify foodborne pathogens and to study food microbial ecology $[458,459]$. Functional nucleic acids, coupled with novel transducers and nanoprobes, offer a variety of biosensors for foodborne contaminant detection [460-462]. These biosensors have achieved rapid and sensitive detection of pathogens (Figure 19(a)) [463], mycotoxins (Figure 19(b)) [464,465], allergens [468], pesticides [467], heavy metal ions [468] and illegal additives [469], with a great applica-
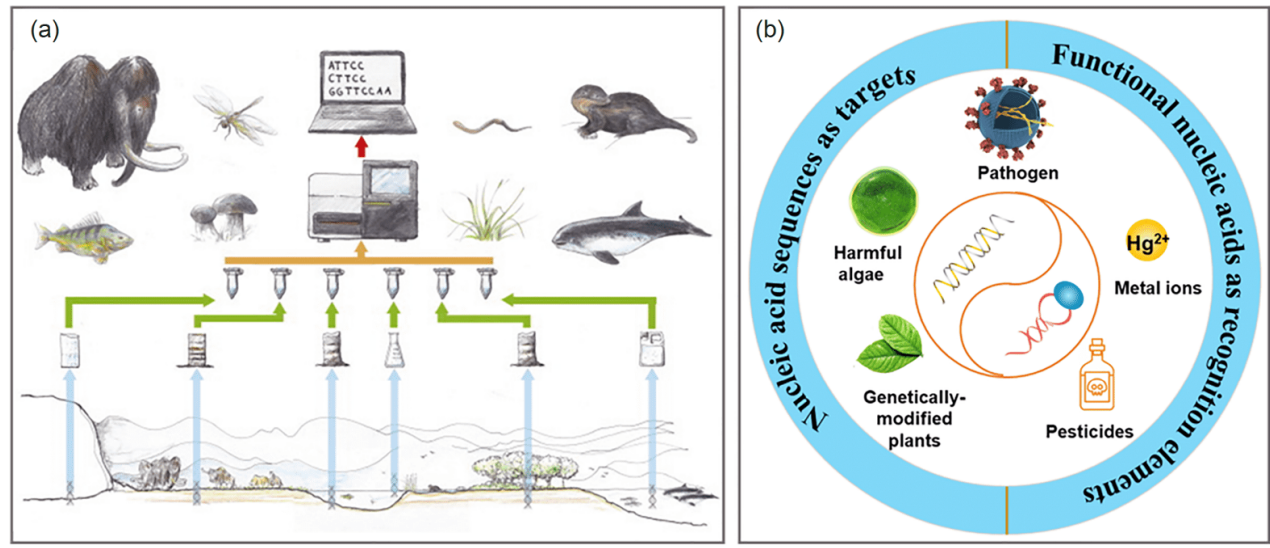

Figure 18 Nucleic acid-based environmental analysis. (a) The overall workflow for environmental DNA analysis [446], Copyright 2015 Elsevier. (b) Nucleic acid-based biosensors for the detection of environmental pollution and toxicity (color online). 

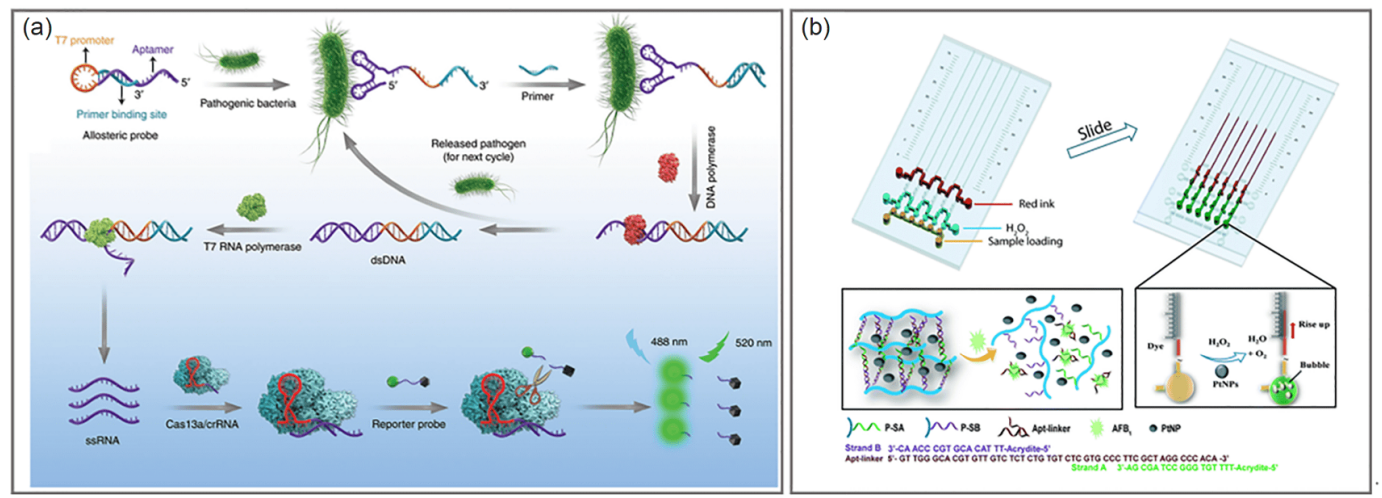

Figure 19 Nucleic acid-based biosensors for food analysis. (a) Aptamer-based allosteric probes for the detection of foodborne pathogens using clustered regularly interspaced short palindromic repeats (CRISPR)-Cas13a [463], Copyright 2020 Nature Publishing Group. (b) Target-responsive aptamer hydrogel for portable visual quantitative detection of aflatoxin B1 using a distance-readout microfluidic chip [465], Copyright 2016 The Royal Society of Chemistry (color online).

tion potential in POCT. In the future, the development of low-cost, rapid and miniaturized analytical technologies will still be the important mainstream in this field.

\subsection{Forensic analysis}

DNA typing has become an indispensable tool for individual identification in forensic analysis, including homicides, sexual assaults, missing persons and parental testing. Short tandem repeat (STR) sequences are most widely utilized for forensic human identification [470]. The genetic markers located on the $\mathrm{Y}$ chromosome can provide male specific information for investigating sexual assault and unestablished paternity [471]. As for degraded or low template samples, single nucleotide polymorphisms (SNPs) and mtDNA could provide additional genetic information to augment forensic analysis. Additionally, mRNA signatures have been widely applied in many forensic laboratories for body fluid identification [472]. The RNA decay analysis facilitates the determination of the post-mortem interval and the age of biological stains [473]. MiRNA is more stable and has greater discriminatory potential than mRNA, and its profiling is attracting more attention in forensic science [474]. Additionally, sequencing-based microbial forensics contributes to human identification, geolocation, postmortem interval estimation and bioterrorism defense [475]. Notably, microfluidic devices have been designed for forensic analysis with merits of reduced risk of contamination, shortened analysis time and supporting POCT [476].

\subsection{Security}

Information security is one of the vital issues in modern society, which requires cryptography schemes to protect messages for secure communication. With the advantages of vast storage density and massive parallelism capacity, nu- cleic acid molecules have attracted considerable attention in the field of information security [477,478]. DNA cryptography is emerged for encryption, authentication and signature by harnessing nucleic acids as informational and computational carriers $[479,480]$. DNA with high memory density makes it possible for one-time-pads (OTP) cipher cryptosystem which is considered as the most secure strategy of private key encryption. Many DNA-based encryption methods have been designed for OTP, and PCR and DNA chip techniques are the most prominent choices [481,482]. DNA chip techniques enable to encrypt both textual data and two-dimension images [483]. Besides sequence information, structural patterns of DNA nanostructures provide an alternative strategy for cryptography (Figure 20) [484]. Nucleic acid-based information steganography can hide secret information as nucleic acid strands for transmission in various carriers, such as DNA microdots, genetic codon and living organisms $[480,485]$. Although significant and promising, nucleic acid-based information security still stay in a theoretical stage, and intensive efforts should be made in this field to improve the accuracy, efficiency and robustness.

\section{Conclusions and perspective}

Nucleic acids analysis holds great promise as a bioanalytical paradigm for various applications in biology, chemistry and clinics. Recent developments on the analysis of nucleic acids including in-vitro analysis based on hybridization, target amplification and sequencing have led to applications for intracellular and in-vivo analysis. The use of nucleic acids as recognition elements (e.g., aptamers, DNAzymes) and engineering tools (e.g., DNA/RNA nanostructures) in bioanalysis is also of particular focus to bring nucleic acids into the analysis of a broad spectrum of targets including ions, metabolites, proteins, exosomes, even whole cells. Furthermore, 


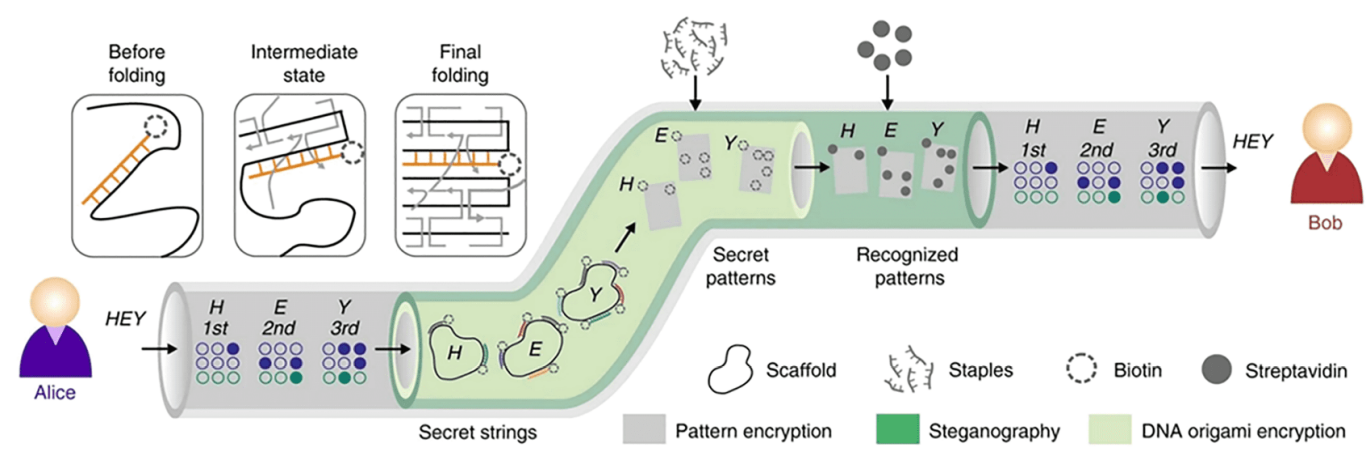

Figure 20 DNA origami-based cryptography with multi-level protection for secure communication [255], Copyright 2019 Nature Publishing Group (color online).

the incorporation of nucleic acids analysis in electronic/ mechanic devices opens new opportunities for translating laboratory techniques to real-world applications. Especially, applications of nucleic acids analysis and nucleic acidsbased analysis in clinical diagnostics, food analysis, environmental analysis, forensic analysis and homeland security have shown great potential. We envision that the field of nucleic acids analysis will continue to grow benefiting from coupling of integrated and miniaturized biosensing devices, which can expand the application of nucleic acidsbased sensors to enable the real-time study of biological process and to minimize the invasion for biomedical applications. The improvement of the aptamer selection strategy will expand the range of detectable targets with high specificity and selectivity. Novel signal transduction and signal amplification strategies may improve the detection sensitivity down to single cells, single particles and single molecules. The development of the high-throughput of biosensors will further increase the capability of biosensors to be coupled with big data analysis to accelerate the development of precision medicine.

Acknowledgements The authors appreciate the invitation of the Editor-inChief Li-Jun Wan and the help of the editorial team of Science China Chemistry.

Conflict of interest The authors declare no conflict of interest.

1 Zhao Y, Chen F, Li Q, Wang L, Fan C. Chem Rev, 2015, 115: 1249112545

2 Seeman NC, Sleiman HF. Nat Rev Mater, 2018, 3: 17068

3 Zheng J, Yang R, Shi M, Wu C, Fang X, Li Y, Li J, Tan W. Chem Soc Rev, 2015, 44: 3036-3055

4 Wang X, Chen F, Zhang D, Zhao Y, Wei J, Wang L, Song S, Fan C, Zhao Y. Chem Sci, 2017, 8: 4764-4770

5 Duan R, Zuo X, Wang S, Quan X, Chen D, Chen Z, Jiang L, Fan C, Xia F. J Am Chem Soc, 2013, 135: 4604-4607

6 Shen J, Li Y, Gu H, Xia F, Zuo X. Chem Rev, 2014, 114: 7631-7677

7 Gomez D, Shankman LS, Nguyen AT, Owens GK. Nat Methods, 2013, 10: 171-177

8 Wang L, Zhang Y, Zhang C. Anal Chem, 2013, 85: 11509-11517

9 Tanaka Y, Xi H, Sato K, Mawatari K, Renberg B, Nilsson M, Kitamori T. Anal Chem, 2011, 83: 3352-3357
10 Han X, Wang R, Zhou Y, Fei L, Sun H, Lai S, Saadatpour A, Zhou Z, Chen H, Ye F, Huang D, Xu Y, Huang W, Jiang M, Jiang X, Mao J, Chen Y, Lu C, Xie J, Fang Q, Wang Y, Yue R, Li T, Huang H, Orkin SH, Yuan GC, Chen M, Guo G. Cell, 2018, 172: 1091-1107.e17

11 Li X, Zhang D, Zhang H, Guan Z, Song Y, Liu R, Zhu Z, Yang C. Anal Chem, 2018, 90: 2570-2577

12 Fu Y, Li C, Lu S, Zhou W, Tang F, Xie XS, Huang Y. Proc Natl Acad Sci USA, 2015, 112: 11923-11928

13 Chen Z, Zhou W, Qiao S, Kang L, Duan H, Xie XS, Huang Y. Nat Biotechnol, 2017, 35: 1170-1178

14 Sundah NR, Ho NRY, Lim GS, Natalia A, Ding X, Liu Y, Seet JE, Chan CW, Loh TP, Shao H. Nat Biomed Eng, 2019, 3: 684-694

15 Goodnow Jr RA, Dumelin CE, Keefe AD. Nat Rev Drug Discov, 2017, 16: 131-147

16 Fu Y, Zhang F, Zhang X, Yin J, Du M, Jiang M, Liu L, Li J, Huang Y, Wang J. Commun Biol, 2019, 2: 147

17 Fu Y, Chen H, Liu L, Huang Y. Anal Chem, 2016, 88: 10795-10799

18 Chen C, Xing D, Tan L, Li H, Zhou G, Huang L, Xie XS. Science, 2017, 356: 189-194

19 Wu C, Cansiz S, Zhang L, Teng IT, Qiu L, Li J, Liu Y, Zhou C, Hu R, Zhang T, Cui C, Cui L, Tan W. J Am Chem Soc, 2015, 137: 49004903

20 Qing Z, Xu J, Hu J, Zheng J, He L, Zou Z, Yang S, Tan W, Yang R. Angew Chem Int Ed, 2019, 58: 11574-11585

21 He X, Zeng T, Li Z, Wang G, Ma N. Angew Chem Int Ed, 2016, 55: 3073-3076

22 Gao R, Xu L, Hao C, Xu C, Kuang H. Angew Chem, 2019, 131: 3953-3957

23 Chen F, Xue J, Bai M, Qin J, Zhao Y. Chem Sci, 2019, 10: 3103 3109

24 Chen F, Bai M, Cao K, Zhao Y, Wei J, Zhao Y. Adv Funct Mater, 2017, 27: 1702748

25 Chen F, Bai M, Cao K, Zhao Y, Cao X, Wei J, Wu N, Li J, Wang L, Fan C, Zhao Y. ACS Nano, 2017, 11: 11908-11914

26 Rouhanifard SH, Mellis IA, Dunagin M, Bayatpour S, Jiang CL, Dardani I, Symmons O, Emert B, Torre E, Cote A, Sullivan A, Stamatoyannopoulos JA, Raj A. Nat Biotechnol, 2019, 37: 84-89

27 Lin R, Feng Q, Li P, Zhou P, Wang R, Liu Z, Wang Z, Qi X, Tang N, Shao F, Luo M. Nat Methods, 2018, 15: 275-278

28 Chen F, Xue J, Zhang J, Bai M, Yu X, Fan C, Zhao Y. J Am Chem Soc, 2020, 142: 2889-2896

29 Chen F, Bai M, Cao X, Zhao Y, Xue J, Zhao Y. Nucleic Acids Res, 2019, 47: e145

30 Tan W, Donovan MJ, Jiang J. Chem Rev, 2013, 113: 2842-2862

31 McGhee CE, Loh KY, Lu Y. Curr Opin Biotech, 2017, 45: 191-201

32 Peng H, Li XF, Zhang H, Le XC. Nat Commun, 2017, 8: 14378

33 Meng HM, Liu H, Kuai H, Peng R, Mo L, Zhang XB. Chem Soc Rev, 2016, 45: 2583-2602

34 Das J, Ivanov I, Sargent EH, Kelley SO. J Am Chem Soc, 2016, 138: 11009-11016 
35 Chen F, Bai M, Zhao Y, Cao K, Cao X, Zhao Y. Anal Chem, 2018, 90: 2271-2276

36 Wilner OI, Willner I. Chem Rev, 2012, 112: 2528-2556

37 Li J, Mo L, Lu CH, Fu T, Yang HH, Tan W. Chem Soc Rev, 2016, 45: 1410-1431

38 Lutz S, Weber P, Focke M, Faltin B, Hoffmann J, Müller C, Mark D, Roth G, Munday P, Armes N, Piepenburg O, Zengerle R, von Stetten F. Lab Chip, 2010, 10: 887-893

39 Wang CH, Lien KY, Wang TY, Chen TY, Lee GB. Biosens Bioelectron, 2011, 26: 2045-2052

40 Garibyan L, Avashia N. J Invest Dermatology, 2013, 133: 1-4

41 Petralia S, Conoci S. ACS Sens, 2017, 2: 876-891

42 Mullis K, Faloona F, Scharf S, Saiki R, Horn G, Erlich H. Cold Spring Harbor Symposia Quantitative Biol, 1986, 51: 263-273

43 Ståhlberg A, Krzyzanowski PM, Jackson JB, Egyud M, Stein L, Godfrey TE. Nucleic Acids Res, 2016, 44: e105

44 Tian H, Sun Y, Liu C, Duan X, Tang W, Li Z. Anal Chem, 2016, 88: 11384-11389

45 Arefian E, Kiani J, Soleimani M, Shariati SAM, Aghaee-Bakhtiari SH, Atashi A, Gheisari Y, Ahmadbeigi N, Banaei-Moghaddam AM, Naderi M, Namvarasl N, Good L, Faridani OR. Nucleic Acids Res, 2011, 39: e80

46 Navarro E, Serrano-Heras G, Castaño MJ, Solera J. Clinica Chim Acta, 2015, 439: 231-250

47 Nacham O, Clark KD, Anderson JL. Anal Chem, 2016, 88: 78137820

48 Bonetta L. Nat Methods, 2005, 2: 305-312

49 Dong J, Chen G, Wang W, Huang X, Peng H, Pu Q, Du F, Cui X, Deng Y, Tang Z. Anal Chem, 2018, 90: 7107-7111

50 Cao L, Cui X, Hu J, Li Z, Choi JR, Yang Q, Lin M, Ying Hui L, Xu F. Biosens Bioelectron, 2017, 90: 459-474

51 Wong YK, Tsang HF, Xue VW, Chan CM, Au TC, Cho WC, Chan LW, Wong SC. Expert Rev Precision Med Drug Dev, 2017, 2: 177186

52 Wang P, Jing F, Li G, Wu Z, Cheng Z, Zhang J, Zhang H, Jia C, Jin Q, Mao H, Zhao J. Biosens Bioelectron, 2015, 74: 836-842

53 Wang F, Zhu L, Liu B, Zhu X, Wang N, Deng T, Kang D, Pan J, Yang W, Gao H, Guo Y. Anal Chem, 2018, 90: 8919-8926

54 Fan X, Zhang X, Wu X, Guo H, Hu Y, Tang F, Huang Y. Genome Biol, 2015, 16: 148

55 Saiki R, Gelfand D, Stoffel S, Scharf S, Higuchi R, Horn G, Mullis K, Erlich H. Science, 1998, 239: 487-491

56 Giljohann DA, Mirkin CA. Nature, 2009, 462: 461-464

57 Guo Q, Yang X, Wang K, Tan W, Li W, Tang H, Li H. Nucleic Acids Res, 2009, 37: e20

58 Connolly A, Trau M. Angew Chem Int Ed, 2010, 49: 2720-2723

59 Deng R, Tang L, Tian Q, Wang Y, Lin L, Li J. Angew Chem Int Ed, 2014, 53: 2389-2393

60 Zhao W, Ali M, Brook M, Li Y. Angew Chem Int Ed, 2008, 47: 6330-6337

61 Deng R, Zhang K, Wang L, Ren X, Sun Y, Li J. Chem, 2018, 4 : 1373-1386

62 Tomita N, Mori Y, Kanda H, Notomi T. Nat Protoc, 2008, 3: 877882

63 Notomi T. Nucleic Acids Res, 2000, 28: 63e-63

64 Weusten JJAM. Nucleic Acids Res, 2002, 30: 26e-26

65 D'Souza DH, Jaykus LA. J Appl Microbiol, 2003, 95: 1343-1350

66 Jia H, Li Z, Liu C, Cheng Y. Angew Chem Int Ed, 2010, 49: 54985501

67 Connolly AR, Trau M. Nat Protoc, 2011, 6: 772-778

68 Yao GH, Liang RP, Yu XD, Huang CF, Zhang L, Qiu JD. Anal Chem, 2015, 87: 929-936

69 Hou T, Wang X, Liu X, Lu T, Liu S, Li F. Anal Chem, 2014, 86: 884-890

70 Liu J, Lu Y. J Am Chem Soc, 2003, 125: 6642-6643

71 Wang F, Elbaz J, Teller C, Willner I. Angew Chem Int Ed, 2011, 50: 295-299
72 Dirks RM, Pierce NA. Proc Natl Acad Sci USA, 2004, 101: 1527515278

73 Yang L, Liu C, Ren W, Li Z. ACS Appl Mater Interfaces, 2012, 4: 6450-6453

74 Wang F, Elbaz J, Orbach R, Magen N, Willner I. J Am Chem Soc, 2011, 133: 17149-17151

75 Yang X, Yu Y, Gao Z. ACS Nano, 2014, 8: 4902-4907

76 Huang F, Zhou X, Yao D, Xiao S, Liang H. Small, 2015, 11: 5800 5806

77 Huang F, You M, Han D, Xiong X, Liang H, Tan W. J Am Chem Soc, 2013, 135: 7967-7973

78 Yin P, Choi HMT, Calvert CR, Pierce NA. Nature, 2008, 451: 318322

79 Jiang YS, Li B, Milligan JN, Bhadra S, Ellington AD. J Am Chem Soc, 2013, 135: 7430-7433

80 Chen X, Briggs N, McLain JR, Ellington AD. Proc Natl Acad Sci USA, 2013, 110: 5386-5391

81 Jiang YS, Bhadra S, Li B, Ellington AD. Angew Chem Int Ed, 2014, 53: $1845-1848$

82 Fan C, Plaxco KW, Heeger AJ. Proc Natl Acad Sci USA, 2003, 100: 9134-9137

83 Li F, Pei H, Wang L, Lu J, Gao J, Jiang B, Zhao X, Fan C. Adv Funct Mater, 2013, 23: 4140-4148

84 Kang D, Zuo X, Yang R, Xia F, Plaxco KW, White RJ. Anal Chem, 2009, 81: 9109-9113

85 Xia F, Zuo X, Yang R, Xiao Y, Kang D, Vallee-Belisle A, Gong X, Yuen JD, Hsu BBY, Heeger AJ, Plaxco KW. Proc Natl Acad Sci USA, 2010, 107: 10837-10841

86 Cai B, Wang S, Huang L, Ning Y, Zhang Z, Zhang GJ. ACS Nano, 2014, 8: 2632-2638

87 Wang J. Biosens Bioelectron, 1998, 13: 757-762

88 Wang J, Palecek E, Nielsen PE, Rivas G, Cai X, Shiraishi H, Dontha N, Luo D, Farias PAM. J Am Chem Soc, 1996, 118: 7667-7670

89 Li F, Huang Y, Yang Q, Zhong Z, Li D, Wang L, Song S, Fan C. Nanoscale, 2010, 2: 1021-1026

90 Wang Q, Chen L, Long Y, Tian H, Wu J. Theranostics, 2013, 3: 395 408

91 Piatek AS, Tyagi S, Pol AC, Telenti A, Miller LP, Kramer FR, Alland D. Nat Biotechnol, 1998, 16: 359-363

92 Ranallo S, Rossetti M, Plaxco KW, Vallée-Bélisle A, Ricci F. Angew Chem Int Ed, 2015, 54: 13214-13218

93 Tyagi S, Kramer FR. Nat Biotechnol, 1996, 14: 303-308

94 Halo TL, McMahon KM, Angeloni NL, Xu Y, Wang W, Chinen AB, Malin D, Strekalova E, Cryns VL, Cheng C, Mirkin CA, Shad Thaxton C. Proc Natl Acad Sci USA, 2014, 111: 17104-17109

95 Dai Y, Furst A, Liu CC. Trends Biotech, 2019, 37: 1367-1382

96 Dunn AR, Hassell JA. Cell, 1977, 12: 23-36

97 Sylla Niang M, Drame N, Jalloh M, Labou I, Niang L, Gaye GW, Gueye SM. Immuno-analyse Biologie Spécialisée, 2010, 25: 67-71

98 Takeuchi T, Matile S. J Am Chem Soc, 2009, 131: 18048-18049

99 Xia F, White RJ, Zuo X, Patterson A, Xiao Y, Kang D, Gong X, Plaxco KW, Heeger AJ. J Am Chem Soc, 2010, 132: 14346-14348

100 Song F, Deng R, Liu H, Wang A, Ma C, Wei Y, Cui X, Wan Y, Li J. Anal Chem, 2019, 91: 14043-14048

101 Liu JM, Liu YY, Zhang DD, Fang GZ, Wang S. ACS Appl Mater Interfaces, 2016, 8: 29939-29949

102 Zuo X, Song S, Zhang J, Pan D, Wang L, Fan C. J Am Chem Soc, 2007, 129: 1042-1043

103 Lin M, Wen Y, Li L, Pei H, Liu G, Song H, Zuo X, Fan C, Huang Q. Anal Chem, 2014, 86: 2285-2288

104 Lu HJ, Pan JB, Wang YZ, Ji SY, Zhao W, Luo XL, Xu JJ, Chen HY. Anal Chem, 2018, 90: 10434-10441

105 Gui G, Zhuo Y, Chai YQ, Liao N, Zhao M, Han J, Zhu Q, Yuan R, Xiang Y. Biosens Bioelectron, 2013, 47: 524-529

106 Ren H, Long Z, Shen X, Zhang Y, Sun J, Ouyang J, Na N. ACS Appl Mater Interfaces, 2018, 10: 25621-25628

107 Fan D, Liu X, Bao C, Feng J, Wang H, Ma H, Wu D, Wei Q. Biosens 
Bioelectron, 2019, 129: 124-131

108 Feng J, Li Y, Li M, Li F, Han J, Dong Y, Chen Z, Wang P, Liu H, Wei Q. Biosens Bioelectron, 2017, 91: 441-448

109 Kim SH, Nam O, Jin ES, Gu MB. Biosens Bioelectron, 2019, 123: 160-166

110 Shao H, Lin H, Guo Z, Lu J, Jia Y, Ye M, Su F, Niu L, Kang W, Wang S, Hu Y, Huang Y. Biosens Bioelectron, 2019, 143: 111616

111 Li LL, Liu X, Yang L, Zhang S, Zheng HJ, Tang Y, Wong DKY. Biosens Bioelectron, 2019, 142: 111525

112 Zhong H, Yu C, Gao R, Chen J, Yu Y, Geng Y, Wen Y, He J. Biosens Bioelectron, 2019, 144: 111635

113 Zhang B, Liu B, Tang D, Niessner R, Chen G, Knopp D. Anal Chem, 2012, 84: 5392-5399

114 Song X, Yue Z, Hong T, Wang Z, Zhang S. Anal Chem, 2019, 91 8549-8557

115 Zhu L, Chen D, Lu X, Qi Y, He P, Liu C, Li Z. Chem Sci, 2018, 9: 6605-6613

116 Zhang J, Song S, Zhang L, Wang L, Wu H, Pan D, Fan C. J Am Chem Soc, 2006, 128: 8575-8580

117 Lin M, Wang J, Zhou G, Wang J, Wu N, Lu J, Gao J, Chen X, Shi J, Zuo X, Fan C. Angew Chem Int Ed, 2015, 54: 2151-2155

118 Lin M, Song P, Zhou G, Zuo X, Aldalbahi A, Lou X, Shi J, Fan C. Nat Protoc, 2016, 11: 1244-1263

119 Zhu D, Pei H, Yao G, Wang L, Su S, Chao J, Wang L, Aldalbahi A, Song S, Shi J, Hu J, Fan C, Zuo X. Adv Mater, 2016, 28: 6860-6865

120 Song P, Shen J, Ye D, Dong B, Wang F, Pei H, Wang J, Shi J, Wang L, Xue W, Huang Y, Huang G, Zuo X, Fan C. Nat Commun, 2020, 11: 838

121 Liu Q, Ge Z, Mao X, Zhou G, Zuo X, Shen J, Shi J, Li J, Wang L, Chen X, Fan C. Angew Chem Int Ed, 2018, 57: 7131-7135

122 Li F, Mao X, Li F, Li M, Shen J, Ge Z, Fan C, Zuo X. J Am Chem Soc, 2020, 142: 9975-9981

123 Ye D, Li L, Li Z, Zhang Y, Li M, Shi J, Wang L, Fan C, Yu J, Zuo X. Nano Lett, 2018, 19: 369-374

124 Li M, Ding H, Lin M, Yin F, Song L, Mao X, Li F, Ge Z, Wang L, Zuo X, Ma Y, Fan C. J Am Chem Soc, 2019, 141: 18910-18915

125 Ankenbruck N, Courtney T, Naro Y, Deiters A. Angew Chem Int Ed, 2018, 57: 2768-2798

126 Shendure J, Balasubramanian S, Church GM, Gilbert W, Rogers J, Schloss JA, Waterston RH. Nature, 2017, 550: 345-353

127 (a)Lee LGS, S. L; (b)Heiner, C. R; (c)Benson, S. C; (d)Rosenblum, B. B; (e)Menchen, S. M; (f)Graham, R. J; (g)Constantinescu, A; (h) Upadhya, K. G; (i) Stoesser G, Sterk P, Tuli MA, Stoehr PJ, Cameron GN. Nucleic Acids Res, 1997, 25: 7-13

128 Shendure J, Porreca GJ, Reppas NB, Lin X, McCutcheon JP, Rosenbaum AM, Wang MD, Zhang K, Mitra RD, Church GM. Science, 2005, 309: 1728-1732

129 Merriman B, R\&D Team IT, Rothberg JM. ELECTROPHORESIS, 2012, 33: 3397-3417

130 Streets AM, Huang Y. Biomicrofluidics, 2013, 7: 011302

131 Braslavsky I, Hebert B, Kartalov E, Quake SR. Proc Natl Acad Sci USA, 2003, 100: 3960-3964

132 Bentley DR, Balasubramanian S, Swerdlow HP, et al. Nature, 2008, 456: 53-59

133 Margulies M, Egholm M, Altman WE, et al. Nature, 2005, 437: 376 380

134 Rothberg JM, Hinz W, Rearick TM, et al. Nature, 2011, 475: 348352

135 Venter JCA, M. D, Myers, E. W, Li, P. W, et al. Science, 2001, 291, 51

136 Smith LM, Sanders JZ, Kaiser RJ, Hughes P, Dodd C, Connell CR, Heiner C, Kent SBH, Hood LE. Nature, 1986, 321: 674-679

137 Metzker ML. Nat Rev Genet, 2010, 11: 31-46

138 Niedringhaus TP, Milanova D, Kerby MB, Snyder MP, Barron AE. Anal Chem, 2011, 83: 4327-4341

139 Koboldt DC, Steinberg KM, Larson DE, Wilson RK, Mardis ER. Cell, 2013, 155: 27-38
140 Goodwin S, McPherson JD, McCombie WR. Nat Rev Genet, 2016, 17: $333-351$

141 Hindorff LA, Bonham VL, Brody LC, Ginoza MEC, Hutter CM, Manolio TA, Green ED. Nat Rev Genet, 2018, 19: 175-185

142 Stark R, Grzelak M, Hadfield J. Nat Rev Genet, 2019, 20: 631-656

143 Monk D, Mackay DJG, Eggermann T, Maher ER, Riccio A. Nat Rev Genet, 2019, 20: 235-248

144 Ho SS, Urban AE, Mills RE. Nat Rev Genet, 2020, 21: 171-189

145 Ramanathan M, Porter DF, Khavari PA. Nat Methods, 2019, 16: $225-234$

146 Wong FCK, Lo YMD. Annu Rev Med, 2016, 67: 419-432

147 Bianchi DW, Chiu RWK. N Engl J Med, 2018, 379: 464-473

148 Bayley H. Clin Chem, 2015, 61: 25-31

149 Quick J, Loman NJ, Duraffour S, et al. Nature, 2016, 530: 228-232

150 Rang FJ, Kloosterman WP, de Ridder J. Genome Biol, 2018, 19: 90

151 Mostovoy Y, Levy-Sakin M, Lam J, Lam ET, Hastie AR, Marks P, Lee J, Chu C, Lin C, Džakula Ž, Cao H, Schlebusch SA, Giorda K, Schnall-Levin M, Wall JD, Kwok PY. Nat Methods, 2016, 13: 587590

152 Kuleshov V, Xie D, Chen R, Pushkarev D, Ma Z, Blauwkamp T, Kertesz M, Snyder M. Nat Biotechnol, 2014, 32: 261-266

153 Amini S, Pushkarev D, Christiansen L, Kostem E, Royce T, Turk C, Pignatelli N, Adey A, Kitzman JO, Vijayan K, Ronaghi M, Shendure J, Gunderson KL, Steemers FJ. Nat Genet, 2014, 46: 1343-1349

154 Wu AR, Wang J, Streets AM, Huang Y. Annu Rev Anal Chem, 2017, 10: 439-462

155 Streets AM, Zhang X, Cao C, Pang Y, Wu X, Xiong L, Yang L, Fu Y, Zhao L, Tang F, Huang Y. Proc Natl Acad Sci USA, 2014, 111: 7048-7053

156 Zhang X, Li T, Liu F, Chen Y, Yao J, Li Z, Huang Y, Wang J. Mol Cell, 2019, 73: 130-142.e5

157 Dang Y, Yan L, Hu B, Fan X, Ren Y, Li R, Lian Y, Yan J, Li Q, Zhang Y, Li M, Ren X, Huang J, Wu Y, Liu P, Wen L, Zhang C, Huang Y, Tang F, Qiao J. Genome Biol, 2016, 17: 130

158 Di L, Fu Y, Sun Y, Li J, Liu L, Yao J, Wang G, Wu Y, Lao K, Lee RW, Zheng G, Xu J, Oh J, Wang D, Xie XS, Huang Y, Wang J. Proc Natl Acad Sci USA, 2020, 117: 2886-2893

159 Lubeck E, Coskun AF, Zhiyentayev T, Ahmad M, Cai L. Nat Methods, 2014, 11: 360-361

160 Chen KH, Boettiger AN, Moffitt JR, Wang S, Zhuang X. Science, 2015, 348: aaa6090

161 Wang X, Allen WE, Wright MA, Sylwestrak EL, Samusik N, Vesuna S, Evans K, Liu C, Ramakrishnan C, Liu J, Nolan GP, Bava FA, Deisseroth K. Science, 2018, 361: eaat5691

162 Lee JH, Daugharthy ER, Scheiman J, Kalhor R, Yang JL, Ferrante TC, Terry R, Jeanty SSF, Li C, Amamoto R, Peters DT, Turczyk BM, Marblestone AH, Inverso SA, Bernard A, Mali P, Rios X, Aach J, Church GM. Science, 2014, 343: 1360-1363

163 Nordhoff E, Kirpekar F, Roepstorff P. Mass Spectrom Rev, 1996, 15: $67-138$

164 Xiong J, Yuan BF, Feng YQ. Chem Res Toxicol, 2019, 32: acs. chemrestox.9b00042

165 Liu T, Ma CJ, Yuan BF, Feng YQ. Sci China Chem, 2018, 61: 381392

166 Dor Y, Cedar H. Lancet, 2018, 392: 777-786

167 Qi C, Jiang H, Xiong J, Yuan B, Feng Y. Chin Chem Lett, 2019, 30: $553-557$

168 Lan MD, Yuan BF, Feng YQ. Chin Chem Lett, 2019, 30: 1-6

169 Qi BL, Liu P, Wang QY, Cai WJ, Yuan BF, Feng YQ. TrAC Trends Anal Chem, 2014, 59: 121-132

170 Liu FL, Qi CB, Cheng QY, Ding JH, Yuan BF, Feng YQ. Anal Chem, 2020, 92: 2301-2309

171 Feng Y, Ma CJ, Ding JH, Qi CB, Xu XJ, Yuan BF, Feng YQ. Anal Chim Acta, 2020, 1098: 56-65

172 Jiang HP, Xiong J, Liu FL, Ma CJ, Tang XL, Yuan BF, Feng YQ. Chem Sci, 2018, 9: 4160-4167

173 Cheng QY, Xiong J, Wang F, Yuan BF, Feng YQ. Chin Chem Lett, 
2018, 29: 115-118

174 Zeng H, Qi CB, Liu T, Xiao HM, Cheng QY, Jiang HP, Yuan BF, Feng YQ. Anal Chem, 2017, 89: 4153-4160

175 Huang W, Lan MD, Qi CB, Zheng SJ, Wei SZ, Yuan BF, Feng YQ. Chem Sci, 2016, 7: 5495-5502

176 Qi C, Ding J, Yuan B, Feng Y. Chin Chem Lett, 2019, 30: 1618-1626

177 Huber CG, Oberacher H. Mass Spectrom Rev, 2001, 20: 310-343

178 Ni J, Pomerantz SC, Rozenski J, Zhang Y, McCloskey JA. Anal Chem, 1996, 68: 1989-1999

179 Liu S, Wang Y. Chem Soc Rev, 2015, 44: 7829-7854

180 Chen B, Yuan BF, Feng YQ. Anal Chem, 2019, 91: 743-756

181 Kolpashchikov DM. Chem Rev, 2010, 110: 4709-4723

182 Epstein JR, Biran I, Walt DR. Anal Chim Acta, 2002, 469: 3-36

183 Dong H, Lei J, Ding L, Wen Y, Ju H, Zhang X. Chem Rev, 2013, 113: 6207-6233

184 Xue J, Chen F, Bai M, Cao X, Huang P, Zhao Y. Anal Chem, 2019, 91: 4696-4701

185 Chinen AB, Guan CM, Ferrer JR, Barnaby SN, Merkel TJ, Mirkin CA. Chem Rev, 2015, 115: 10530-10574

186 Xiao M, Lai W, Man T, Chang B, Li L, Chandrasekaran AR, Pei H. Chem Rev, 2019, 119: 11631-11717

187 Wu L, Qu X. Chem Soc Rev, 2015, 44: 2963-2997

188 Ma D, Liu T, Yao Q, Peng X. Sci China Chem, 2018, 61: 468-475

189 He S, Song B, Li D, Zhu C, Qi W, Wen Y, Wang L, Song S, Fang H, Fan C. Adv Funct Mater, 2010, 20: 453-459

190 Pan W, Zhang T, Yang H, Diao W, Li N, Tang B. Anal Chem, 2013, 85: $10581-10588$

191 Venkatesan N, Jun Seo Y, Hyean Kim B. Chem Soc Rev, 2008, 37 : 648-663

192 Lin Q, Ye X, Huang Z, Yang B, Fang X, Chen H, Kong J. Anal Chem, 2019, 91: 15694-15702

193 Yoshino Y, Sato Y, Nishizawa S. Anal Chem, 2019, 91: 1425414260

194 Bai M, Chen F, Cao X, Zhao Y, Xue J, Yu X, Fan C, Zhao Y. Angew Chem Int Ed, 2020, 59: 13267-13272

195 Shen Y, Zhang N, Sun Y, Zhao WW, Ye D, Xu JJ, Chen HY. ACS Appl Mater Interfaces, 2017, 9: 25107-25113

196 Zou X, Shi Y, Zhu R, Han J, Han S. Anal Chem, 2019, 91: 1589915907

197 Li N, Chang C, Pan W, Tang B. Angew Chem Int Ed, 2012, 51: 7426-7430

198 Wu H, Chen TT, Wang XN, Ke Y, Jiang JH. Chem Sci, 2020, 11: 6269

199 Zhao J, Chu H, Zhao Y, Lu Y, Li L. J Am Chem Soc, 2019, 141: 7056-7062

200 Raman CV, Krishnan KS. Nature, 1928, 121: 501-502

201 Fleischmann M, Hendra PJ, McQuillan AJ. Chem Phys Lett, 1974, 26: $163-166$

202 Langer J, Jimenez de Aberasturi D, Aizpurua J, et al. ACS Nano, 2020, 14: 28-117

203 Kneipp K, Haka AS, Kneipp H, Badizadegan K, Yoshizawa N, Boone C, Shafer-Peltier KE, Motz JT, Dasari RR, Feld MS. Appl Spectrosc, 2002, 56: 150-154

204 Chao J, Cao W, Su S, Weng L, Song S, Fan C, Wang L. J Mater Chem B, 2016, 4: 1757-1769

205 Kneipp J, Kneipp H, Kneipp K. Chem Soc Rev, 2008, 37: 1052-1060

206 Kneipp J, Kneipp H, McLaughlin M, Brown D, Kneipp K. Nano Lett, 2006, 6: 2225-2231

207 Kneipp J, Kneipp H, Rice WL, Kneipp K. Anal Chem, 2005, 77: 2381-2385

208 Wang Y, Li D, Li P, Wang W, Ren W, Dong S, Wang E. J Phys Chem C, 2007, 111: 16833-16839

209 Zhang P, Fu H, Du S, Wang F, Yang J, Cai W, Liu D. Anal Chem, 2019, 91: 15740-15747

210 Ma W, Sun M, Fu P, Li S, Xu L, Kuang H, Xu C. Adv Mater, 2017, 29: 1703410

211 Zhou W, Li Q, Liu H, Yang J, Liu D. ACS Nano, 2017, 11: 3532-
3541

212 Xu L, Gao Y, Kuang H, Liz-Marzán LM, Xu C. Angew Chem Int Ed, 2018, 57: 10544-10548

213 Liu H, Li Q, Li M, Ma S, Liu D. Anal Chem, 2017, 89: 4776-4780

214 Wang HN, Register JK, Fales AM, Gandra N, Cho EH, Boico A, Palmer GM, Klitzman B, Vo-Dinh T. Nano Res, 2018, 11: 40054016

215 Bettazzi F, Hamid-Asl E, Esposito CL, Quintavalle C, Formisano N, Laschi S, Catuogno S, Iaboni M, Marrazza G, Mascini M, Cerchia L, De Franciscis V, Condorelli G, Palchetti I. Anal Bioanal Chem, 2013, 405: 1025-1034

216 Lee AC, Dai Z, Chen B, Wu H, Wang J, Zhang A, Zhang L, Lim TM, Lin Y. Anal Chem, 2008, 80: 9402-9410

217 Islam MN, Gopalan V, Haque MH, Masud MK, Hossain MSA, Yamauchi Y, Nguyen NT, Lam AKY, Shiddiky MJA. Biosens Bioelectron, 2017, 98: 227-233

218 Kilic T, Topkaya SN, Ozkan Ariksoysal D, Ozsoz M, Ballar P, Erac Y, Gozen O. Biosens Bioelectron, 2012, 38: 195-201

219 Won BY, Shin S, Fu R, Shin SC, Cho DY, Park HG. Biosens Bioelectron, 2011, 30: 73-77

220 Thiruppathiraja C, Kamatchiammal S, Adaikkappan P, Santhosh DJ, Alagar M. Anal Biochem, 2011, 417: 73-79

221 Pal S, Alocilja EC. Biosens Bioelectron, 2010, 26: 1624-1630

222 Lau HY, Wu H, Wee EJH, Trau M, Wang Y, Botella JR. Sci Rep, 2017, 7: 38896

223 Henihan G, Schulze H, Corrigan DK, Giraud G, Terry JG, Hardie A, Campbell CJ, Walton AJ, Crain J, Pethig R, Templeton KE, Mount AR, Bachmann TT. Biosens Bioelectron, 2016, 81: 487-494

224 Ahmed MU, Nahar S, Safavieh M, Zourob M. Analyst, 2013, 138: 907-915

225 de la Escosura-Muniz A, Baptista-Pires L, Serrano L, Altet L, Francino O, Sánchez A, Merkoçi A. Small, 2016, 12: 205-213

226 Manzanares-Palenzuela CL, Martín-Clemente JP, Lobo-Castañón MJ, López-Ruiz B. Talanta, 2017, 164: 261-267

227 del Río JS, Svobodova M, Bustos P, Conejeros P, O’Sullivan CK. Anal Bioanal Chem, 2016, 408: 8611-8620

228 Barrios Eguiluz KI, Salazar-Banda GR, Funes-Huacca ME, Alberice JV, Carrilho E, Spinola Machado SA, Avaca LA. Analyst, 2009, 134: 314-319

229 Paniel N, Baudart J. Talanta, 2013, 115: 133-142

230 Huffnagle IM, Joyner A, Rumble B, Hysa S, Rudel D, Hvastkovs EG. Anal Chem, 2014, 86: 8418-8424

231 Cao Y, Hjort M, Chen H, Birey F, Leal-Ortiz SA, Han CM, Santiago JG, Paşca SP, Wu JC, Melosh NA. Proc Natl Acad Sci USA, 2017, 114: E1866-E1874

232 Liu J, Zhou H, Xu JJ, Chen HY. Analyst, 2012, 137: 3940-3945

233 Zhang Y, Xu G, Lian G, Luo F, Xie Q, Lin Z, Chen G. Biosens Bioelectron, 2020, 147: 111789

234 Wu MS, Qian G, Xu JJ, Chen HY. Anal Chem, 2012, 84: 5407-5414

235 Zhang H, Gao W, Liu Y, Sun Y, Jiang Y, Zhang S. Anal Chem, 2019, 91: 12581-12586

236 McKeague M, McConnell EM, Cruz-Toledo J, Bernard ED, Pach A, Mastronardi E, Zhang X, Beking M, Francis T, Giamberardino A, Cabecinha A, Ruscito A, Aranda-Rodriguez R, Dumontier M, DeRosa MC. J Mol Evol, 2015, 81: 150-161

237 Savory N, Abe K, Sode K, Ikebukuro K. Biosens Bioelectron, 2010, 26: $1386-1391$

238 Hamula CLA, Zhang H, Li F, Wang Z, Chris Le X, Li XF. TrAC Trends Anal Chem, 2011, 30: 1587-1597

239 Mascini M, Palchetti I, Tombelli S. Angew Chem Int Ed, 2012, 51: 1316-1332

240 Elenko MP, Szostak JW, van Oijen AM. J Am Chem Soc, 2009, 131: 9866-9867

241 Zhao Y, Xu D, Tan W. Integr Biol, 2017, 9: 188-205

242 Wengerter BC, Katakowski JA, Rosenberg JM, Park CG, Almo SC, Palliser D, Levy M. Mol Ther, 2014, 22: 1375-1387

243 Wang J, Wei Y, Hu X, Fang YY, Li X, Liu J, Wang S, Yuan Q. J Am 
Chem Soc, 2015, 137: 10576-10584

244 Mallikaratchy PR, Ruggiero A, Gardner JR, Kuryavyi V, Maguire WF, Heaney ML, McDevitt MR, Patel DJ, Scheinberg DA. Nucleic Acids Res, 2011, 39: 2458-2469

245 Malik MT, O’Toole MG, Casson LK, Thomas SD, Bardi GT, ReyesReyes EM, Ng CK, Kang KA, Bates PJ. Oncotarget, 2015, 6: 2227022281

246 Sprangers AJ, Hao L, Banga RJ, Mirkin CA. Small, 2017, 13: 1602753

247 Lee J, Lee KH, Jeon J, Dragulescu-Andrasi A, Xiao F, Rao J. $A C S$ Chem Biol, 2010, 5: 1065-1074

248 Wang X, Hoshika S, Peterson RJ, Kim MJ, Benner SA, Kahn JD. ACS Synth Biol, 2017, 6: 782-792

249 Matsunaga KI, Kimoto M, Hanson C, Sanford M, Young HA, Hirao I. Sci Rep, 2016, 5: 18478

250 Zhu G, Niu G, Chen X. Bioconjugate Chem, 2015, 26: 2186-2197

251 Breaker RR, Joyce GF. Chem Biol, 1994, 1: 223-229

252 Lan T, Furuya K, Lu Y. Chem Commun, 2010, 46: 3896-3898

253 Zhou W, Saran R, Liu J. Chem Rev, 2017, 117: 8272-8325

254 Li J, Lu Y. J Am Chem Soc, 2000, 122: 10466-10467

255 Lake RJ, Yang Z, Zhang JJ, Lu Y. Acc Chem Res, 2019, 52: 3275 3286

256 Liu J, Brown AK, Meng X, Cropek DM, Istok JD, Watson DB, Lu Y. Proc Natl Acad Sci USA, 2007, 104: 2056-2061

257 Torabi SF, Wu P, McGhee CE, Chen L, Hwang K, Zheng N, Cheng J, Lu Y. Proc Natl Acad Sci USA, 2015, 112: 5903-5908

258 Huang PJJ, Vazin M, Lin JJ, Pautler R, Liu J. ACS Sens, 2016, 1: 732-738

259 He Y, Chen D, Huang PJJ, Zhou Y, Ma L, Xu K, Yang R, Liu J. Nucleic Acids Res, 2018, 46: 10262-10271

260 Huang PJJ, Liu J. Nucleic Acids Res, 2015, 43: 6125-6133

261 Hollenstein M, Hipolito C, Lam C, Dietrich D, Perrin D. Angew Chem Int Ed, 2008, 47: 4346-4350

262 Huang P-J, Rochambeau D, Sleiman HF, Liu J. Angew Chem Int Ed, 2020, 59: 3573-3577

263 Roth A, Breaker RR. Proc Natl Acad Sci USA, 1998, 95: 6027-6031

264 Shen Z, Wu Z, Chang D, Zhang W, Tram K, Lee C, Kim P, Salena BJ, Li Y. Angew Chem Int Ed, 2016, 55: 2431-2434

265 Ali MM, Aguirre SD, Lazim H, Li Y. Angew Chem Int Ed, 2011, 50: 3751-3754

266 Travascio P, Li Y, Sen D. Chem Biol, 1998, 5: 505-517

267 Peng D, Li Y, Huang Z, Liang RP, Qiu JD, Liu J. Anal Chem, 2019, 91: 11403-11408

268 Carmi N, Balkhi SR, Breaker RR. Proc Natl Acad Sci USA, 1998, 95: 2233-2237

$269 \mathrm{Gu}$ H, Furukawa K, Weinberg Z, Berenson DF, Breaker RR. J Am Chem Soc, 2013, 135: 9121-9129

270 Chandrasekar J, Silverman SK. Proc Natl Acad Sci USA, 2013, 110 : 5315-5320

271 Cuenoud B, Szostak JW. Nature, 1995, 375: 611-614

272 Famulok M, Hartig JS, Mayer G. Chem Rev, 2007, 107: 3715-3743

273 Seeman NC. Nano Lett, 2020, 20: 1477-1478

274 Seeman NC. Annu Rev Biophys Biomol Struct, 1998, 27: 225-248

275 Seeman NC. Mol Biotechnol, 2007, 37: 246-257

276 Rothemund PWK. Nature, 2006, 440: 297-302

277 Wei B, Dai M, Yin P. Nature, 2012, 485: 623-626

278 Ong LL, Hanikel N, Yaghi OK, Grun C, Strauss MT, Bron P, LaiKee-Him J, Schueder F, Wang B, Wang P, Kishi JY, Myhrvold C, Zhu A, Jungmann R, Bellot G, Ke Y, Yin P. Nature, 2017, 552: 72 77

279 Zhang DY, Seelig G. Nat Chem, 2011, 3: 103-113

280 Ijäs H, Nummelin S, Shen B, Kostiainen M, Linko V. IJMS, 2018, 19: 2114

281 Bath J, Turberfield AJ. Nat Nanotech, 2007, 2: 275-284

282 Sparvath SL, Geary CW, Andersen ES. Methods Mol Biol, 2017, 1500: $51-80$

283 Chworos A, Severcan I, Koyfman AY, Weinkam P, Oroudjev E,
Hansma HG, Jaeger L. Science, 2004, 306: 2068-2072

284 Guo P. Nat Nanotech, 2010, 5: 833-842

285 Geary C, Rothemund PWK, Andersen ES. Science, 2014, 345: 799804

286 Bastings MMC, Anastassacos FM, Ponnuswamy N, Leifer FG, Cuneo G, Lin C, Ingber DE, Ryu JH, Shih WM. Nano Lett, 2018, 18: $3557-3564$

287 Delebecque CJ, Lindner AB, Silver PA, Aldaye FA. Science, 2011, 333: 470-474

288 Han D, Qi X, Myhrvold C, Wang B, Dai M, Jiang S, Bates M, Liu Y, An B, Zhang F, Yan H, Yin P. Science, 2017, 358: eaao2648

289 Monferrer A, Zhang D, Lushnikov AJ, Hermann T. Nat Commun, 2019, 10: 608

290 Xia K, Shen J, Li Q, Fan C, Gu H. ACS Nano, 2020, 14: 1319-1337

291 Schueder F, Lara-Gutiérrez J, Beliveau BJ, Saka SK, Sasaki HM, Woehrstein JB, Strauss MT, Grabmayr H, Yin P, Jungmann R. Nat Commun, 2017, 8: 2090

292 Schnitzbauer J, Strauss MT, Schlichthaerle T, Schueder F, Jungmann R. Nat Protoc, 2017, 12: 1198-1228

293 Rinker S, Ke Y, Liu Y, Chhabra R, Yan H. Nat Nanotech, 2008, 3: 418-422

294 Kwon PS, Ren S, Kwon SJ, Kizer ME, Kuo L, Xie M, Zhu D, Zhou F, Zhang F, Kim D, Fraser K, Kramer LD, Seeman NC, Dordick JS, Linhardt RJ, Chao J, Wang X. Nat Chem, 2020, 12: 26-35

295 Yang Y, Zhang R, Fan C. Trends Chem, 2020, 2: 137-147

296 Douglas SM, Bachelet I, Church GM. Science, 2012, 335: 831-834

297 Funke JJ, Ketterer P, Lieleg C, Schunter S, Korber P, Dietz H. Sci $A d v, 2016,2$ : e1600974

298 Bhatia D, Arumugam S, Nasilowski M, Joshi H, Wunder C, Chambon V, Prakash V, Grazon C, Nadal B, Maiti PK, Johannes L, Dubertret B, Krishnan Y. Nat Nanotech, 2016, 11: 1112-1119

299 Sun L, Gao Y, Wang Y, Wei Q, Shi J, Chen N, Li D, Fan C. Chem Sci, 2018, 9: 5967-5975

300 Wang P, Rahman MA, Zhao Z, Weiss K, Zhang C, Chen Z, Hurwitz SJ, Chen ZG, Shin DM, Ke Y. J Am Chem Soc, 2018, 140: 24782484

301 Tang Z, Mallikaratchy P, Yang R, Kim Y, Zhu Z, Wang H, Tan W. J Am Chem Soc, 2008, 130: 11268-11269

302 Wilson BD, Hariri AA, Thompson IAP, Eisenstein M, Soh HT. Nat Commun, 2019, 10: 5079

303 Xiong Y, Zhang J, Yang Z, Mou Q, Ma Y, Xiong Y, Lu Y. J Am Chem Soc, 2020, 142: 207-213

304 Yang L, Meng L, Song J, Xiao Y, Wang R, Kang H, Han D. Chem Sci, 2019, 10: 7466-7471

305 Wu R, Karunanayake Mudiyanselage APKK, Shafiei F, Zhao B, Bagheri Y, Yu Q, McAuliffe K, Ren K, You M. Angew Chem Int Ed, 2019, 58: 18271-18275

306 Cha TG, Baker BA, Sauffer MD, Salgado J, Jaroch D, Rickus JL, Porterfield DM, Choi JH. ACS Nano, 2011, 5: 4236-4244

307 Wang W, Yang Q, Du Y, Zhou X, Du X, Wu Q, Lin L, Song Y, Li F, Yang C, Tan W. Angew Chem Int Ed, 2020, 59: 2628-2633

308 Samanta D, Ebrahimi SB, Mirkin CA. Adv Mater, 2020, 32: 1901743

309 Zhu Z, Wu C, Liu H, Zou Y, Zhang X, Kang H, Yang C, Tan W. Angew Chem Int Ed, 2010, 49: 1052-1056

310 Zeng Y, Ren J, Shen A, Hu J. ACS Appl Mater Interfaces, 2016, 8: 27772-27778

311 Li Y, Fang Q, Miao X, Zhang X, Zhao Y, Yan J, Zhang Y, Wu R, Nie B, Hirtz M, Liu J. ACS Sens, 2019, 4: 2605-2614

312 Fu Q, Zhu R, Song J, Yang H, Chen X. Adv Mater, 2018, 31: 1805875

313 Bamrungsap S, Chen T, Shukoor MI, Chen Z, Sefah K, Chen Y, Tan W. ACS Nano, 2012, 6: 3974-3981

314 Ma W, Xu L, Wang L, Kuang H, Xu C. Biosens Bioelectron, 2016, 79: $220-236$

315 Tang L, Li S, Han F, Liu L, Xu L, Ma W, Kuang H, Li A, Wang L, Xu C. Biosens Bioelectron, 2015, 71: 7-12

316 Xu Z, Xu L, Liz-Marzán LM, Ma W, Kotov NA, Wang L, Kuang H, 
Xu C. Adv Opt Mater, 2013, 1: 626-630

317 Fu P, Sun M, Xu L, Wu X, Liu L, Kuang H, Song S, Xu C. Nanoscale, 2016, 8: 15008-15015

318 Tang L, Li S, Xu L, Ma W, Kuang H, Wang L, Xu C. ACS Appl Mater Interfaces, 2015, 7: 12708-12712

319 Gao R, Xu L, Hao C, Xu C, Kuang H. Angew Chem Int Ed, 2019, 58: 3913-3917

320 Zhao Y, Xu L, Ma W, Wang L, Kuang H, Xu C, Kotov NA. Nano Lett, 2014, 14: 3908-3913

321 Li S, Xu L, Ma W, Wu X, Sun M, Kuang H, Wang L, Kotov NA, Xu C. J Am Chem Soc, 2016, 138: 306-312

322 Wu X, Xu L, Ma W, Liu L, Kuang H, Kotov NA, Xu C. Adv Mater, 2016, 28: 5907-5915

323 Ma W, Fu P, Sun M, Xu L, Kuang H, Xu C. J Am Chem Soc, 2017, 139: 11752-11759

324 Dewar JM, Walter JC. Nat Rev Mol Cell Biol, 2017, 18: 507-516

325 Pilié PG, Tang C, Mills GB, Yap TA. Nat Rev Clin Oncol, 2019, 16: 81-104

326 Nong J, Gong Y, Guan Y, Yi X, Yi Y, Chang L, Yang L, Lv J, Guo Z, Jia H, Chu Y, Liu T, Chen M, Byers L, Roarty E, Lam VK, Papadimitrakopoulou VA, Wistuba I, Heymach JV, Glisson B, Liao Z, Lee JJ, Futreal PA, Zhang S, Xia X, Zhang J, Wang J. Nat Commun, 2018, 9: 3114

327 Park BH, Oh SJ, Jung JH, Choi G, Seo JH, Kim DH, Lee EY, Seo TS. Biosens Bioelectron, 2017, 91: 334-340

328 Liu S, Jiang Q, Wang Y, Ding B. Adv Healthcare Mater, 2019, 8: 1801658

329 Li M, Tian J, Al-Tamimi M, Shen W. Angew Chem Int Ed, 2012, 51: 5497-5501

330 Ansari MIH, Hassan S, Qurashi A, Khanday FA. Biosens Bioelectron, 2016, 85: 247-260

331 Ahrberg CD, Manz A, Chung BG. Lab Chip, 2016, 16: 3866-3884

332 Csordas A, Gerdon A, Adams J, Qian J, Oh S, Xiao Y, Soh H . Angew Chem Int Ed, 2010, 49: 355-358

333 Li N, Ma J, Guarnera MA, Fang HB, Cai L, Jiang F. J Cancer Res Clin Oncol, 2014, 140: 145-150

334 Yin J, Hu J, Sun J, Wang B, Mu Y. Analyst, 2019, 144: 7032-7040

335 Nikam C, Kazi M, Nair C, Jaggannath M, M M, R V, Shetty A, Rodrigues C. Int J Mycobacteriology, 2014, 3: 205-210

336 Dobnik D, Štebih D, Blejec A, Morisset D, Žel J. Sci Rep, 2016, 6: 35451

337 Fermér C, Nilsson P, Larhed M. Eur J Pharmaceutical Sci, 2003, 18: 129-132

338 Hurth C, Yang J, Barrett M, Brooks C, Nordquist A, Smith S, Zenhausern F. Biomed Microdevices, 2014, 16: 905-914

339 Sposito A, Hoang V, DeVoe DL. Lab Chip, 2016, 16: 3524-3531

340 Helb D, Jones M, Story E, Boehme C, Wallace E, Ho K, Kop JA, Owens MR, Rodgers R, Banada P, Safi H, Blakemore R, Lan NTN, Jones-López EC, Levi M, Burday M, Ayakaka I, Mugerwa RD, McMillan B, Winn-Deen E, Christel L, Dailey P, Perkins MD, Persing DH, Alland D. J Clin Microbiol, 2010, 48: 229-237

341 Hatch AC, Ray T, Lintecum K, Youngbull C. Lab Chip, 2014, 14: $562-568$

342 Li TJ, Chang CM, Chang PY, Chuang YC, Huang CC, Su WC, Shieh DB. NPG Asia Mater, 2016, 8: e277

343 Adams NM, Gabella WE, Hardcastle AN, Haselton FR. Anal Chem, 2017, 89: 728-735

344 Hudecova I. Clin Biochem, 2015, 48: 948-956

345 Huggett JF, Whale A. Clin Chem, 2013, 59: 1691-1693

346 Li T, Shao Y, Fu L, Xie Y, Zhu L, Sun W, Yu R, Xiao B, Guo J. J Mol Med, 2018, 96: 85-96

347 Gou T, Hu J, Wu W, Ding X, Zhou S, Fang W, Mu Y. Biosens Bioelectron, 2018, 120: 144-152

348 Zhou S, Gou T, Hu J, Wu W, Ding X, Fang W, Hu Z, Mu Y. Biosens Bioelectron, 2019, 128: 151-158

349 Zhang L, Ding B, Chen Q, Feng Q, Lin L, Sun J. TrAC Trends Anal Chem, 2017, 94: 106-116
350 Yin J, Suo Y, Zou Z, Sun J, Zhang S, Wang B, Xu Y, Darland D, Zhao JX, Mu Y. Lab Chip, 2019, 19: 2769-2785

351 Sayad A, Ibrahim F, Mukim Uddin S, Cho J, Madou M, Thong KL. Biosens Bioelectron, 2018, 100: 96-104

352 He X, Wang S, Liu Y, Wang X. Sci China Chem, 2019, 62: 1064 1071

353 Song J, Mauk MG, Hackett BA, Cherry S, Bau HH, Liu C. Anal Chem, 2016, 88: 7289-7294

354 Yeh EC, Fu CC, Hu L, Thakur R, Feng J, Lee LP. Sci Adv, 2017, 3 : e1501645

355 Zhang L, Tian F, Liu C, Feng Q, Ma T, Zhao Z, Li T, Jiang X, Sun J. Lab Chip, 2018, 18: 610-619

356 Bruch R, Baaske J, Chatelle C, Meirich M, Madlener S, Weber W, Dincer C, Urban GA. Adv Mater, 2019, 31: 1905311

357 Stumpf F, Schwemmer F, Hutzenlaub T, Baumann D, Strohmeier O, Dingemanns G, Simons G, Sager C, Plobner L, von Stetten F, Zengerle R, Mark D. Lab Chip, 2016, 16: 199-207

358 Liu D, Wang J, Wu L, Huang Y, Zhang Y, Zhu M, Wang Y, Zhu Z, Yang C. TrAC Trends Anal Chem, 2020, 122: 115701

359 Xiang Y, Lu Y. Nat Chem, 2011, 3: 697-703

360 Yan L, Zhu Z, Zou Y, Huang Y, Liu D, Jia S, Xu D, Wu M, Zhou Y, Zhou S, Yang CJ. J Am Chem Soc, 2013, 135: 3748-3751

361 Xu J, Jiang B, Xie J, Xiang Y, Yuan R, Chai Y. Chem Commun, 2012, 48: 10733-10735

362 Si Y, Li L, Wang N, Zheng J, Yang R, Li J. ACS Appl Mater Interfaces, 2019, 11: 7792-7799

363 Zhu Z, Guan Z, Liu D, Jia S, Li J, Lei Z, Lin S, Ji T, Tian Z, Yang CJ. Angew Chem Int Ed, 2015, 54: 10448-10453

364 Shi L, Lei J, Zhang B, Li B, Yang CJ, Jin Y. ACS Appl Mater Interfaces, 2018, 10: 12526-12533

365 Toumazou C, Shepherd LM, Reed SC, Chen GI, Patel A, Garner DM, Wang CJA, Ou CP, Amin-Desai K, Athanasiou P, Bai H, Brizido IMQ, Caldwell B, Coomber-Alford D, Georgiou P, Jordan KS, Joyce JC, La Mura M, Morley D, Sathyavruthan S, Temelso S, Thomas RE, Zhang L. Nat Methods, 2013, 10: 641-646

366 Xie S, Yuan Y, Song Y, Zhuo Y, Li T, Chai Y, Yuan R. Chem Commun, 2014, 50: 15932-15935

367 Zhou W, Hu K, Kwee S, Tang L, Wang Z, Xia J, Li XJ. Anal Chem, 2020, 92: 2739-2747

368 Wang A, Ma X, Ye Y, Luo F, Guo L, Qiu B, Lin Z, Chen G. Anal Chem, 2018, 90: 1087-1091

369 Yu Z, Tang Y, Cai G, Ren R, Tang D. Anal Chem, 2019, 91: 12221226

370 Wang Q, Liu F, Yang X, Wang K, Liu P, Liu J, Huang J, Wang H. Sens Actuat B-Chem, 2013, 186: 515-520

371 Wang S, Ge L, Song X, Yan M, Ge S, Yu J, Zeng F. Analyst, 2012, 137: $3821-3827$

372 West PW. Ind Eng Chem Anal Ed, 1945, 17: 740-741

373 Consden R, Gordon AH, Martin AJP. Biochem J, 1944, 38: 224-232

374 Martinez AW, Phillips ST, Whitesides GM. Proc Natl Acad Sci USA, 2008, 105: 19606-19611

375 Martinez A, Phillips S, Butte M, Whitesides G. Angew Chem Int Ed, 2007, 46: 1318-1320

376 Yager P, Domingo GJ, Gerdes J. Annu Rev Biomed Eng, 2008, 10: 107-144

377 Pelton R. TrAC Trends Anal Chem, 2009, 28: 925-942

378 Sun X, Wang H, Jian Y, Lan F, Zhang L, Liu H, Ge S, Yu J. Biosens Bioelectron, 2018, 105: 218-225

379 Cunningham JC, Brenes NJ, Crooks RM. Anal Chem, 2014, 86: 6166-6170

380 Su S, Ali MM, Filipe CDM, Li Y, Pelton R. Biomacromolecules, 2008, 9: 935-941

381 Carrilho E, Martinez AW, Whitesides GM. Anal Chem, 2009, 81: 7091-7095

382 Savolainen A, Zhang Y, Rochefort D, Holopainen U, Erho T, Virtanen J, Smolander M. Biomacromolecules, 2011, 12: 2008-2015

383 Callahan FE, Norman HA, Srinath T, St. John JB, Dhar R, Mattoo 
AK. Anal Biochem, 1989, 183: 220-224

384 Martinez AW, Phillips ST, Whitesides GM, Carrilho E. Anal Chem, 2010, 82: 3-10

385 Li X, Ballerini DR, Shen W. Biomicrofluidics, 2012, 6: 011301

386 Yetisen AK, Akram MS, Lowe CR. Lab Chip, 2013, 13: 2210-2251

387 Sun J, Xianyu Y, Jiang X. Chem Soc Rev, 2014, 43: 6239-6253

388 Delaney JL, Hogan CF, Tian J, Shen W. Anal Chem, 2011, 83: 13001306

389 Teengam P, Siangproh W, Tuantranont A, Henry CS, Vilaivan T, Chailapakul O. Anal Chim Acta, 2017, 952: 32-40

390 Chen F, Wang X, Cao X, Zhao Y. Anal Chem, 2017, 89: 1046810473

391 Sun X, Jian Y, Wang H, Ge S, Yan M, Yu J. ACS Appl Mater Interfaces, 2019, 11: 16198-16206

392 Dungchai W, Chailapakul O, Henry CS. Anal Chem, 2009, 81: 58215826

393 Wang H, Jian Y, Kong Q, Liu H, Lan F, Liang L, Ge S, Yu J. Sens Actuat B-Chem, 2018, 257: 561-569

394 Fu LM, Wang YN. TrAC Trends Anal Chem, 2018, 107: 196-211

395 Teengam P, Siangproh W, Tuantranont A, Vilaivan T, Chailapakul O, Henry CS. Anal Chem, 2017, 89: 5428-5435

396 Liu M, Hui CY, Zhang Q, Gu J, Kannan B, Jahanshahi-Anbuhi S, Filipe CDM, Brennan JD, Li Y. Angew Chem Int Ed, 2016, 55: 2709-2713

397 Fakhri N, Abarghoei S, Dadmehr M, Hosseini M, Sabahi H, Ganjali MR. SpectroChim Acta Part A-Mol Biomol Spectr, 2020, 227: 117529

398 Bender AT, Borysiak MD, Levenson AM, Lillis L, Boyle DS, Posner JD. Anal Chem, 2018, 90: 7221-7229

399 Sun Y, Chang Y, Zhang Q, Liu M. Micromachines, 2019, 10: 531

400 Huang JY, Lin HT, Chen TH, Chen CA, Chang HT, Chen CF. ACS Sens, 2018, 3: 174-182

401 Zhou M, Yang M, Zhou F. Biosens Bioelectron, 2014, 55: 39-43

402 Koesdjojo MT, Pengpumkiat S, Wu Y, Boonloed A, Huynh D, Remcho TP, Remcho VT. J Chem Educ, 2015, 92: 737-741

403 Martinez AW, Phillips ST, Carrilho E, Thomas SW, Sindi H, Whitesides GM. Anal Chem, 2008, 80: 3699-3707

404 Faraday M. Philos Trans R Soc London, 1857, 147: 145-181

405 Murdock RC, Shen L, Griffin DK, Kelley-Loughnane N, Papautsky I, Hagen JA. Anal Chem, 2013, 85: 11634-11642

406 Tsai TT, Shen SW, Cheng CM, Chen CF. Sci Tech Adv Mater, 2013, 14: 044404

407 Yu J, Ge L, Huang J, Wang S, Ge S. Lab Chip, 2011, 11: 1286-1291

408 Ali MM, Brown CL, Jahanshahi-Anbuhi S, Kannan B, Li Y, Filipe CDM, Brennan JD. Sci Rep, 2017, 7: 12335

409 Chen X, Lan J, Liu Y, Li L, Yan L, Xia Y, Wu F, Li C, Li S, Chen J. Biosens Bioelectron, 2018, 102: 582-588

410 Hui CY, Liu M, Li Y, Brennan JD. Angew Chem Int Ed, 2018, 57: 4549-4553

411 Forouzandeh M. Front Biosci, 2019, 11: 122-135

412 Wang Y, Wang S, Ge S, Wang S, Yan M, Zang D, Yu J. Anal Methods, 2013, 5: 1328-1336

413 Liang L, Su M, Li L, Lan F, Yang G, Ge S, Yu J, Song X. Sens Actuat B-Chem, 2016, 229: 347-354

414 Seok Y, Joung HA, Byun JY, Jeon HS, Shin SJ, Kim S, Shin YB, Han HS, Kim MG. Theranostics, 2017, 7: 2220-2230

415 Park S, Zhang Y, Lin S, Wang TH, Yang S. Biotech Adv, 2011, 29: 830-839

416 Magro L, Jacquelin B, Escadafal C, Garneret P, Kwasiborski A, Manuguerra JC, Monti F, Sakuntabhai A, Vanhomwegen J, Lafaye P, Tabeling P. Sci Rep, 2017, 7: 1347

417 Zhao W, Ali M, Brook M, Li Y. Angew Chem, 2008, 120: 64286436

418 Li J, Macdonald J. Lab Chip, 2016, 16: 242-245

419 Toley BJ, Covelli I, Belousov Y, Ramachandran S, Kline E, Scarr N, Vermeulen N, Mahoney W, Lutz BR, Yager P. Analyst, 2015, 140: $7540-7549$
420 Jauset-Rubio M, Svobodová M, Mairal T, McNeil C, Keegan N, Saeed A, Abbas MN, El-Shahawi MS, Bashammakh AS, Alyoubi AO, O'Sullivan CK. Sci Rep, 2016, 6: 37732

421 Liu H, Xiang Y, Lu Y, Crooks RM. Angew Chem Int Ed, 2012, 51: 6925-6928

422 Parolo C, Merkoçi A. Chem Soc Rev, 2013, 42: 450-457

423 Poste G. Expert Rev Mol Diagnostics, 2001, 1: 1-5

424 Marchant J, Mange A, Larrieux M, Costes V, Solassol J. BMC Cancer, 2014, 14: 519

425 Zhao J, Wu R, Au A, Marquez A, Yu Y, Shi Z. Mod Pathol, 2002, 15: $657-665$

426 Parkinson DR, McCormack RT, Keating SM, Gutman SI, Hamilton SR, Mansfield EA, Piper MA, DeVerka P, Frueh FW, Jessup JM, McShane LM, Tunis SR, Sigman CC, Kelloff GJ. Clin Cancer Res, 2014, 20: 1428-1444

427 Suzuki H, Maruyama R, Yamamoto E, Kai M. Mol Oncology, 2012, 6: $567-578$

428 Caine A, Maltby AE, Parkin CA, Waters JJ, Crolla JA. Lancet, 2005, 366: $123-128$

429 Best MG, Sol N, Kooi I, Tannous J, Westerman BA, Rustenburg F, Schellen P, Verschueren H, Post E, Koster J, Ylstra B, Ameziane N, Dorsman J, Smit EF, Verheul HM, Noske DP, Reijneveld JC, Nilsson RJA, Tannous BA, Wesseling P, Wurdinger T. Cancer Cell, 2015, 28: $666-676$

430 Lewis JM, Heineck DP, Heller MJ. Expert Rev Mol Diagnostics, 2015, 15: 1187-1200

431 Cho WC. Expert Rev Mol Diagnostics, 2011, 11: 9-12

432 Taly V, Pekin D, Benhaim L, Kotsopoulos SK, Le Corre D, Li X, Atochin I, Link DR, Griffiths AD, Pallier K, Blons H, Bouché O, Landi B, Hutchison JB, Laurent-Puig P. Clin Chem, 2013, 59: 17221731

433 Norton ME. Proc Natl Acad Sci USA, 2016, 113: 14173-14175

434 Lv SW, Liu Y, Xie M, Wang J, Yan XW, Li Z, Dong WG, Huang WH. ACS Nano, 2016, 10: 6201-6210

435 Zhang H, Yang Y, Li X, Shi Y, Hu B, An Y, Zhu Z, Hong G, Yang CJ. Lab Chip, 2018, 18: 2749-2756

436 Versalovic J, Lupski JR. Trends MicroBiol, 2002, 10: s15-s21

437 Pardee K, Green AA, Takahashi MK, Braff D, Lambert G, Lee JW, Ferrante T, Ma D, Donghia N, Fan M, Daringer NM, Bosch I, Dudley DM, O’Connor DH, Gehrke L, Collins JJ. Cell, 2016, 165: 1255-1266

$438 \mathrm{Hu}$, Wen CY, Zhang ZL, Xie M, Hu J, Wu M, Pang DW. Anal Chem, 2013, 85: 11929-11935

439 Wang D, Coscoy L, Zylberberg M, Avila PC, Boushey HA, Ganem D, DeRisi JL. Proc Natl Acad Sci USA, 2002, 99: 15687-15692

440 Didelot X, Bowden R, Wilson DJ, Peto TEA, Crook DW. Nat Rev Genet, 2012, 13: 601-612

441 Neher RA, Bedford T. J Clin Microbiol, 2018, 56: e00480-18

442 Liu J, Liu H, Kang H, Donovan M, Zhu Z, Tan W. Anal Bioanal Chem, 2012, 402: 187-194

443 Zhang H, Zhou L, Zhu Z, Yang C. Chem Eur J, 2016, 22: 9886-9900

444 Qi L, Liu S, Jiang Y, Lin JM, Yu L, Hu Q. Anal Chem, 2020, 92: 3867-3873

445 Traykovska M, Miedema S, Penchovsky R. Int J BioMed Clin Eng, 2018, 7: 46-60

446 Song Y, Song J, Wei X, Huang M, Sun M, Zhu L, Lin B, Shen H, Zhu Z, Yang C. Anal Chem, 2020, 92: 9895-9900

447 Zhang L, Fang X, Liu X, Ou H, Zhang H, Wang J, Li Q, Cheng H, Zhang W, Luo Z. Chem Commun, 2020, 56: 10235-10238

448 Rangan R, Watkins AM, Kladwang W, Das R. bioRxiv, 2020, doi: 10.1101/2020.03.27.012906

449 Thomsen PF, Willerslev E. Biol Conservation, 2015, 183: 4-18

450 Breakwell K, Tetu SG, Elbourne LDH. Methods Mol Biol, 2014, 1096: 101-110

451 Gilbert JA, Dupont CL. Annu Rev Mar Sci, 2011, 3: 347-371

452 Ju F, Zhang T. Appl Microbiol Biotechnol, 2015, 99: 4119-4129

453 Sayler GS, Layton AC. Annu Rev Microbiol, 1990, 44: 625-648 
454 Palchetti I, Mascini M. Analyst, 2008, 133: 846-854

455 Hayat A, Marty JL. Front Chem, 2014, 2: 41

456 Nguyen VT, Kwon YS, Gu MB. Curr Opin Biotech, 2017, 45: 15-23

457 Hlavata L, Benikova K, Vyskocil V, Labuda J. Electrochim Acta, 2012, 71: 134-139

458 Ercolini D. Appl Environ Microbiol, 2013, 79: 3148-3155

459 Wang X, Xiong E, Tian T, Cheng M, Lin W, Wang H, Zhang G, Sun J, Zhou X. ACS Nano, 2020, 14: 2497-2508

460 Wu J, Zhu Y, Xue F, Mei Z, Yao L, Wang X, Zheng L, Liu J, Liu G, Peng C, Chen W. Microchim Acta, 2014, 181: 479-491

461 Xu H, Zhu X, Wang J, Lin Z, Chen G. Luminescence, 2019, 34: 308315

462 Lan L, Yao Y, Ping J, Ying Y. ACS Appl Mater Interfaces, 2017, 9: 23287-23301

463 Shen J, Zhou X, Shan Y, Yue H, Huang R, Hu J, Xing D. Nat Commun, 2020, 11: 267

464 Goud KY, Reddy KK, Satyanarayana M, Kummari S, Gobi KV. Microchim Acta, 2020, 187: 29

465 Ma Y, Mao Y, Huang D, He Z, Yan J, Tian T, Shi Y, Song Y, Li X, Zhu Z, Zhou L, Yang CJ. Lab Chip, 2016, 16: 3097-3104

466 Khedri M, Ramezani M, Rafatpanah H, Abnous K. TrAC Trends Anal Chem, 2018, 103: 126-136

467 Jiang M, Chen C, He J, Zhang H, Xu Z. Food Chem, 2020, 307: 125534

468 Khoshbin Z, Housaindokht MR, Verdian A, Bozorgmehr MR. Biosens Bioelectron, 2018, 116: 130-147

469 Feng X, Gan N, Zhang H, Yan Q, Li T, Cao Y, Hu F, Yu H, Jiang Q. Biosens Bioelectron, 2015, 74: 587-593

470 Novroski NMM, Woerner AE, Budowle B. Forensic Sci Int-Genets, 2018, 37: 162-171
471 Diegoli TM. Forensic Sci Int-Genets, 2015, 18: 140-151

472 Juusola J, Ballantyne J. Forensic Sci Int, 2005, 152: 1-12

473 Courts C, Madea B. Forensic Sci Int, 2010, 203: 106-111

474 Dumache CR, Ciocan CV, Muresan CC, Rogobete CA, Enache CA. Clin Lab, 2015, 61: 1129

475 Oliveira M, Amorim A. Appl Microbiol Biotechnol, 2018, 102: 10377-10391

476 Bruijns B, van Asten A, Tiggelaar R, Gardeniers H. Biosensors, 2016, 6: 41

477 Cui G, Li C, Li H, Li X. DNA Computing and Its Application to Information Security Field. IEEE. Tianjin, China, 2009. 148-152

478 Ratna Kishore D, Suneetha D, Praddep GGS. Enhancement in Data Security Using DNA Cryptography. Springer Singapore. London, England, 2020. 63-70

479 Singh S, Sharma Y. A Review on DNA based Cryptography for Data hiding. IEEE. SCAD Institute of Technology, India, 2019. 282-285

480 Clelland CT, Risca V, Bancroft C. Nature, 1999, 399: 533-534

481 Tanaka K, Okamoto A, Saito I. Biosystems, 2005, 81: 25-29

482 Cui G, Qin L, Wang Y, Zhang X. An encryption scheme using DNA technology. In: Kearney D, Nguyen V, Gioiosa G, Hendtlass T, Eds. 3rd International Conference on Bio-Inspired Computing. Adelaide, Australia, 2008. 37-42

483 Zhang XC, Zhou Z, Jiao YY, Niu Y, Wang YF. Int J Performability Eng, 2018, 14: 334-340

484 Zhang Y, Wang F, Chao J, Xie M, Liu H, Pan M, Kopperger E, Liu X, Li Q, Shi J, Wang L, Hu J, Wang L, Simmel FC, Fan C. Nat Commun, 2019, 10: 5469

485 Zicheng W, Xiaohang Z, Hong W, Guangzhao C. Information hiding based on DNA steganography. IEEE. Beijing, China, 2013. 946949 